\title{
THE EFFECTS OF MULTITASKING ON QUALITY INSPECTION IN ADVANCED MANUFACTURING SYSTEMS
}

\author{
by \\ José A. Pesante-Santana \\ Dissertation submitted to the Faculty of the \\ Virginia Polytechnic Institute and State University \\ in partial fulfillment of the requirements for the degree of \\ Doctor of Philosophy \\ in \\ Industrial and Systems Engineering
}

Approved:

\begin{tabular}{c}
\hline $\begin{array}{c}\text { Robert C. Williges, Ph.D. } \\
\text { Chairperson }\end{array}$ \\
\hline C. Patrick Koelling, Ph.D. \\
\hline Pedro Resto, Ph.D. \\
\hline Walter W. Wierwille, Ph.D. \\
\hline Jeffrey C. Woldstad, Ph.D \\
November 7, 1997 \\
Blacksburg, Virginia
\end{tabular}

Keywords: Quality Inspection, Multitasking, Manufacturing Copyright 1997, José A. Pesante-Santana 


\title{
THE EFFECTS OF MULTITASKING ON QUALITY INSPECTION IN ADVANCED MANUFACTURING SYSTEMS
}

\author{
José A. Pesante-Santana
}

(ABSTRACT)

Technological and strategic developments have changed the role of human operators in the manufacturing environment. The highly specialized work force of the low-tech manufacturing system has evolved into the multi-functional work force of the high-tech manufacturing system. Among the multiple tasks that an operator is expected to conduct in advanced manufacturing systems (AMS) are job scheduling, inventory planning, machine set-up, problem solving, and quality inspection.

The quality inspection task in AMS consists of a search component, frequently conducted by a machine, and a decision making component conducted by the operator. This quality inspection system is often referred to as a hybrid inspection system (HIS). It has been demonstrated that in general the performance of HIS is better than that of pure human or pure automated inspection systems. This research investigated the effects of different types of defects (presented at the same time in the inspected parts), multitasking (concurrently conducting independent tasks), and their interaction on the operator's performance in the quality inspection task (with a memorized quality criteria) in an AMS.

The results indicate that the performance of the operator in the quality inspection task while multitasking in an AMS will be determined not only by the variety of defects that can be present in the inspected parts, but also by the mental processing resources required to meet the demand imposed by the multiple independent tasks and the memorized quality criteria. The best performance will be obtained when the additional tasks' load minimizes the monotony of the quality inspection task without interfering with the processing resources needed for the memorized quality criteria. 
Dedicated to the memory of my father, José Pesante 


\section{TABLE OF CONTENTS}

ABSTRACT

LIST OF FIGURES vi

LIST OF TABLES vii

LIST OF APPENDICES viii

Chapter 1. INTRODUCTION 1

RATIONALE 1

REVIEW OF THE LITERATURE

ADVANCED MANUFACTURING SYSTEMS 3

Technocentric AMS

Human-Centered AMS 6

$\begin{array}{ll}\text { THE QUALITY INSPECTION TASK } & 10\end{array}$

Visual Quality Inspection Taxonomy 11

Visual search component of the quality inspection task 11

Decision making component of the quality inspection task 13

SDT Studies on Visual Quality Inspection 15

Decision making performance changes over time 17

Determinants of decision making performance criterion $\quad 18$

$\begin{array}{ll}\text { Quality Inspection Training } & 21\end{array}$

Hybrid Inspection System $\quad 21$

Quality Inspection Task Load 25

MULTITASKING 26

Human Supervisory Control 27

Determinants of Multitasking Performance 32

RESEARCH OBJECTIVES 35

Chapter 2. EXPERIMENTAL METHOD 36

$\begin{array}{ll}\text { SUBJECTS } & 36\end{array}$ 
APPARATUS 36

$\begin{array}{ll}\text { EXPERIMENTAL DESIGN } & 37\end{array}$

Independent Variables $\quad 37$

Task Description 39

Dependent Variables 43

EXPERIMENTAL PROCEDURES 44

DATA ANALYSIS 45

$\begin{array}{ll}\text { Chapter 3. RESULTS } & 47\end{array}$

HIT RATE

FALSE ALARM RATE $\quad 49$

SDT METRICS $\left(\mathrm{d}^{\prime}, \beta\right.$, and $\left.c\right) \quad 49$

AVERAGE TIME $\quad 52$

SUBJECTIVE WORKLOAD QUESTIONNAIRE SCORES 54

Chapter 4. DISCUSSION 57

$\begin{array}{ll}\text { HYPOTHESIS } 1 & 57\end{array}$

HYPOTHESIS 2

HYPOTHESIS $3 \quad 59$

Chapter 5. CONCLUSIONS AND FUTURE RESEARCH 62

$\begin{array}{ll}\text { REFERENCES } & 64\end{array}$

$\begin{array}{ll}\text { APPENDICES } & 74\end{array}$

$\begin{array}{ll}\text { VITA } & 115\end{array}$ 


\section{LIST OF FIGURES}

Figure 1 Framework of human factors issues in AMS 9

Figure 2 Flow diagram for visual search 13

Figure 3 Theoretical SDT distribution $\quad 14$

Figure 4 Framework for function allocation in inspection 24

Figure 5 General paradigm of supervisory control 28

Figure 6 Temporal nesting of the general paradigm of supervisory control $\begin{array}{ll}\text { functions } & 29\end{array}$

Figure 7 Performance-resource function for multitasking 34

Figure 8 Experimental scenario - AMS Cell 37

Figure 9 Experimental unit and defect types 39

Figure 10 Quality Inspection Station screen $\quad 40$

Figure 11 Scheduling screen at the Production Scheduling and Inventory $\begin{array}{ll}\text { Control Station } & 41\end{array}$

Figure 12 Inventory screen at the Production Scheduling and Inventory Control Station 42

Figure 13 Setup screen at the Adjacent Process Station 43

Figure 14 Problem solving screen at the Adjacent Process Station 43

Figure 15 Mean plot of the effects of the Defect Type and Tasks interaction on hit 48

Figure 16 Mean plot of the effects of the Defect Type and Tasks interaction on $c \quad 52$

Figure 17 Mean plot of Defect Type and Tasks effects on the average time to make a decision $\quad 54$

Figure 18 Mean plot of Defect Type and Tasks effects on the temporal demand 56 


\section{LIST OF TABLES}

Table 1 Advanced manufacturing concepts and technologies by company function 4

Table 2 Human skills required for the quality inspection task 11

Table 3 Applications of industrial inspection training programs 22

Table 4 Automated inspection systems 23

Table 5 Capabilities of human and computer in planning/scheduling tasks $\begin{array}{ll}\text { of AMS } & 30\end{array}$

Table 6 Different types of disturbances in AMS 31

Table 7 Experimental conditions 38

Table 8 Balanced Latin Square design 38

Table 9 ANOVA summary table of hit $\quad 47$

Table 10 Newman-Keuls analysis of the effect of the Defect Type and $\begin{array}{ll}\text { Task interaction on hit } & 48\end{array}$

Table 11 ANOVA summary table of false alarm 49

Table 12 ANOVA summary table of $\mathrm{d}^{\prime} \quad 50$

Table 13 ANOVA summary table of $B$

Table 14 ANOVA summary table of $c$

Table 15 Newman-Keuls analysis of the effect of the Defect Type and Task interaction on $c \quad 52$

Table 16 ANOVA summary table of average time to make a decision 53

Table 17 Newman-Keuls analysis of the effect of Tasks on the average time to make a decision $\quad 54$

Table 18 ANOVA summary table of temporal demand 55

Table 19 Newman-Keuls analysis of the effect of Tasks on temporal demand 56 


\section{LIST OF APPENDICES}

APPENDIX A General Information: The Effects of Multitasking on Quality Inspection in AMS. $\quad 74$

APPENDIX B Informed Consent Form 76

APPENDIX C The Forced Choice Procedure $\quad 80$

APPENDIX D Instructions for the Two Alternatives Forced Choice Procedure 81

APPENDIX E The Constant Stimuli Method Procedure to Determine

Difference Threshold $\quad 82$

APPENDIX F Instructions for the Constant Stimuli Method Procedure to Determine Difference Threshold (DL) 83

APPENDIX G Instructions for the Experimental Treatments 84

APPENDIX H Likert-like Scale for Subjective Mental Workload 92

APPENDIX I Computational Formulas and Experimental Data 95

APPENDIX J Calculated DL for the Scratch and Specks Defects 102 


\section{Chapter 1. INTRODUCTION}

\section{$\underline{\text { Rationale }}$}

The development of numerically controlled machines, group technology, cellular manufacturing, and just-in-time production systems have changed the role of human operators in the manufacturing environment. The highly specialized work force of the low-tech manufacturing system has evolved into the multi-skilled work force of the hightech manufacturing system. Throughout the manufacturing evolution, from the mass production era to the present advanced manufacturing systems (AMS), human sensory detection capabilities have been a vital but often ignored component of the quality inspection task.

Mass production was the prevailing manufacturing system of the first half of the twentieth century. Some of the manufacturing concepts that shaped the mass production era were: Babbage's division of labor, Taylor's scientific management, the Gilbreths' motion studies, and Ford's specialization of labor (Konz, 1995; Niebel, 1993; Turner, Mize, Case, and Nazemetz, 1993). During World War II, the demand for war materiel pushed mass production to its peak, causing a significant expansion for many industries. Such growth resulted in increasing employment of unskilled personnel (Banks, 1989). Quality control inspection became a very important and specialized task. Statistically based acceptance sampling and $100 \%$ inspection were the main quality control tools used to detect and reject unacceptable products. Even though the quality inspector's performance was significantly less than $100 \%$, more emphasis was placed on meeting the large production demands than on understanding or improving the performance of the inspectors.

By the mid-1960's, competition for consumer goods had increased, and consumer interest in more variety and availability of products had started to drive the market (Talavage and Hannam, 1992). Batch manufacturing became the answer to a consumerdriven market. High volume production of the same product was replaced by shorter 
production runs of products with different designs and a shorter life cycle. With this variety of products manufactured in batches, the different types of defects that the inspector was expected to detect increased significantly. As a result, the difficulty of the quality inspection task also increased. Once again the sensory limitations of human inspectors were in most cases overlooked. Instead, more interest was placed on developing production scheduling and inventory strategies to protect the manufacturer from demand fluctuations and quality problems.

During the 1970's, many Japanese companies adopted the just-in-time (JIT) production system developed by the Toyota Motor Corporation. Highly influenced by the loss of market share, some of the major North American companies adopted JIT by the early 1980's (Schonberger, 1986). The main objective of JIT is to increase productivity and reduce cost by completely eliminating waste; this is done by producing just what is needed, in the needed quantity, when needed (Monden, 1993). A key concept of the JIT production system is a flexible work force. In order to avoid excess work force, operators must be trained to be skilled in multiple jobs of various processes (Monden, 1993). This caused a significant shift in the quality inspection task responsibilities. The specialized quality inspector was replaced by an operator who, in addition to the inspection task, concurrently conducted other tasks such as job scheduling, inventory planning, dissimilar machines setup, and problem solving.

Various production systems have been developed and implemented since the introduction of JIT. Although most of them modify JIT to some extent, their cornerstones remain the same as for JIT: quantity control and quality assurance. Numerically controlled machines, group technology, and cellular manufacturing have become instrumental elements of quantity control, while quality assurance has been relying mostly on the performance of a flexible work force performing multitasking. A significant number of these current production strategies take place in manufacturing environments referred to as advanced manufacturing systems (AMS). These systems are characterized by a high degree of human-computer interaction during practically every aspect of manufacturing. Most of the on-line tasks (such as machine setup, problem solving, and 
quality inspection), as well as the off-line tasks (such as job scheduling and inventory control), are conducted using video display terminals (VDTs). This has minimized the operator's physical contact with both the process machine and the unit being produced.

In the present highly competitive world class manufacturing (WCM) scenario, where manufacturers in almost every industry sector find themselves competing with companies from every part of the world, quality is a key element for survival and success. A better understanding of the operator's performance in a quality inspection task while multitasking in AMS is essential for the continuous improvement of the manufacturing industry.

\section{Review of the Literature}

\section{Advanced Manufacturing Systems}

Advanced manufacturing systems (AMS) is a generally accepted term for production systems that are based on advanced manufacturing technology (AMT). The main AMT components are: computer aided design (CAD), computer aided engineering (CAE), computer assisted manufacturing (CAM), computer integrated manufacturing (CIM), and flexible manufacturing systems (FMS) (Karwowski and Salvendy, 1991). Some of the AMT contributions to manufacturing systems are: 1) high flexibility in product design, mix, and fabrication, 2) rapid response to changes in market demand, 3) greater control, accuracy, and repeatability of processes, and 4) faster throughput. In addition to AMT, a wide range of production strategies are used in AMS: product-based cell manufacturing, group technology, JIT, total quality control (TQC), and optimized production technology (OPT), among others (Mize, 1988; Wilson, 1991). A list of AMS technologies and strategies organized by major company function is presented in Table 1 (Mize, 1988). 
Table 1. Advanced manufacturing concepts and technologies by company function (Mize, 1988).

\begin{tabular}{|c|c|}
\hline Company Function & Applicable Advanced Concepts and Technologies \\
\hline $\begin{array}{l}\text { Strategic business } \\
\text { planning }\end{array}$ & $\begin{array}{l}\text { Flexible manufacturing strategies/automation/design } \\
\text { for differentiation/rapid order completion/high manu- } \\
\text { facturing velocity strategies }\end{array}$ \\
\hline $\begin{array}{l}\text { Sales and } \\
\text { quotations }\end{array}$ & $\begin{array}{l}\text { Interactive, integrated databases/data communication } \\
\text { links to field and customer locations }\end{array}$ \\
\hline Product design & $\begin{array}{l}\text { CAD/CAE analysis/simulation and animation/design } \\
\text { for manufacturability, for automated handling and } \\
\text { assembly, and cost targets/group technology, design } \\
\text { retrieval/engineering change control }\end{array}$ \\
\hline Process design & $\begin{array}{l}\text { CAD equipment and process design/simulation } \\
\text { models/cellular and flexible machining systems }\end{array}$ \\
\hline $\begin{array}{l}\text { Capacity analysis } \\
\text { and facility design }\end{array}$ & $\begin{array}{l}\text { Facility layout analysis algorithms/simulation models/ } \\
\text { family of parts analysis/computer-aided facilities } \\
\text { planning }\end{array}$ \\
\hline $\begin{array}{l}\text { Process planning } \\
\text { and tool design }\end{array}$ & $\begin{array}{l}\text { Computer-aided process planning/group technology/ } \\
\text { classification and coding/time standards database }\end{array}$ \\
\hline $\begin{array}{l}\text { Production planning } \\
\text { and scheduling }\end{array}$ & $\begin{array}{l}\text { Master production scheduling/production smoothing/ } \\
\text { MRP/MRPII/OPT/JIT/Kanban/scheduling algorithms/ } \\
\text { simulation/plant-wide monitoring systems }\end{array}$ \\
\hline $\begin{array}{l}\text { Purchasing and } \\
\text { vendor management }\end{array}$ & $\begin{array}{l}\text { Automated purchasing/electronic links to vendors/ } \\
\text { automated follow-up }\end{array}$ \\
\hline $\begin{array}{l}\text { Order entry and } \\
\text { order processing }\end{array}$ & $\begin{array}{l}\text { Demand management/forecasting/integrated } \\
\text { databases/on-line, real-time order tracking }\end{array}$ \\
\hline $\begin{array}{l}\text { Shop floor } \\
\text { management }\end{array}$ & $\begin{array}{l}\text { Dispatching, handling controls/automated identifica- } \\
\text { tion systems, bar coding, etc./automated input of per- } \\
\text { formance data as order progresses through shop/ } \\
\text { data integrity audit procedures, cycle counting, etc./ } \\
\text { preventive maintenance scheduling/advanced con- } \\
\text { cepts in performance measurement }\end{array}$ \\
\hline Fabrication & $\begin{array}{l}\text { NC/CNC/DNC/programmable controllers/automated } \\
\text { processes/automated tool changing/machine and tool } \\
\text { monitoring/robotics/quick change setups }\end{array}$ \\
\hline Assembly & $\begin{array}{l}\text { Automated assembly/robotics assembly/automated } \\
\text { testing by assembly stages }\end{array}$ \\
\hline $\begin{array}{l}\text { Inspection and } \\
\text { testing, quality } \\
\text { assurance }\end{array}$ & $\begin{array}{l}\text { Computer-aided inspection and testing/machine } \\
\text { monitoring and diagnostic systems/statistical process } \\
\text { control/machine vision/adaptive control/inspection } \\
\text { "on the fly" }\end{array}$ \\
\hline $\begin{array}{l}\text { Material handling } \\
\text { and storage }\end{array}$ & $\begin{array}{l}\text { Automated storage and retrieval systems/automated } \\
\text { guided vehicles/automated conveyors/robotic hand- } \\
\text { ling/part transfer systems, hard automation }\end{array}$ \\
\hline $\begin{array}{l}\text { Data processing } \\
\text { and factory } \\
\text { communications }\end{array}$ & $\begin{array}{l}\text { MAP/TOP, other communication protocol standards/ } \\
\text { factory networks/postprocessors and preprocessors/ } \\
\text { paperless control and reporting/electronic process } \\
\text { plans, instructions to operators/integrated databases }\end{array}$ \\
\hline
\end{tabular}


The AMT and production strategies configuration used in AMS varies among manufacturing organizations. However, JIT and TQC are the production strategies most recommended for AMS, to make production processes more visible and to enable the elimination of waste, the cutting of required lead times, and the optimization of manufacturing activities (Zairi, 1992; Pinochet, Matsubara, and Nagamachi, 1996). This integration of AMT and JIT/TQC strategies represented a major conflict with the original organizational assumptions of AMS (Berniker, 1990). When AMS was originally conceived, its goal was to improve productivity by creating a fully automated factory, often referred to as the factory of the future, where the operator's role on the manufacturing shop floor would be minimized or eliminated. This contrasts with JIT, which is highly dependent on a flexible work force's mental capacity and problem solving abilities to increase productivity. After several alarming failures in the implementation and operation of the technocentric "factory of the future," the manufacturing leaders realized that the key to success in WCM is the effective integration of people, organization, and technology (Brödner, 1991; Wilson, 1991; Wobbe, 1992; Bessant, Levy, Ley, Smith, and Tranfield, 1992). Furthermore, Wilson (1992) stated that "Implicit in WCM developments involving AMT and JIT and similar principles of manufacturing organization, must be a human-centered rather than a technocentric approach.”

Technocentric AMS. The technocentric AMS was supposed to herald the coming of the "factory of the future." Davies (1986) described the "factory of the future" as an almost workerless, paperless, and fully automated production facility that was going to alter manufacturing "at least as dramatically as large-scale industrialization changed earlier guild forms of industrial organization." It has been suggested that for the technocentric AMS to succeed, there should be a full integration of engineering, design, production scheduling and control, quality control, and manufacturing systems in a single computerized network (Berniker, 1990; Davies, 1986; Davidow and Malone, 1992). 
By the mid-1980's there was a growing realization of the unfulfilled promise of the technocentric AMS (Bessant, et al., 1992; Mize, 1988; Unterweger, 1988). Some of the most publicized cases of failure have been in the automotive industry. Under the heading of "Tricky Technology: American Car Makers Discover 'Factory of the Future' Is Headache Just Now," the Wall Street Journal (1986) reported that all U.S. automakers were having significant difficulties with their factory modernization programs. Business Week (1987) reported that after investing $\$ 60$ billion in vast amounts of AMT, General Motors was unable to achieve the anticipated results. Some of the factors identified as the most significant barriers to the successful implementation of the technocentric AMS according to Mize (1988) are: 1) unanticipated difficulties in transferring technology from the isolated pilot projects to the manufacturing real world, 2) underestimation of the magnitude of the task resulting in an organization's inability to absorb the vast amount of change in a short period of time, 3) the misunderstanding of the critical role played by humans as operating systems integrators, 4) inadequate internal technical skills leading to excessive dependency on external consultants and vendors, and 5) unrealistic expectations of stand alone automation. The major weakness of the technocentric AMS was best described by Unterweger (1988), when he stated that "the attempt to eliminate the gaps or deficiencies in machine designs by means other than skilled human operators leads to a vicious circle that can only add cost and complexity to a system that is already overly complex."

Human-Centered AMS. The objective of human-centered AMS is to employ the best technological and organizational qualities of AMT and of people, with complete integrated roles and functions. Wilson (1991) indicated that in this AMS the actual manufacturing processes will be computer controlled, but setup, programming, monitoring, intervention, maintenance, diagnosis, rectification, innovation, and optimization will be the responsibility of operating and supervisory staff. For these tasks the operating and supervisory staff will have any recourse from the information and technical systems to aid their decision. In essence, this manufacturing system stresses a 
re-skilling rather than a de-skilling perspective, emphasizes operator local control, follows the human factors principles of good job design, and encourages social communication and interaction (Corbett, 1987).

Wilson (1991) indicated that operator local control is related to the job characteristic of autonomy, seen at the core of individual and group work design changes as well as of job design models and theories. Bainbridge (1982) expressed the opinion that "the more advanced a control system is, so the more crucial may be the contribution of the human operator." The degree of control and breadth of influence exerted by operators will be determined by the skill-, rule-, or knowledge-based behaviors that the task interface will support (Rasmussen, 1986). Rasmussen (1983) described his skill/rule/knowledge-based classifications as follows: 1) skill-based behavior represents psychomotor behavior without conscious control, consisting of automated routines that are driven by information received from the environment, 2) rule-based behavior represents consciously controlled, goal-oriented behavior guided by sets of rules or stored patterns that have been empirically derived during previous occasions or communicated as instructions from an external source, and 3) knowledge-based behavior represents goal-controlled, problem solving performance in unfamiliar situations, requiring a functional understanding of the system, analysis of the current state, and response of the environment based on conscious, advanced reasoning while utilizing feedback control for error correction. According to Schott and Wilkinson (1989), the process of developing control down to the operator level requires that AMS designers be able to allocate functions optimally.

From a human-centered AMS perspective it is widely recognized that people, just like machines, have limitations and weaknesses. Still, they have to be involved in the operation and management of AMS. Some of the reasons for this inclusion are: 1) AMT limitations in receiving information and decision making, 2) AMT have the potential to diagnose the origin of failures, but have difficulties in repairing the system that failed, 3) human complex knowledge-based skills for problem solving in novel situations, and 4) human flexibility and adaptability (Salvendy, 1992; Pinochet, et al., 1996). According 
to Mize (1988) and Wilson (1991), the success of the human-centered AMS will be significantly dependent on the effective integration of people, organization, and technology. A human factors knowledge base is vital for this integration (Karwowski, Salvendy, Badham, Brodner, Clegg, Hwang, Iwasawa, Kidd, Kobayashi, Koubek, LaMarsh, Nagamachi, Naniwada, Salzman, Seppala, Schallock, Sheridan, and Warschat, 1994). Critical human factors issues particularly pertinent to AMS are presented in Figure 1 (Wilson, 1991). 


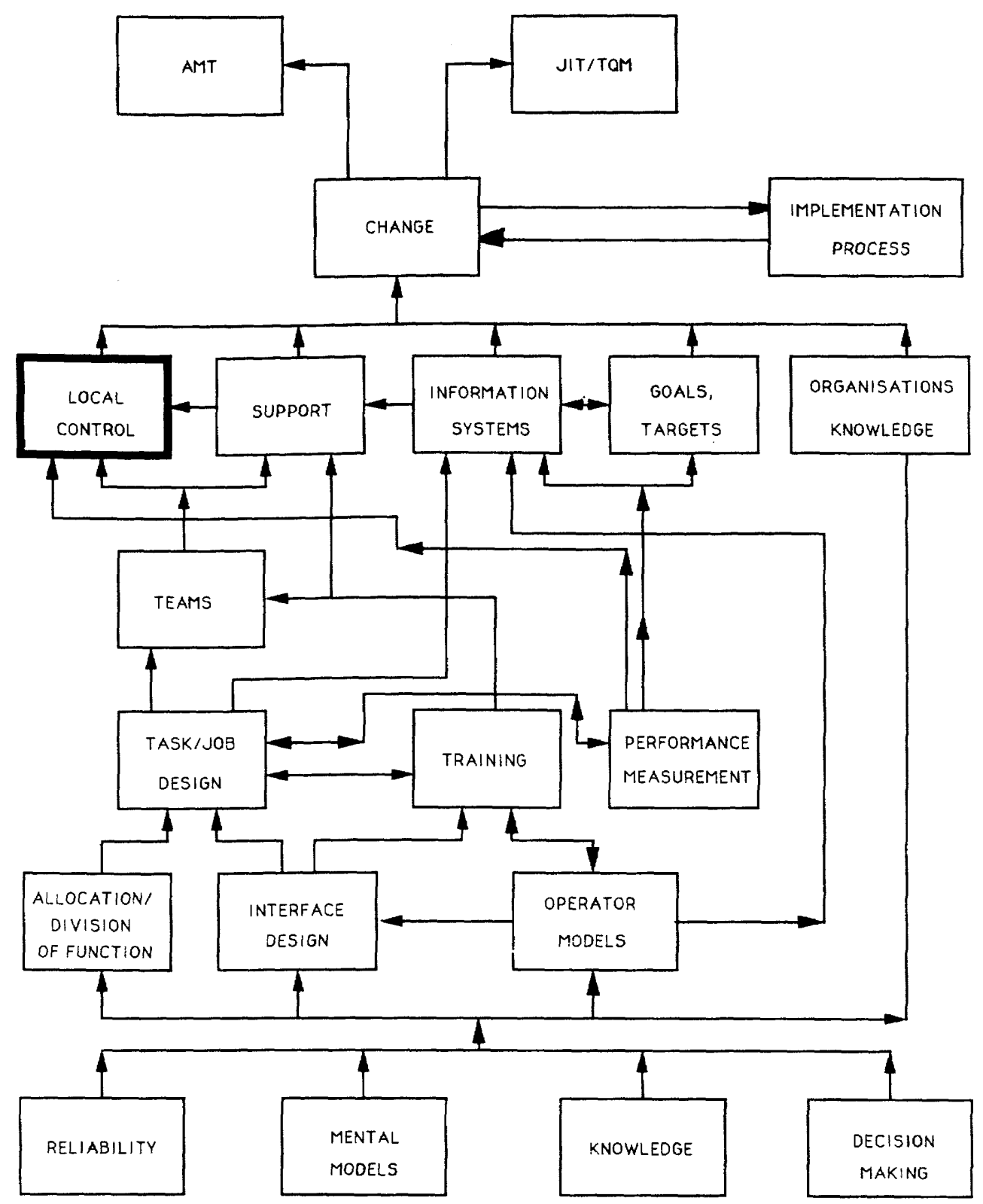

Figure 1. Framework of human factors issues in AMS (Wilson, 1991). 


\section{The Quality Inspection Task}

Quality has been defined as fitness for use, or the extent to which a product meets the consumer requirements (Juran and Gryna, 1980). Inspection is the act of measuring or examining carefully the quality of a product. Sensory inspections (performed by means of the human senses to assess a product's qualitative characteristics) and physical inspections (performed by means of measuring devices to assess a product's quantitative characteristics) are the main types of quality inspections. It has been widely accepted that the quality inspection task performed by humans is prone to error (Bennet, 1975; Konz, Peterson, and Joshi, 1981; Schilling, 1982). In fact, Juran (1974) indicated that human inspectors typically find about $80 \%$ of the defects. This recognized level of inspection error has been mostly attributed to the sensory aspects of the inspection. Shingo (1985) indicated that it tends to be difficult to set criterions for sensory inspection because different people will make different judgments and even the same person might make different judgments on different days. Efforts to automate the quality inspection task have not been as successful with sensory inspections as with various physical inspections (Drury, 1992b).

During the last four decades a substantial amount of human factors research has been conducted on the visual quality inspection task. The human operator's performance on the visual quality inspection task has been extensively studied from the signal detection theory (SDT) standpoint. In addition, the machine and human-plus-machine system's performance on the visual quality inspection task has been studied and compared to the human operator's performance. Despite the contributions of research to the understanding of human performance in the quality inspection task, the manufacturing trend has been to design quality schemes that compensate for poor inspector performance instead of trying to improve it (Drury, 1992). 


\section{Visual Quality Inspection Taxonomy}

The visual quality inspection task has been described as consisting of the following subtasks (Wang and Drury, 1989): 1) orient the item, 2) search the item, 3) detect any defect, 4) recognize/classify the defect, 5) decide the status of the item, 6) dispatch the item, and 7) record the information about the item. Table 2 shows the human skills required should all the subtasks be assigned to human operators (Wang and Drury, 1989). Drury (1992) indicated that these subtasks can be combined into two main components: search and decision making. Thus, the simplest description of the visual quality inspection task is to search, recognize a defect, and make a decision on the part's acceptability within the quality limits.

Table 2. Human skills required for the quality inspection task (Wang and Drury, 1989).

\begin{tabular}{|c|c|c|c|}
\hline Subtask & $\begin{array}{c}\text { Task } \\
\text { Description }\end{array}$ & $\begin{array}{l}\text { Major } \\
\text { Type or } \\
\text { Skill }\end{array}$ & $\begin{array}{c}\text { Mental } \\
\text { Attributes } \\
\text { Required }\end{array}$ \\
\hline 1 & Orient the item & Manual & - \\
\hline 2 & Search the item & Perceptual & Attention, perception, memory \\
\hline 3 & Detect a flaw & Perceptual & $\begin{array}{l}\text { Detection, recognition, mem- } \\
\text { ory }\end{array}$ \\
\hline 4 & $\begin{array}{l}\text { Recognize/ } \\
\text { classify }\end{array}$ & Perceptual & $\begin{array}{l}\text { Recognition, classification, } \\
\text { memory }\end{array}$ \\
\hline 5 & $\begin{array}{l}\text { Decide status } \\
\text { of item }\end{array}$ & Perceptual & $\begin{array}{l}\text { Judgment, classification, mem- } \\
\text { ory }\end{array}$ \\
\hline $\begin{array}{l}6 \\
7\end{array}$ & $\begin{array}{l}\text { Dispatch item } \\
\text { Record of in- } \\
\text { formation } \\
\text { about item }\end{array}$ & $\begin{array}{l}\text { Manual } \\
\text { Manual and } \\
\text { percep- } \\
\text { tual }\end{array}$ & Memory \\
\hline
\end{tabular}

Visual search component of the quality inspection task. Visual search is a sequential process that proceeds as a series of fixations linked by eye movements and which terminates upon successful detection of a defect or the complete inspection of the unit (Drury and Prabhu, 1994). It has been indicated that almost all of the information in a visual search is obtained during the fixations which account for more than $90 \%$ of the search time (Morawski, Drury, and Karwan, 1980). In the inspector's field of view, a defect is only visible within a limited area referred to as the visual lobe. During a fixation the visual lobe is located around the central fixation point. According to Drury (1992), 
the visual lobe size will be affected by the luminance of the object inspected, the contrast between the object and the defect on the object, the defect size, and the distance of the defect from the inspector's eyes. Figure 2 shows a flow diagram for visual search (Howarth and Bloomfields, 1971).

Megaw and Richardson (1979) conducted eye movement studies of inspectors and concluded that inspectors do not follow a simple pattern in searching an object. They observed that while a very random appearing search pattern was used for the inspection of complex units (e.g., circuit boards), a more systematic search pattern was used for the inspection of simpler ones (e.g., knitwear). Bloomfield (1975) suggested that the most efficient strategy will occur when: 1) the distance that the eyes move from one fixation to the next is short enough that no point on the unit is missed, and 2) the distance between fixation points is large enough to minimize the overlap between the areas in which the defect could be seen. However, Bloomfield acknowledged that when the search is for more than one type of defect, with different levels of discriminability, the most efficient strategy for one type of defect might not necessarily be efficient for the other type of defect.

Drury (1992) indicated that in addition to the lobe size and the search strategy, the time available for the inspection will affect human performance in the visual search component of the inspection. The more time the inspector has to search, the better the chances are of finding the defect. Nevertheless, Schoonard, Gould, and Miller (1973) found that the best inspectors for the visual search subtask were those who detected the defect in the fewest fixations, not those with more rapid fixations. Three factors that led to a thorough investigation of search automation were: 1) the significant time consumption of the visual search, 2) the need for the selection and implementation of an optimal search strategy, and 3) the quality at the source and 100\% inspection strategies strongly recommended for AMS (Drury and Prabhu, 1994; Shingo, 1985). 


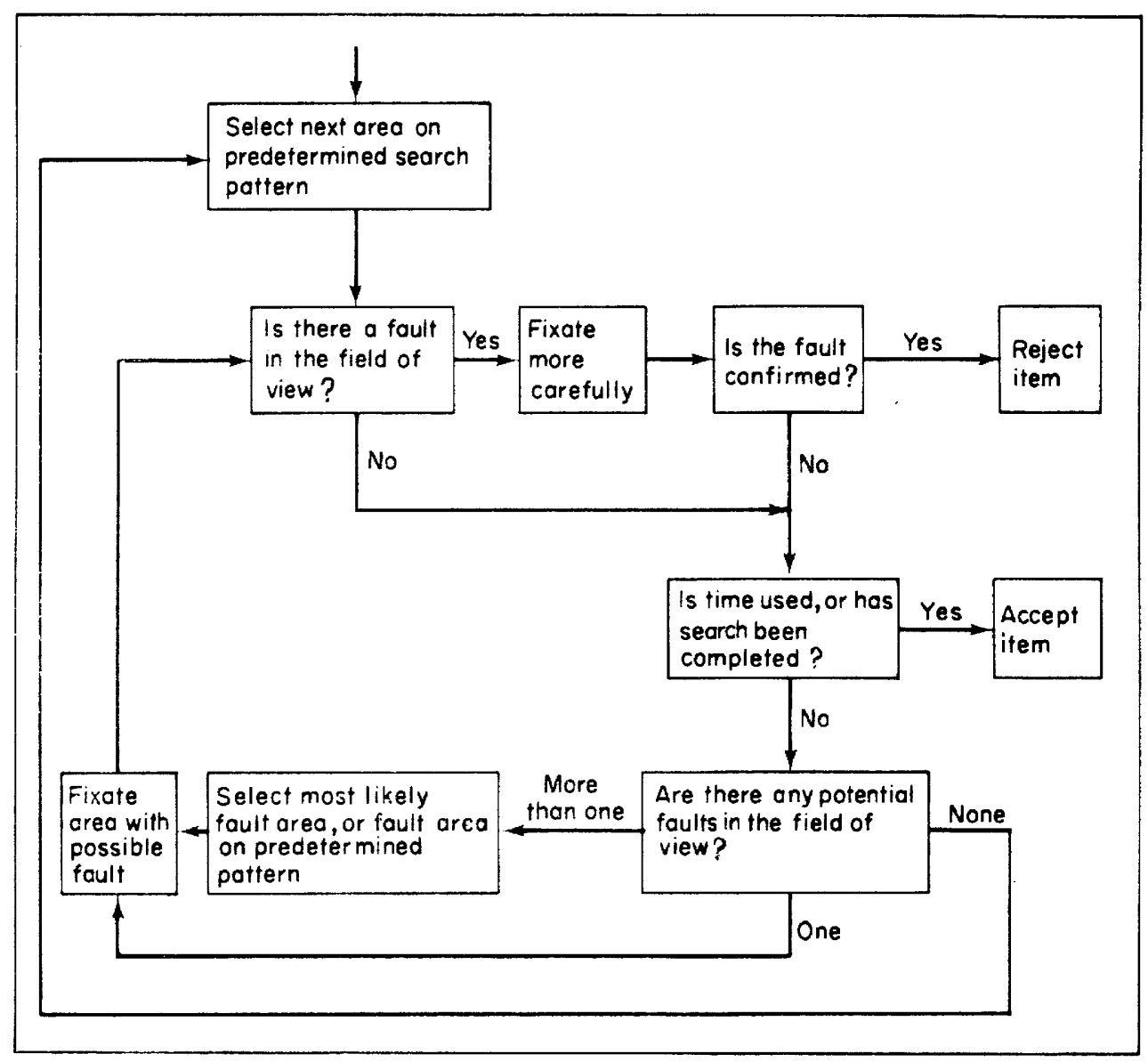

Figure 2. Flow diagram for visual search (Howarth and Bloomfield, 1971).

\section{Decision making component of the quality inspection task. Given its strict}

relevance to decision making, signal detection theory (SDT) has been used to explain the decision making component of the quality control inspection task (Wallack and Adams, 1969; Drury and Fox, 1975). In the fundamental signal detection problem, as defined by Swets, Tanner and Birdsall (1964), an observation is made of events occurring in a fixed interval of time, and a decision is made whether the interval contained only the always present noise $(\mathrm{N})$ or the signal plus noise $(\mathrm{SN})$. As opposed to classic methods of psychophysics, SDT provides both an independent quantitative measure of the criterion $(\beta)$ that the observer uses in making a perceptual judgment, and a relatively pure measure 
of sensitivity (d'). The major assumptions of SDT are: 1) the observations (sensory data) on which the decision is based may arise from either conforming or nonconforming items, 2) the observations may be represented as varying continuously along a single dimension forming two probability density functions ( $\mathrm{N}$ and $\mathrm{SN}$ ), and 3) both probability density functions can be described by two normal distribution with equal variances. The criterion (B) or policy to determine whether the observation results from the $\mathrm{N}$ or the $\mathrm{SN}$ distribution is established by a cutoff value $X_{c}$ on the continuum of observations.

In a quality inspection context, as described by Drury and Fox (1975), SDT proposes that the human, functioning as a defect detection device, builds up in the neural system two distributions of activity: one relating to the probability of accepting an unit, the other to the probability of rejecting it. The degree of separation of these two distributions' means is a measure of the inspector's discriminability of the defects $\left(\mathrm{d}^{\prime}\right)$. The criterion level $(\beta)$, which is the ratio of the two ordinates of the curves at a given level $\mathrm{X}_{\mathrm{c}}$, delineates the boundary between accepting and rejecting a unit, and in doing so takes in some good units to be rejected and some faulty units to be accepted. Inspectors make a correct decision either by accepting a good unit (correct rejection) or by rejecting an unacceptable unit (hit). They fail either by not detecting a rejectable defect (miss) or by falsely reporting the presence of a rejectable defect (false alarm). A theoretical SDT distribution is shown in Figure 3 (Wickens, 1992).

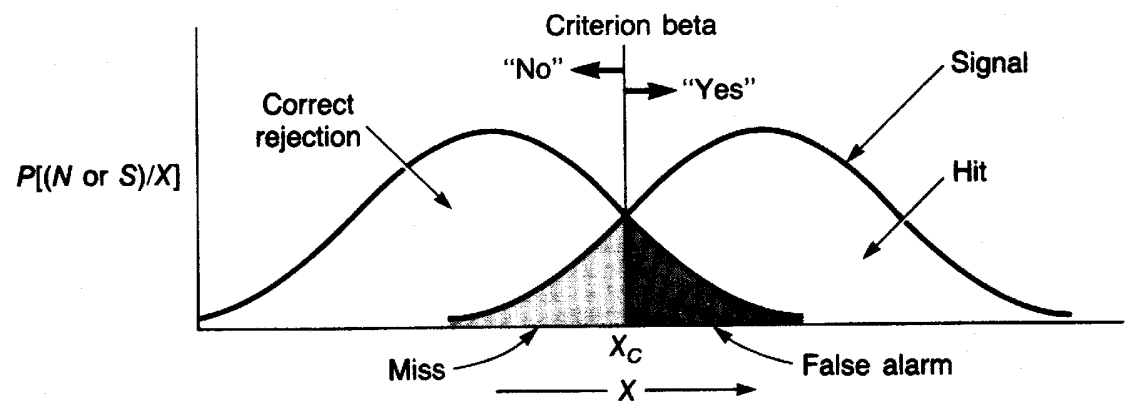

Figure 3. Theoretical SDT distribution (Wickens, 1992). 
Both decision making performance measures $\left(\mathrm{d}^{\prime}\right.$ and $\left.\beta\right)$ are derived from the hit rate and the false alarm rate. Drury (1992) indicated that the pure decision making component of the quality inspection task can be measured by concentrating on tasks that require no search. The general conclusion of quality inspection studies reviewed by Drury and Fox (1975b) is that "the decision making component is among those rare tasks where a human being behaves like a rational economic decision maker, balancing the costs and payoffs involved to arrive at an optimum performance." As a normative model, SDT defines the optimal criterion $\left(\beta_{\mathrm{opt}}\right)$ used by the ideal observer to optimize economic gains (Green and Swets, 1966). Based upon the values of a hit and a correct rejection, and the costs of a miss and a false alarm, the $\beta_{\text {obs }}$ of a rational observer can be calculated and compared to that of the theoretical ideal observer $\left(\beta_{\mathrm{opt}}\right)$. Gescheider $(1985)$ reported that after comparing $\beta_{\mathrm{obs}}$ with $\beta_{\mathrm{opt}}$, it has been generally found that rational observers do fairly well at optimizing their winnings. However, they tend not to set extremely low or high criterion, even in situations where these strategies would lead to optimal performance.

\section{SDT Studies on Visual Quality Inspection}

Signal Detection Theory (SDT) was first used to model the decision making performance of the quality inspection task by Wallack and Adams in 1969 (Thapa, Gramopadhye, and Melloy, 1996). After using SDT to study the performance of industrial electronics inspectors in a visual, subject-paced task, they concluded that SDT performance measures $\left(d^{\prime}\right.$ and $\left.\beta\right)$ were more useful than the other available measures. Wallack and Adams (1969) concluded that SDT is useful because, in addition to relating performance to payoff, it also indicates the magnitude and the direction of improvement required. Although not all of the research using SDT to study the decision making performance has been conducted in an industrial inspection context, its findings have been beneficial in understanding human quality inspector performance.

More recently another measure of criterion level or decision making response bias called the index $c$ has been developed (Macmillan and Creelman, 1991). The main 
difference between $B$ and the index $c$ is in the way these bias indices locate the criterion $\left(X_{c}\right)$. The likelihood ratio measure, $B$, locates $X_{c}$ by the ratio of the heights of the SDT distributions ( $\mathrm{N}$ and $\mathrm{SN}$ ), while the index $c$ locates $\mathrm{X}_{\mathrm{c}}$ by its distance from the intersection of the two distributions. The range of $\mathrm{c}$ is therefore the same as that of $\mathrm{d}^{\prime}$, although zero is at the center rather than an endpoint. This parametric index is considered to be more effective than $\beta$ over a full range of sensitivity in recognition memory experiments and in vigilance (Snodgrass and Corwin, 1988; See, Warm, Dember, and Howe, 1997). Unlike the index $c, \beta$ has a tendency to produce extremely high values for conservative observers resulting in a scale that does not produce equal intervals. See et al. (1997) conducted three experiments involving factors that affect response bias (signal probability, payoff matrix, and signal salience) in order to calculate and compare $\beta$ and $c$. All three experiments employed a 40 minute task without performance feedback in which the subjects were required to detect increments of $3 \mathrm{~mm}$ in the height of a single $32 \mathrm{x} 4$ $\mathrm{mm}$ white line. The white line flashed on and off at a rate of 20 events/minute in the center of a computer screen. The researchers found that the index $c$ was generally more sensitive than $B$ to the nonperceptual manipulations of signal probability, payoff, and probability shifts. Also, they reported that $\beta$ was less effective than $c$ at differentiating variations in response bias tendencies when sensitivity approached chance. The computational formulas for $\mathrm{d}^{\prime}, \beta$, and the index $c$ are presented in Appendix I.

In most if not all of the research using SDT, the quality inspection task has been characterized as a vigilance situation in which the inspector's sole task is to examine a stream of products to detect and remove the defective ones. This characterization is no longer consistent with the reality of the operator's responsibilities in AMS. The quality inspection task in AMS is no longer a specialized task; instead, it is one of multiple dissimilar tasks conducted by a highly skilled operator. However, many of these studies make a significant contribution to our understanding of human decision making performance in the visual quality inspection task. By the late 1960's SDT had become the preferred tool for the analysis and description of the inspector's decision making performance (Drury and Fox, 1975). Some of the assumptions underlying SDT, in 
particular the normal distributions with equal variance assumption, are not always true in every inspection situation. Swets (1977) indicated that this assumption is only necessary for the calculation of d'. From a theoretical perspective Green and Swets (1966) identified the Central Limit Theorem as the reason for the normal distribution assumption. From a practical and empirical perspective the reason for SDT assumptions is that when checks are made on the results of SDT studies on quality inspection, they seem to be in basic agreement with predictions from the theory (Chapman and Sinclair, 1975; Drury and Fox, 1975).

Decision making performance changes over time. Based on the review of twelve studies conducted between 1969 and 1975, Swets (1977) indicated that all twelve experiments showed an increasingly strict criterion (ß) over time when the signal-to-noise ratio was low; eight of the experiments showed a constant sensitivity ( $\left.\mathrm{d}^{\prime}\right)$ over time. In the four studies in which $\mathrm{d}^{\prime}$ did not remain constant it was found to decrease by $20 \%$. An increase in $\beta$ (conservative criterion) represents a decrease in signals detected as well as a decrease in false alarm errors. As Williges (1969) indicated, a performance change over time is characterized by a shift in the subject's response criterion ( $(B)$.

Williges (1969) conducted a study in which the subjects were required to detect a signal (the longer of two fixed-duration changes from a standard brightness) during a 60 minute monitoring session. A distraction element was introduced by asking the subject to time share a secondary task (four numerical processing operations) with the primary monitoring task. The events in both tasks were occurring at intervals of 10 seconds. Two signal-to-noise ratios (1/5 and 5/1), a correct and an incorrect set of instructions (expected number of signals in the sample), and the distraction vs. no distraction element were combined factorially to measure the hit and false alarm rates. The ANOVA conducted for the performance measures ( $d^{\prime}$ and $\beta$ ) showed the following results: 1) $d^{\prime}$ remained constant over time and 2) $B$ increased over time when the signal-to-noise ratio was low. The same results were obtained by Colquhoun and Edwards (1970). They conducted a 
study in which the subjects were required to indicate which one of six disks, if any, was larger than the others. They found $\mathrm{d}^{\prime}$ to be constant and $\beta$ to increase over time. On the other hand, Guralnick's (1972) results differed from those obtained by Williges (1969). He conducted an experiment in which the signal was the longer of a pair of vertical lines, and the events were presented at a rate of eight per minute. Although his results showed a $\beta$ increase over time, $d^{\prime}$ was found to decrease by $20 \%$.

\section{Determinants of decision making performance. A study of on-line quality} inspection for mass-produced jam tarts was conducted in the baking industry by Chapman and Sinclair (1975). They tested the hypothesis that speed of movement of the tarts on the conveyor and the presentation time of the tarts had no effect upon the performance of the inspectors. The two levels of the tarts movement factor (moving and stationary) and the three levels of the presentation time $(22.5 \mathrm{sec} ., 15 \mathrm{sec} .$, and $7.5 \mathrm{sec}$.$) were combined$ factorially to measure the hit and false alarm rates. The ANOVA conducted for the performance measures ( $d^{\prime}$ and $\beta$ ) showed the following results: 1) $d^{\prime}$ decreased as the presentation time was reduced, and 2) $B$ increased as the presentation time was reduced. The authors acknowledged that since slowing down the production line was not an option the only possible solution was to double the number of inspectors. The outcome of this research suggested the need for conducting the assessment of quality inspection agents' capabilities early during the design stage of the particular manufacturing system in order to avoid solutions incompatible with world class AMS.

Smith and Barany (1970) conducted an experiment in which the varied inspection task variables were task pace, percentage of defective, and payoff matrices (consequences of the decision made). The experimental task was the on-line inspection of aluminum disks ( 1 inch in diameter) containing four equally spaced holes (1/16 inch in diameter). The subjects inspected the product units and indicated a defective (three holes instead of four) by pressing a micro switch. It was found that $\mathrm{d}^{\prime}$ decreased as the task pace increased and remained invariant with respect to the other two independent variables. 
The decision criterion ( $($ ) utilized by the inspectors increased (became more stringent) as the percentage of defective increased and remained invariant with respect to the other two independent variables. The researchers attributed the unexpected result (conservative $B$ when signal probability was high) to the failure of the inspectors to adopt the payoff system as instructed.

Williges (1971) conducted a study in which the subjects were required to detect a signal (the longer of two fixed-duration changes from a standard brightness) during a 60 minute monitoring session. The events were presented on a 6 second time base. Two signal-to-noise ratios (1/9 and 1/1) and three payoffs (lax, neutral, and strict) were the varied inspection task variables. Based on the results of the study he concluded that the signal probability rather than payoffs seem to play the major role in determining inspection performance. When the signal probability is high the observers maintain a "lax" response criterion, but, when the probability is low the observers adopt a "conservative" one.

The effect of knowledge of results (KR) on decision making performance is beneficial but complex. Craig and Colquhoun (1975), referencing the work of Mackworth (1964, 1965), indicated that the performance increase caused by false KR suggests that at least some part of the effect of providing true KR may be due to an initial increase in arousal or alertness. Williges and North (1972) conducted a $2^{3}$ factorial experiment in which the presence or absence of correct detection $\mathrm{KR}$, false alarm $\mathrm{KR}$, and cumulative total event KR were randomly assigned to subjects. The experimental task was the same one used in Williges' previous SDT studies $(1969,1971)$. They concluded that: 1) the specificity of KR influences d' more than $\beta, 2$ ) positive KR on the correctness of a detection response is used by the observer to increase their d', 3) observers use signal-to-noise ratio KR to manipulate their $\beta, 4$ ) false alarm KR results in fewer detections overall when cumulative total events KR are provided, and 5) subjects appear to use the cumulative total events KR to guide their frequency of responding. The results of a study on the effect of information on industrial inspection performance conducted by Zunzanyika and Drury (1975) are consistent with some of Williges and 
North (1972) findings. In their experiment, the independent variables were the percentage of defective $(10 \%, 20 \%$, and $30 \%)$ and the method of transmitting information about the batch quality (feedback, feedforward, and both). Based on the analysis of the results, the authors stated that the percentage of defective KR had a significant effect on d' and a more obvious effect on $\beta$.

Various researchers argue that the traditional laboratory findings about vigilance task performance are not particularly relevant to real operational problems, partly because real world tasks are of a more complex nature than the simple tasks which have been used in the laboratory studies (Alluisi, Coates, and Morgan, 1977; Craig and Colquhoun, 1977; Craig, 1979). As an example of a complex vigilance task they mentioned the industrial quality inspection that frequently requires the operator to look for the occurrence of several kinds of signals. Craig and Colquhoun (1977) conducted an experiment in which two different type of defects (with equal probability of 10\% each) were presented to the subjects. Each defect consisted of a circle with a single radial spoke. One of the defects needed to be rejected whenever a change in the angle of the radial spoke was observed. The second defect needed to be rejected whenever a change in diameter was observed. The defects were presented on a television monitor. A control group only inspected one type of defects, while a second group inspected both types simultaneously. Based on the results of this experiment the researchers concluded that the effect of what they called complex inspection (inspection of both defects simultaneously) on the overall level of detections was not significant. Craig (1979) conducted the same type of experiment, but used unequal probabilities (5\% and 15\%) for the two types of defects, and reached the same conclusion. He indicated that these research findings (Craig and Colquhoun, 1977; Craig, 1979) do not invalidate the traditional laboratory findings about vigilance task performance, but rather suggest the value of further research on this issue. 


\section{Quality Inspection Training}

Training has been identified as essential to improving the decision making performance of human operators (Embrey, 1975; Wiener, 1975). Juran and Gryna (1980) indicated that chronic deficiency in knowledge (e.g., education or training) is a cause of errors consistently made by inspectors. Czaja and Drury (1981) claimed that despite the existence of a profound knowledge base on training, it is a neglected area for improvement in industrial inspection performance. They indicated that KR is fundamental to learning. Thapa, Gramopadhye, and Melloy (1996) mentioned that the results of the KR transmission strategies (feedback, feedforward, or both) used in training programs are consistent with the research findings of the effect of KR on decision making performance. Drury (1992) listed five techniques that have proven effective in training for inspection: 1) Cueing, 2) Feedback, 3) Active training, 4) Progressive parts, and 5) Develop schema. Table 3 summarizes various applications of industrial inspection training programs (Drury, 1992).

\section{Hybrid Inspection Systems}

Zero-defect products and shorter lead-time production are vital for the survival and success of AMS in a highly competitive WCM. According to Drury and Sinclair (1983), "this can often be achieved only by 100\% inspection, which is known to be unreliable when performed by humans." This dilemma prompted an industry movement towards automated inspection systems. Various automated inspection systems are listed in Table 4 (Drury and Prabhu, 1994). The advent of these microprocessor-based automated inspection devices, at prices competitive with human inspection, called for a human factors reassessment of the human-machine function allocation possibilities in quality control (Drury and Sinclair, 1983). Gramopadhye, Drury, Sharit, and Sudit (1992) proposed a framework for function allocation in inspection (see Figure 4). They recommended accuracy, speed, flexibility, and reliability as the performance criterion for the inspection system. 
Table 3. Applications of industrial inspection training programs (Drury, 1992)

\begin{tabular}{|c|c|c|c|}
\hline Investigator(s) & Training Technique & $\begin{array}{l}\text { Type of } \\
\text { Task }\end{array}$ & Results \\
\hline $\begin{array}{l}\text { Tiffin and } \\
\text { Rodgers }\end{array}$ & $\begin{array}{l}\text { Knowledge of results } \\
\text { and training sessions } \\
\text { that included lectures } \\
\text { and demonstrations }\end{array}$ & Inspection of tin plates & $\begin{array}{l}\text { General improvements } \\
\text { in inspection perform- } \\
\text { ance; greater detection } \\
\text { of faults }\end{array}$ \\
\hline Evans & $\begin{array}{l}\text { 30-min class instruction; } \\
11 \text { tests with knowl- } \\
\text { edge of results over } 2 \\
\text { weeks }\end{array}$ & $\begin{array}{l}\text { Micrometer inspection } \\
\text { of gauge blocks }\end{array}$ & $\begin{array}{l}50 \% \text { reduction in aver- } \\
\text { age error, but no ef- } \\
\text { fect on retention }\end{array}$ \\
\hline $\begin{array}{l}\text { Martineck and } \\
\text { Sadacca }\end{array}$ & $\begin{array}{l}\text { Knowledge of results } \\
\text { using an error key }\end{array}$ & Photointerpretation & $\begin{array}{l}\text { Decrease in errors of } \\
\text { commission }\end{array}$ \\
\hline $\begin{array}{l}\text { Chaney and } \\
\text { Teel }\end{array}$ & $\begin{array}{l}\text { Four, 1-hr sessions that } \\
\text { included lectures, } \\
\text { demonstrations, and } \\
\text { knowledge of results } \\
\text { from a question and } \\
\text { answer period }\end{array}$ & $\begin{array}{l}\text { Inspection of machine } \\
\text { parts }\end{array}$ & $\begin{array}{l}\text { Training resulted in a } \\
32 \% \text { increase in de- } \\
\text { fects detected }\end{array}$ \\
\hline $\begin{array}{l}\text { Cockrell and } \\
\text { Sadacca }\end{array}$ & $\begin{array}{l}\text { Knowledge of results } \\
\text { and group discussion }\end{array}$ & Photointerpretation & $\begin{array}{l}\text { Significant improve- } \\
\text { ment in inspection } \\
\text { performance and a } \\
\text { decrease in false } \\
\text { alarms }\end{array}$ \\
\hline $\begin{array}{l}\text { Parker and } \\
\text { Perry }\end{array}$ & $\begin{array}{l}\text { Demonstrations, use of } \\
\text { photographs simulat- } \\
\text { ing items and faults, } \\
\text { examples of faulty } \\
\text { items, practice with } \\
\text { knowlege of results }\end{array}$ & Inspection of glass bowls & $\begin{array}{l}50 \% \text { increase in faulty } \\
\text { detection, } 50 \% \text { in- } \\
\text { crease in false rejec- } \\
\text { tions }\end{array}$ \\
\hline $\begin{array}{l}\text { Duncan and } \\
\text { Gray }\end{array}$ & $\begin{array}{l}\text { Gradual approach to the } \\
\text { task (diagnosis of } \\
\text { faults then verifica- } \\
\text { tion) using pro- } \\
\text { grammed instruction }\end{array}$ & $\begin{array}{l}\text { Fault detection in a pe- } \\
\text { troleum refinery pro- } \\
\text { cess }\end{array}$ & $\begin{array}{l}\text { Training resulted in an } \\
\text { increase in faults de- } \\
\text { tected, decrease in de- } \\
\text { tection time, and de- } \\
\text { crease in false } \\
\text { rejections }\end{array}$ \\
\hline Houghton & $\begin{array}{l}\text { Product knowledge, } \\
\text { standards, search } \\
\text { training, practice with } \\
\text { knowlege of results, } \\
\text { progressive part }\end{array}$ & Solder joint, inspection & $\begin{array}{l}\text { Efficiency up from } 33- \\
67 \% \text { to } 89-97 \%\end{array}$ \\
\hline Kleiner & $\begin{array}{l}\text { Progressive part, cueing, } \\
\text { knowledge of results, } \\
\text { active }\end{array}$ & $\begin{array}{l}\text { Aircraft bearing inspec- } \\
\text { tion }\end{array}$ & $\begin{array}{l}\text { Rest errors reduced to } \\
\text { zero, } 50 \% \text { scrap re- } \\
\text { duction }\end{array}$ \\
\hline
\end{tabular}

One of the first efforts to reassess the human-machine function allocation possibilities in quality control was conducted by Drury and Sinclair (1983). They compared the performance of experienced inspectors and a prototype

optical/microprocessor inspection device in an inspection task of small steel cylinders with four different possible defect types. The comparison was done in terms of both hit rate and false alarm rate. These SDT metrics were plotted one against the other to form a Receiver-Operating Characteristic (ROC) curve. Drury and Sinclair's (1983) main 
findings were: 1) neither the human nor the automated systems achieved an outstanding performance and 2) the automated system was better at locating the defects (search) but could not classify them as acceptable or rejectable (decision making) as well as the human inspectors.

Table 4. Automated inspection systems (Drury and Prabhu, 1994).

\begin{tabular}{|c|c|c|c|c|}
\hline INDUSTRY & TASK & $\begin{array}{c}\text { PARAMETERS } \\
\text { DETECTED DEFECTS }\end{array}$ & TECHNOLOGY & $\begin{array}{l}\text { LIMITATIONS \& } \\
\text { CAPABILITIES }\end{array}$ \\
\hline $\begin{array}{l}\text { Micro-electronic IC } \\
\text { Device Manufacturing } \\
\text { (Bose \& Kim, 1990) }\end{array}$ & $\begin{array}{l}\text { Inspection of defects } \\
\text { during the process of } \\
\text { banding IC chips to its } \\
\text { carrier }\end{array}$ & $\begin{array}{l}\text { Missing chip, } \\
\text { misregistration of chip, } \\
\text { odge cracks, scratches, } \\
\text { surface contamination, } \\
\text { misorientation }\end{array}$ & $\begin{array}{l}\text { Computer vision using } \\
\text { CCD camera, dark and } \\
\text { bright field illumination } \\
\text { and vision algorithms }\end{array}$ & $\begin{array}{l}\text { Scratches of width } 20 \mu \text { or } \\
\text { more. Automated system per- } \\
\text { formed better than inspectors. } \\
\text { False reject rate }<1 \% \text {. }\end{array}$ \\
\hline $\begin{array}{l}\text { Research Lab } \\
\text { (Chi, et al., 1990) }\end{array}$ & $\begin{array}{l}\text { Classification of } \\
\text { defects in wafer } \\
\text { images }\end{array}$ & $\begin{array}{l}\text { Void, scratch, bridge, } \\
\text { diffusion, crack, } \\
\text { probemark, random (dust } \\
\text { and dir) }\end{array}$ & $\begin{array}{l}\text { Computer vision and rule- } \\
\text { based expert system }\end{array}$ & $\begin{array}{l}\text { Relatively simple wafer } \\
\text { images. }\end{array}$ \\
\hline $\begin{array}{l}\text { Continuous Strip Steel } \\
\text { Production } \\
\text { (Seitzler, 1990) }\end{array}$ & $\begin{array}{l}\text { Inspection of surface } \\
\text { defects on steel strips }\end{array}$ & $\begin{array}{l}\text { Slivers, scratches, dents, } \\
\text { bumps, scale, rust, stain, } \\
\text { dirt, nicks, pits, etc. }\end{array}$ & $\begin{array}{l}\text { APA512 Cardset } \\
\text { implementing video rate } \\
\text { geometric analysis }\end{array}$ & $\begin{array}{l}88-95 \% \text { of defect types found } \\
\text { at inspection rate of } 40 \text { feet } \\
\text { per second. }\end{array}$ \\
\hline $\begin{array}{l}\text { Research Lab } \\
\text { (Park \& Mitchell, } \\
\text { 1989) }\end{array}$ & $\begin{array}{l}\text { On-line inspection of } \\
\text { machine parts }\end{array}$ & $\begin{array}{l}\text { Dimensions related to size, } \\
\text { position and orientation of } \\
\text { features }\end{array}$ & $\begin{array}{l}\text { Sierra Scientific CCD high } \\
\text { reolution camera, CAD } \\
\text { based 3-D part recognition }\end{array}$ & $\begin{array}{l}\text { Performance measure not } \\
\text { stated. }\end{array}$ \\
\hline $\begin{array}{l}\text { Printed Wiring Board } \\
\text { Manufacturing }\end{array}$ & $\begin{array}{l}\text { Inspection of defects } \\
\text { on inner layer patterns } \\
\text { before lamination }\end{array}$ & $\begin{array}{l}\text { Narrow tracks, poor } \\
\text { spacing }\end{array}$ & $\begin{array}{l}\text { Black line illumination and } \\
\text { a CCD sensor, radial } \\
\text { matching algorithm }\end{array}$ & $\begin{array}{l}\text { Resolution of } 5 \mu \mathrm{m} \text {, inspects } \\
490 \times 540 \mathrm{~mm} \text { area in } 5 \\
\text { minutes. }\end{array}$ \\
\hline $\begin{array}{l}\text { Fabric Manufacturing } \\
\text { (Takato, et al., 1988) }\end{array}$ & $\begin{array}{l}\text { Inspection of defects } \\
\text { in plain and patterned } \\
\text { cloth }\end{array}$ & $\begin{array}{l}\text { Oil stains, dye stains, white } \\
\text { stains, holes, flaws }\end{array}$ & $\begin{array}{l}\text { Industrial television } \\
\text { cameras, image processing } \\
\text { system, vision algorithm } \\
\text { for defect detection }\end{array}$ & $\begin{array}{l}\text { Stable detection of oil layer } \\
\text { stains under third grade in } \\
\text { grey scale, white stains, and } \\
\text { dye flaws over } 1 \mathrm{~mm} \text {. }\end{array}$ \\
\hline $\begin{array}{l}\text { Paper Industry } \\
\text { (Mueller, et al., 1989) }\end{array}$ & $\begin{array}{l}\text { Inspection of defects at } \\
\text { multiple production } \\
\text { stages }\end{array}$ & $\begin{array}{l}\text { Holes during initial } \\
\text { forming }\end{array}$ & Laser scanning & High speed $100 \%$ inspection. \\
\hline
\end{tabular}




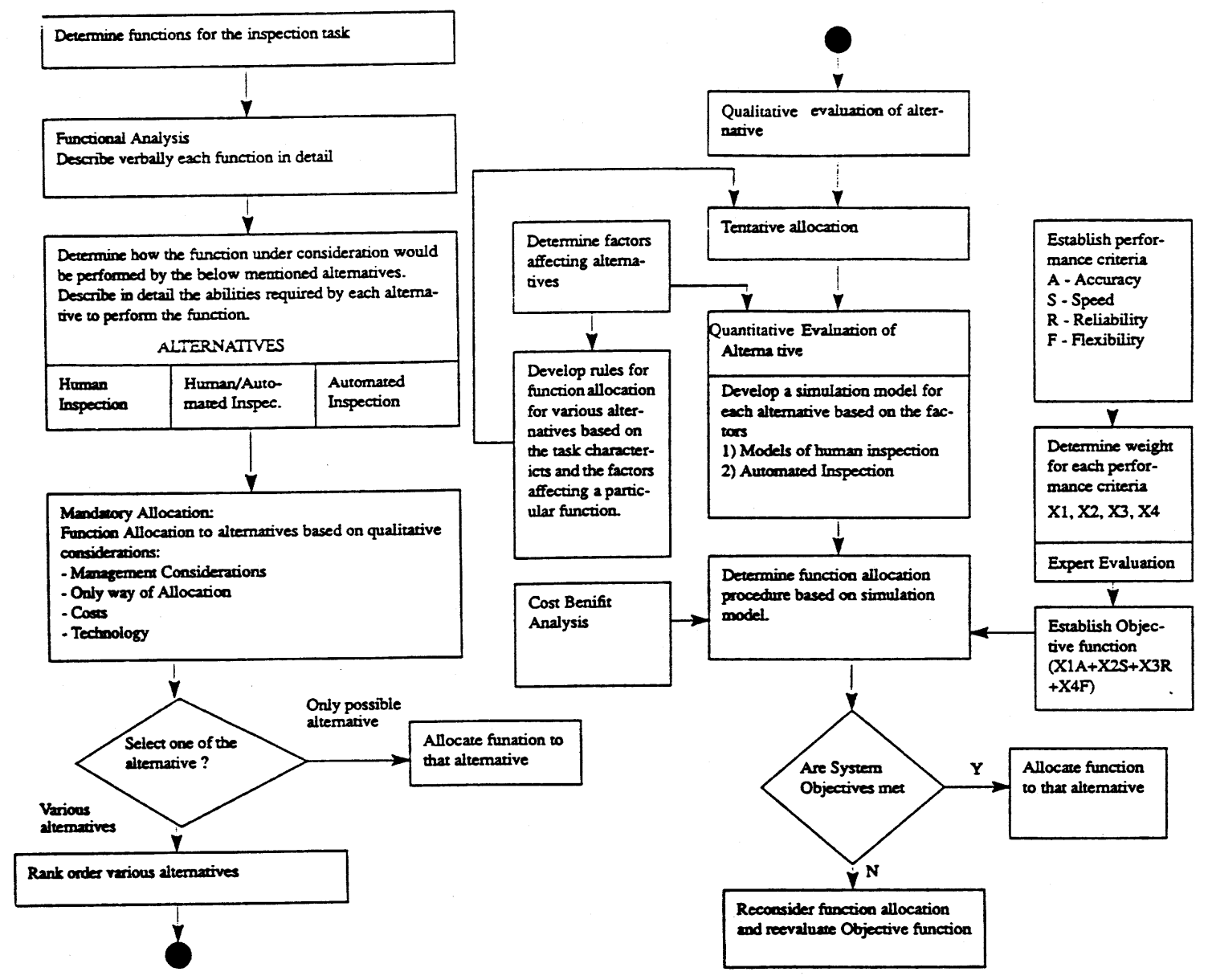

Figure 4. Framework for function allocation in inspection (Gramopadhye, Drury, Sharit, and Sudit, 1992).

Hou, Lin, and Drury (1993) conducted a $3^{3}$ factorial experiment in which the experimental task was the quality inspection of printed circuit boards containing surface mounted devices. The independent variables were the complexity of the product (number of components in the board), the contrast level between components and background, and the visual noise in the displayed image (the noise coming from the lighting conditions and the imaging system). Using the accuracy and speed performance criterion measures combined with the false alarm rate and the hit rate, they calculated a cost-based evaluation function. This cost-based evaluation function coupled with the Drury and Sinclair (1983) findings led to the conclusion that allocating the search function to 
machines and the decision making function to humans results in better performance than pure human or pure machine inspection. This computer-search/human-decision making system is known as a Hybrid Inspection System (HIS). The idea behind HIS is to capitalize on the machine speed and precision to scan the inspection unit, and on the decision making ability exhibited by humans.

\section{Quality Inspection Task Load}

Quality inspection tasks that impose a sustained load on working memory (to recall what the quality acceptability criterion looks like) will demand the continuous supply of processing resources (Parasuraman, 1979; Parasuraman, Warm, and Dember, 1987, Wickens, 1992). Parasuraman (1979) conducted an experiment using a successivediscrimination task (that imposed a memory load) in which the signal was specified as the decrease in the intensity of a flashing light. The signals were presented irregularly at a mean rate of two signals per minute, and the event rate was 30 events per minute. The duration of the task was 45 minutes. He concluded that the performance in such areas of vigilance application as radar monitoring and industrial quality inspection could be adversely affected when the operator has to discriminate a signal from a standard represented in memory and when the event rate is high. This performance decrement may result either from signal-data limits (weak signal in noise), or memory-data limits (quality of stored representation of the standard in delayed comparison memory tasks).

Like many other tasks, quality inspection has been identified as having an inverted-U shaped relationship between task demand and performance level (McGrath, 1965, Wiener, Curry, and Faustina, 1984). The Inverted-U theory states that for a given task, there is an optimal level of workload or demand that yields the highest level of performance. A departure in either direction from the optimal level of work will result in a performance decrement. Wiener (1975) indicated that while most of the results of vigilance research support the right-hand side of the inverted-U theory (overload) there is a lack of support for the left-hand branch (assertion that the task performance level can be improved by increasing the load). One of the first experiments that supported the left- 
hand side in a vigilance task was conducted by McGrath (1965). After comparing easy and hard visual monitoring tasks conducted concurrently he concluded that the presence of the hard task facilitated performance on the easy one. Wiener et al. (1984) conducted an experiment in which a control group performed a vigilance task (the signal was the decrease in distance between two dots presented on a computer screen), and a second group performed a one-dimensional compensatory tracking task in addition to the vigilance task. They found that performance of the second group (vigilance and tracking tasks) in terms of signal detection exceeded the performance of the control group (vigilance task only). They concluded that these research results provided support for the facilitating effect of increasing the task load (left side of the inverted-U).

Some researchers describe the quality inspection task as being intrinsically boring (Craig, 1984; Poulton, 1977). According to them, this explains why it is often the case that mild stress will increase the performance in terms of detection and response time. However, Wickens (1992) has indicated that vigilance tasks with working memory load are susceptible to interference from concurrent tasks.

\section{Multitasking}

Multitasking (often referred to as timesharing) has been extensively studied from a mental workload and human performance perspective. However, a relatively small amount of research has been conducted in the manufacturing domain (Wickens, 1992). As the level of system automation increases, the role of the human has shifted from that of a manual controller to system supervisor (Sheridan and Johannsen, 1976). According to Sheridan (1994), "human operators in AMS make their way among machines, inspecting parts, observing displays, and modifying control settings or keying in commands, most of it through computer-mediated control panels adjacent to various machines." This role of human operators in AMS has been identified as supervisory control. 


\section{Human Supervisory Control}

Supervisory control refers to one or more human operators programming and receiving information from a computer that interconnects through artificial effectors and sensors to the controlled process or task environment (Sheridan, 1987). Ammons, Govindaraj, and Mitchell (1988) described the supervisory controller as "an operator responsible for a group of complex machinery where the operations require intermittent attention and depend on higher-level perceptual and cognitive functions." Sheridan (1976) defined a general paradigm of supervisory control consisting of five functions: 1)

Plan, 2) Teach, 3) Monitor, 4) Intervene, and 5) Learn. For each of the main supervisory functions the computer provides decision-aiding and implementation capabilities, as shown in Figure 5. A description of these functions is presented in Figure 6.

Job scheduling, inventory planning, and problem solving (disturbance control) have been among the supervisory control responsibilities commonly assigned to human operators in AMS (Suri and Whitney, 1984; Ammons et al., 1988). The capabilities of humans and computers in AMS planning/scheduling tasks are presented in Table 5 (Nakamura and Salvendy, 1994). Table 6 shows examples of different types of unexpected contingencies (disturbances) in AMS (Kuivanen, 1996). Ammons et al. (1988) stated that two ways in which the unique skills of the human decision maker are used in supervisory control are to fine-tune or refine standard operating procedures for particular system states and to compensate for unplanned events and unexpected contingencies. 


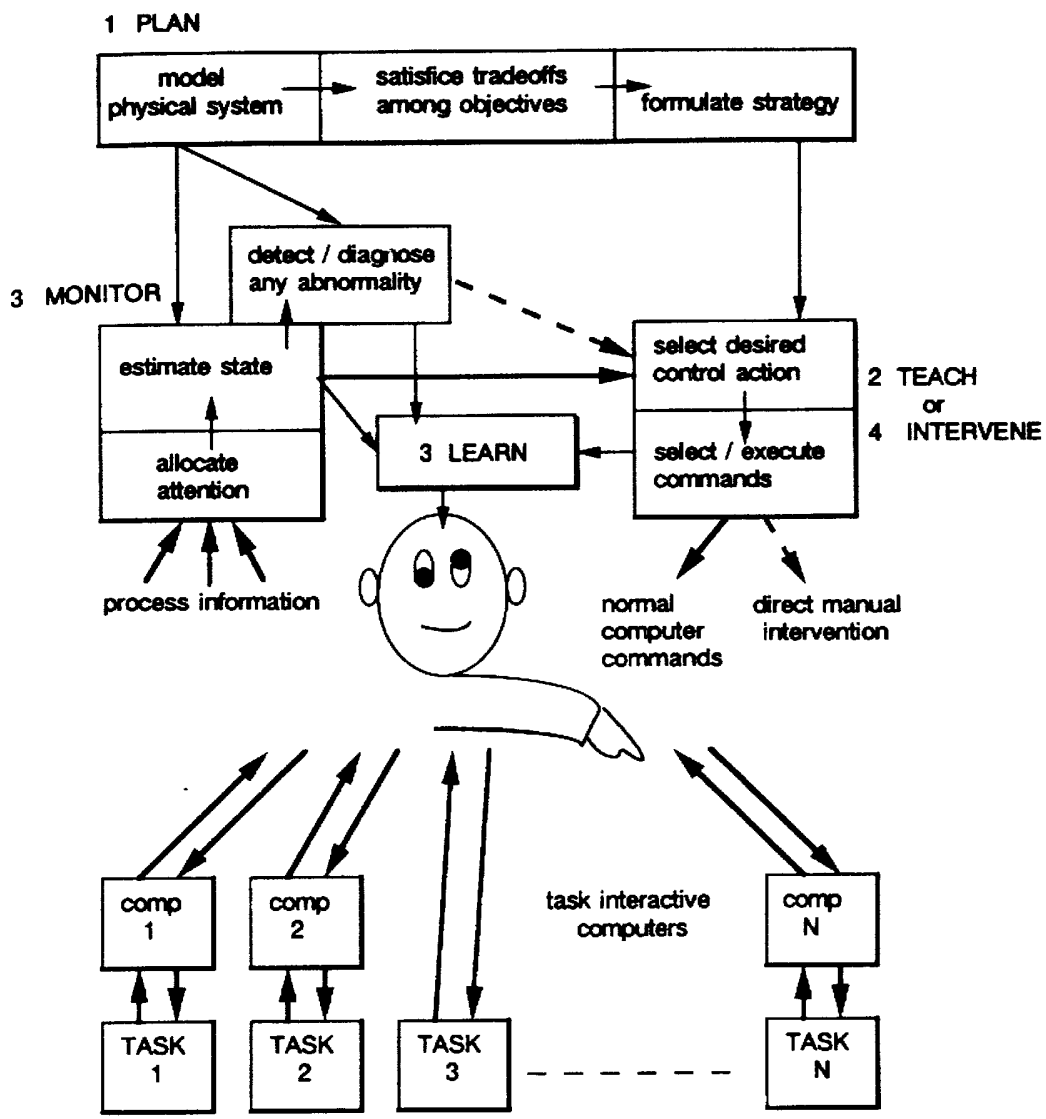

Figure 5. General paradigm of supervisory control (Sheridan, 1976). 
Plan

a) model the physical system to be controlled

b) decide on overall goal or goals, the objective function, tradeoffs among goals, and criteria for handling uncertainties

c) formulate a strategy or general procedure

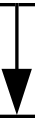

\section{Teach}

a) select the control action to best achieve the desired goal

b) select and execute the commands to computers to achieve the goal

Monitor
a) allocate attention appropriately among the various subsystems to
measure salient state variables
b) estimate the current state of the system
c) detect and diagnose any abnormality

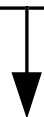

\section{Intervene}

a) make minor adjustments of system parameters when necessary, as the automatic control continues

b) take over manual control if there has been a failure of the automatic control

c) abort the process in case of a major failure

Figure 6. Temporal nesting of the general paradigm of supervisory control functions (Sheridan, 1976). 
Table 5. Capabilities of human and computer in planning/scheduling tasks of AMS (Nakamura, and Salvendy, 1994).

\begin{tabular}{|c|c|c|c|}
\hline Subtask & Description & Computer & Human \\
\hline 1. Detection & $\begin{array}{l}\text { - Detect information and } \\
\text { data for jobs and } \\
\text { machines. }\end{array}$ & $\begin{array}{l}\text { - Computer can easily } \\
\text { detect information and } \\
\text { data. }\end{array}$ & $\begin{array}{l}\text { Human takes a long } \\
\text { time to detect the } \\
\text { presence of } \\
\text { information and data }\end{array}$ \\
\hline $\begin{array}{l}\text { 2. Identification of } \\
\text { system status }\end{array}$ & $\begin{array}{l}\text { - Identify the present } \\
\text { state of the system. }\end{array}$ & $\begin{array}{l}\text { - If the identified } \\
\text { pattern was predeter- } \\
\text { mined, computer can } \\
\text { quickly identify it. }\end{array}$ & $\begin{array}{l}\text { - Human can recognize } \\
\text { the important features } \\
\text { in the planning / } \\
\text { scheduling environ- } \\
\text { ment. (but this is } \\
\text { noniinguistis } \\
\text { knowledge.) }\end{array}$ \\
\hline 3. Interpretation & $\begin{array}{l}\text { - Interpret performance } \\
\text { criteria and set the final } \\
\text { goal for planning / } \\
\text { scheduling. }\end{array}$ & $\begin{array}{l}\text { - Computer can decide } \\
\text { if the program connect } \\
\text {-ing the present state } \\
\text { with the final goal is } \\
\text { stored. }\end{array}$ & $\begin{array}{l}\text { - Human can set the } \\
\text { reasonable goal from } \\
\text { among many criteria } \\
\text { which conflict with } \\
\text { each other. }\end{array}$ \\
\hline 4. Order selection & $\begin{array}{l}\text { Select an order to } \\
\text { be scheduled according } \\
\text { to a priority. }\end{array}$ & $\begin{array}{l}\text { - Heuristic algorithm } \\
\text { can provide a "good" } \\
\text { solution, but no guar- } \\
\text { antee on optimat one. }\end{array}$ & $\begin{array}{l}\text { - Human intuition } \\
\text { makes the best feasible } \\
\text { solution. }\end{array}$ \\
\hline $\begin{array}{l}\text { 5. Time assign- } \\
\text { ment }\end{array}$ & $\begin{array}{l}\text { Determine the start } \\
\text { time and finish time } \\
\text { for each operation } \\
\text { of the selected order. }\end{array}$ & $\begin{array}{l}\text { - It is difficult to take } \\
\text { balance between job } \\
\text { waiting time and } \\
\text { machine idle time. }\end{array}$ & $\begin{array}{l}\text { - Coordinating human } \\
\text { with computer helps to } \\
\text { determine efficient } \\
\text { time assignment. }\end{array}$ \\
\hline $\begin{array}{l}\text { 6. Resource } \\
\text { allocation }\end{array}$ & $\begin{array}{l}\text { Select the resources } \\
\text { (machines, tools, } \\
\text { fixtures, NC program, } \\
\text { etc.) to produce an } \\
\text { order. }\end{array}$ & $\begin{array}{l}\text { - Computer program } \\
\text { can easily check } \\
\text { whether machines } \\
\text { tools, fixtures and NC } \\
\text { program are available. }\end{array}$ & $\begin{array}{l}\text { Human selects many } \\
\text { alternative solutions. }\end{array}$ \\
\hline $\begin{array}{l}\text { 7. Evaluation and } \\
\text { modification }\end{array}$ & $\begin{array}{l}\text { Evaluate the plan / } \\
\text { schedule and if not } \\
\text { satisfied, modify it. }\end{array}$ & $\begin{array}{l}\text { - Poor, but updates the } \\
\text { overall plan / schedule } \\
\text { at least once every } \\
\text { minute. }\end{array}$ & $\begin{array}{l}\text { - Human modifies } \\
\text { overall pian / schedule } \\
\text { with flexible decision } \\
\text { making abilities. }\end{array}$ \\
\hline 8. Generation & $\begin{array}{l}\text { - Generate the plan / } \\
\text { schedule sheet and issue } \\
\text { it to the floor. }\end{array}$ & $\begin{array}{l}\text { - Computer can do it } \\
\text { very easily. }\end{array}$ & - Slow, not suitable. \\
\hline 9. Control & $\begin{array}{l}\text { - Check the difference } \\
\text { between the plan / } \\
\text { schedule and the practice. }\end{array}$ & $\begin{array}{l}\text { - Computer can do it } \\
\text { easily under normal } \\
\text { conditions. }\end{array}$ & $\begin{array}{l}\text { Human can adapt at } \\
\text { abnormal conditions. }\end{array}$ \\
\hline
\end{tabular}


Table 6. Different type of disturbances in AMS (Kuivanen, 1996).

\begin{tabular}{|c|c|c|c|}
\hline Target Group & Viewpoint & Definition & $\begin{array}{l}\text { Example of the } \\
\text { Cause of the } \\
\text { Disturbance }\end{array}$ \\
\hline General & $\begin{array}{l}\text { All the situations } \\
\text { concerning the } \\
\text { organization, } \\
\text { technique, or human } \\
\text { action }\end{array}$ & $\begin{array}{l}\text { A disturbance is an } \\
\text { unplanned or } \\
\text { undesirable state } \\
\text { or function of the }\end{array}$ & $\begin{array}{l}\text {-a missing work } \\
\text { order } \\
\text {-machine or device } \\
\text { failure } \\
\text { - broken tool } \\
\text {-overloading } \\
\text {-insufficient training }\end{array}$ \\
\hline $\begin{array}{l}\text { Operator of the } \\
\text { system }\end{array}$ & $\begin{array}{l}\text { All the situations } \\
\text { that harm the normal } \\
\text { normalworking } \\
\text { routine }\end{array}$ & $\begin{array}{l}\text { A disturbance is a } \\
\text { a state or function } \\
\text { of the system, which } \\
\text { causes extra work }\end{array}$ & $\begin{array}{l}\text {-error in the work } \\
\text { program } \\
\text {-error in the work } \\
\text {-broken tool } \\
\text {-machine or device } \\
\text { failure }\end{array}$ \\
\hline Maintenance & $\begin{array}{l}\text { All the situa tions, } \\
\text { that make it neces- } \\
\text { sary for the main- } \\
\text { tenance personnel } \\
\text { to take action } \\
\text { towards the systems } \\
\text { operation }\end{array}$ & $\begin{array}{l}\text { A disturbance is a } \\
\text { state or function } \\
\text { of the system that } \\
\text { requires remedial } \\
\text { actions }\end{array}$ & $\begin{array}{l}\text {-machine or device } \\
\text { failure } \\
\text {-overloading } \\
\text {-maintenance and } \\
\text { cleaning }\end{array}$ \\
\hline $\begin{array}{l}\text { Labor management } \\
\text { and design }\end{array}$ & $\begin{array}{l}\text { All the situations } \\
\text { that prevent } \\
\text { production }\end{array}$ & $\begin{array}{l}\text { A disturbance is a } \\
\text { state or function of } \\
\text { the system which } \\
\text { stops production }\end{array}$ & $\begin{array}{l}\text {-raw materials, tools, } \\
\text { or plans missing } \\
\text {-machine or device } \\
\text {-machine or device } \\
\text { failure } \\
\text {-workers or key } \\
\text { personnel taken ill } \\
\text {-strike }\end{array}$ \\
\hline $\begin{array}{l}\text { Production } \\
\text { management }\end{array}$ & $\begin{array}{l}\text { All that disables a } \\
\text { delivery in agreed } \\
\text { time }\end{array}$ & $\begin{array}{l}\text { A disturbance is } \\
\text { a state or function } \\
\text { of the system, which } \\
\text { makes it impossible } \\
\text { for the producer to } \\
\text { deliver the products } \\
\text { to the customer in } \\
\text { agreed time }\end{array}$ & $\begin{array}{l}\text {-strike } \\
\text {-overloading } \\
\text { - machine and device } \\
\text { failure } \\
\text { - bad quality }\end{array}$ \\
\hline Marketing & $\begin{array}{l}\text { All the events in } \\
\text { production, that } \\
\text { complicate } \\
\text { marketing }\end{array}$ & $\begin{array}{l}\text { A distance is a state } \\
\text { or function of the } \\
\text { system, which } \\
\text { disables or makes it } \\
\text { makes it difficult to } \\
\text { make a business } \\
\text { agreement }\end{array}$ & $\begin{array}{l}\text {-too long time of } \\
\text { delivery } \\
\text {-inferior quality }\end{array}$ \\
\hline
\end{tabular}




\section{Determinants of Multitasking Performance}

Different mental models have been used to describe multitasking performance. Scheduling, switching, confusion, cooperation, and processing resources are mechanisms often identified as determinants of multitasking performance (Damos, 1991; Adams, Tenney, and Pew, 1991; Wickens, 1992). In particular, the concept of processing resources is the basis for understanding the other mechanisms, and hence for multitasking performance. According to Wickens (1991), the resources concept is founded on the underlying assumption that the human operator has a limited capacity for processing resources that may be allocated to task performance; therefore, multitasking can lead to one or more tasks with less resources than required, causing a performance deterioration. This deterioration in the performance of one task because of competition with another task for critical resources is known as interference.

Two major processing resources theories of task performance are Single-Resource Theory and Multiple-Resources Theory. The Single-Resource theory proposed by Kahneman (1973) postulates one undifferentiated limited pool of resources available to all tasks and mental activities. According to this theory, multitasking performance declines as the difficulty of one of the tasks increases, because it demands more resources from the limited pool, thus leaving fewer resources for performing the other tasks. Sanders and McCormick (1993) indicated that the Single-Resource Theory has difficulty explaining: 1) why tasks that require the same memory codes or processing modalities interfere more than tasks not sharing the same memory codes or processing modalities, 2) why with some combinations of tasks increasing the difficulty of one task has no effect on the performance of the others, and 3) why some tasks can be time-shared perfectly. According to Sanders and McCormick (1993), these three issues can be explained by the Multiple-Resources Theory proposed by Wickens (1984).

The Multiple-Resources Theory proposes that there are three dimensions along which resources can be allocated. The first dimension is stages (encoding and central processing vs. responding), which explains why tasks requiring response selection and allocation resources are not disrupted by tasks requiring central processing resources. 
The second dimension is input modality (auditory vs. visual), which explains why multitasking is better when the tasks do not require resources from the same modality than when they do. The third dimension is processing codes (spatial vs. verbal), which explains why multitasking is performed better when one task involves moving or positioning objects in space and the other involves language or logical operations. In addition to the three dimensions mentioned above, this theory suggests a response dimension (vocal vs. manual), which explains why multitasking is performed better when the tasks responses are of opposite types. Although the Multiple-Resources Theory was developed based on dual task multitasking, it can be used to explain more complex multitasking.

Scheduling and switching are highly influential on performance for both dual-task and more complex multitasking. The operator's scheduling and switching ability depends on an understanding of the temporal constraints, the objective, and the cost associated with each task (Wood, 1982; Moray, Dessouky, Kijowski, and Adapathya,1990). Poor scheduling, inefficient switching between tasks, or insufficient time to do the multiple tasks sequentially will force the person to engage in concurrent processing. Wickens (1991) indicated that when the operator is engaged in concurrent processing, multitasking performance will be influenced by: 1) confusion (elements of one task become confused with the processing of another task because of their similarity), 2) cooperation between task processes (caused by high similarity of processing routines), and 3) competition for task resources. When the amount of resources demanded by the multiple tasks exceeds the amount of the operator's mental resources available, he or she will experience mental workload, consequently decreasing multitasking performance (McCloy, Derrick, and Wickens, 1983; Bi and Salvendy, 1994). Figure 7 shows the relationship among the performance-resource function for multitasking (Wickens, 1992). Sheridan (1994) stated that mental workload is very important for supervisory control in AMS where the human operator is constantly called upon to do multiple complex sensory and judgmental tasks. The central issue for vigilance research is to determine the effect of the additional tasks to the vigilance performance (Craig, 1991). 

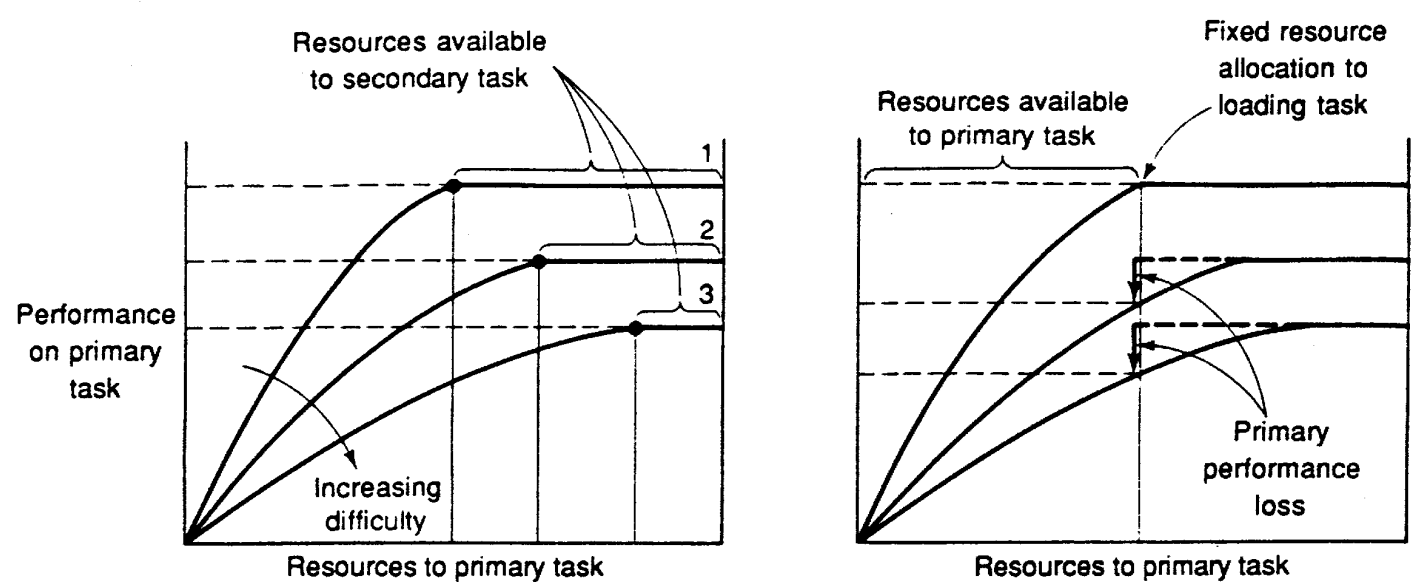

Figure 7. Performance-resource function for multitasking (Wickens, 1992). 


\section{$\underline{\text { Research Objectives }}$}

There are still a surprising number of parts in AMS that can only be inspected by means of human visual sensory detection. Even when the quality inspection search component has been automated, human operators must make a final decision on the acceptability of a manufactured part. In many cases, this judgment must be made on the basis of a comparison with a memorized criteria for acceptable parts. The objective of this research was to characterize the operator's performance in the quality inspection task while conducting multitasking in an AMS.

The experiment tested the following hypotheses:

Hypothesis 1: The operator's decision making component of the quality inspection task in AMS will be significantly affected by the appearance of different types of defects in the units being produced.

Hypothesis 2: The operator's decision making component of the quality inspection task in AMS will be significantly affected by multitasking.

Hypothesis 3: The operator's decision making component of the quality inspection task in AMS will be significantly affected by the interaction of multitasking with the appearance of different types of defects in the units being produced. 


\section{Chapter 2. EXPERIMENTAL METHOD}

\section{$\underline{\text { Subjects }}$}

Twelve subjects (9 male, 3 female) with 20/20 vision and no previous quality inspection task experience participated in the experiment. They were compensated for their participation at a rate of $\$ 5.00$ per hour. All of the subjects were selected from the Virginia Polytechnic Institute and State University community. Subjects participation was in accordance with the Virginia Tech IRB \#97-161.

\section{Apparatus}

A real-time, interactive simulation of an AMS cell was the scenario for the experimental tasks. It consisted of three main stations: 1) quality inspection station, 2) production scheduling and inventory control station, and 3) adjacent process station. At the quality inspection station the subject (operator) was expected to decide whether to accept or reject the units presented on a computer screen. At the production scheduling and inventory control station the operator was expected to decide whether to schedule a new order before those already in the system or not. Also, the operator was expected to determine the quantity of a particular raw material order that needed to be placed. Bins with dummy parts used for the inventory task were located in this station. At the adjacent process station the operator was expected to conduct machine setup and disturbance control tasks.

Each station was represented by a 486-DX personal computer with a high resolution monitor located in a standing work table. This representation was consistent with human-machine interfaces in AMS. Visual Basic 4.0 was used to generate the three computer-based stations code. Two video cameras were used to transmit images of what was taking place in the AMS cell to the video cube located in experimenter area (see Figure 8). 


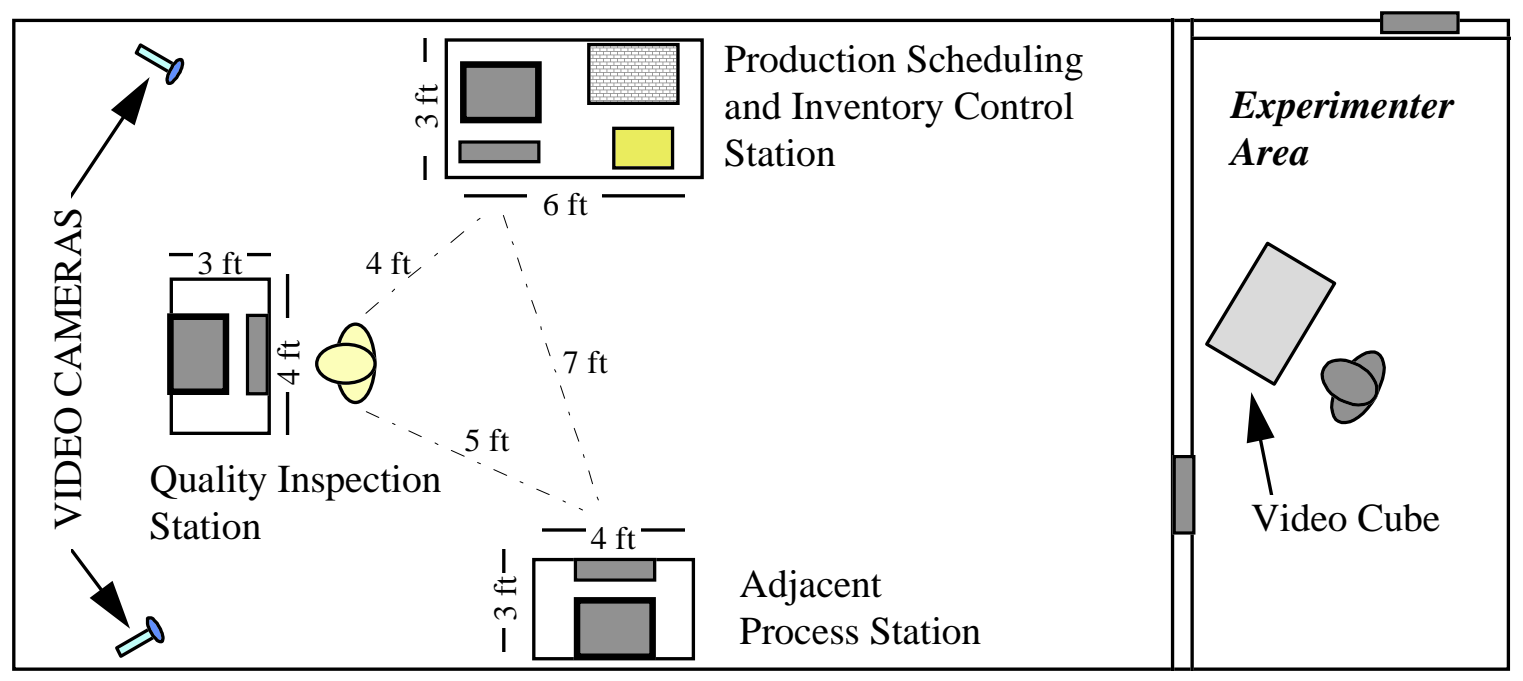

Figure 8. Experimental scenario - AMS Cell.

\section{Experimental Design}

A 2x3 within-subject factorial experiment was conducted (see Table 7). The two independent variables were Defect Type with two levels (one or two types of defects presented at a time), and Tasks with three levels (one task, three tasks, or five tasks concurrently conducted). The experimental unit was a white rectangle $(16 \mathrm{~cm}$ wide $\mathrm{x} 10$ $\mathrm{cm}$ high). A Balanced Latin Square design was used to order the experimental treatments (see Table 8).

\section{Independent Variables}

Defect Type and Tasks were the independent variables used in the experiment. The two types of defects used were a speck (small circular spot) and a scratch (a narrow, shallow straight line). Only one of these defects (speck or scratch) was presented in the faulty units produced during a treatment when the Defect Type level was one type. Both defects (speck and scratch) were presented in the faulty units produced during a treatment 
when the Defect Type level was two types. The experimental unit and defect types are shown in Figure 9.

Table 7. Experimental conditions for the $2 \times 3$ design.

\begin{tabular}{|c|c|c|}
\hline Treatment & Defect Type & Tasks \\
\hline 1 & $\begin{array}{l}\text { one type } \\
\text { (scratch or speck) }\end{array}$ & - quality inspection \\
\hline 2 & $\begin{array}{l}\text { two types } \\
\text { (scratch and speck) }\end{array}$ & $\begin{array}{l}\text { - quality inspection } \\
\text { - production scheduling and inventory }\end{array}$ \\
\hline 3 & $\begin{array}{l}\text { one type } \\
\text { (scratch or speck) }\end{array}$ & $\begin{array}{l}\text { - quality inspection } \\
\text { - production scheduling and inventory } \\
\text { - machine setup and disturbance control }\end{array}$ \\
\hline 4 & $\begin{array}{l}\text { two types } \\
\text { (scratch and speck) }\end{array}$ & - quality inspection \\
\hline 5 & $\begin{array}{l}\text { one type } \\
\text { (scratch or speck) }\end{array}$ & $\begin{array}{l}\text { - quality inspection } \\
\text { - production scheduling and inventory }\end{array}$ \\
\hline 6 & $\begin{array}{l}\text { two types } \\
\text { (scratch and speck) }\end{array}$ & $\begin{array}{l}\text { - quality inspection } \\
\text { - production scheduling and inventory } \\
\text { - machine setup and disturbance control }\end{array}$ \\
\hline
\end{tabular}

Table 8. Balanced Latin Square design.

\begin{tabular}{|c|c|c|c|c|c|c|}
\cline { 2 - 7 } \multicolumn{1}{c|}{} & \multicolumn{6}{c|}{ Subjects } \\
\cline { 2 - 7 } Order & S1 & S2 & S3 & S4 & S5 & S6 \\
\cline { 2 - 7 } & S7 & S8 & S9 & S10 & S11 & S12 \\
\hline 1 & T1 & T2 & T3 & T4 & T5 & T6 \\
\hline 2 & $\mathrm{~T} 2$ & $\mathrm{~T} 3$ & $\mathrm{~T} 4$ & $\mathrm{~T} 5$ & $\mathrm{~T} 6$ & $\mathrm{~T} 1$ \\
\hline 3 & $\mathrm{~T} 6$ & $\mathrm{~T} 1$ & $\mathrm{~T} 2$ & $\mathrm{~T} 3$ & $\mathrm{~T} 4$ & $\mathrm{~T} 5$ \\
\hline 4 & $\mathrm{~T} 3$ & $\mathrm{~T} 4$ & $\mathrm{~T} 5$ & $\mathrm{~T} 6$ & $\mathrm{~T} 1$ & $\mathrm{~T} 2$ \\
\hline 5 & $\mathrm{~T} 5$ & $\mathrm{~T} 6$ & $\mathrm{~T} 1$ & $\mathrm{~T} 2$ & $\mathrm{~T} 3$ & $\mathrm{~T} 4$ \\
\hline 6 & $\mathrm{~T} 4$ & $\mathrm{~T} 5$ & $\mathrm{~T} 6$ & $\mathrm{~T} 1$ & $\mathrm{~T} 2$ & $\mathrm{~T} 3$ \\
\hline
\end{tabular}




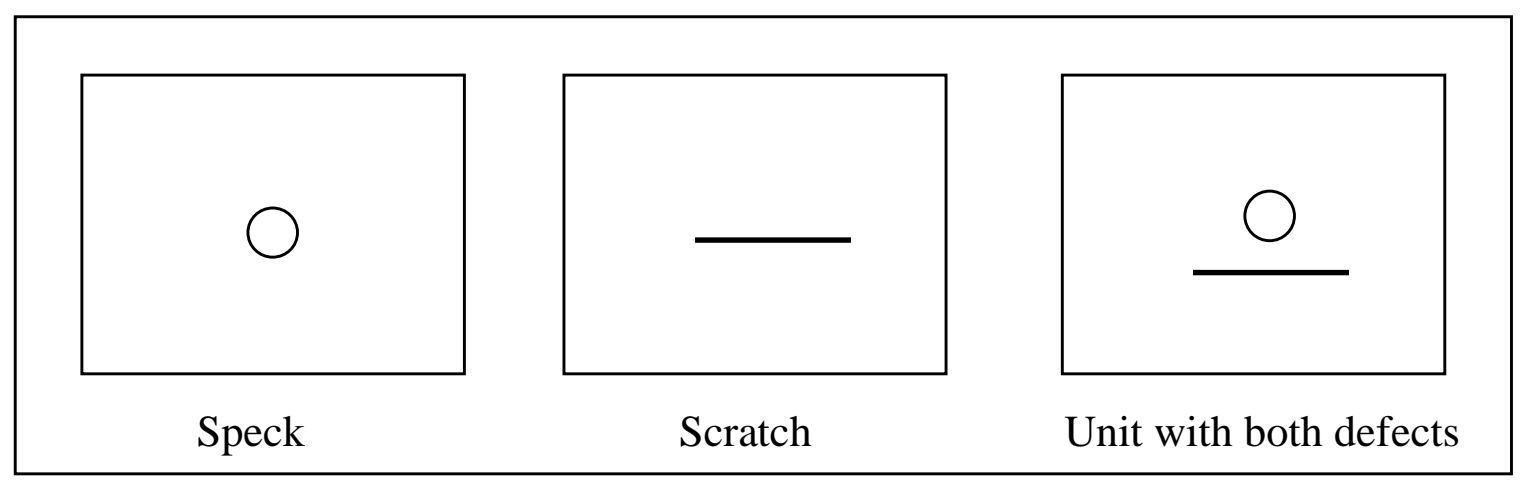

Figure 9. Experimental unit and defect types.

The Tasks factor consisted of five different tasks conducted at the three main stations. Only the quality inspection task was conducted at the one task level of the Tasks factor. In addition to the quality inspection task, the operator conducted a scheduling task and an inventory control task concurrently at the three tasks level of the Tasks factor. At the five tasks level of the Tasks factor, the operator concurrently conducted a machine setup task and a machine disturbance control task in addition to the quality inspection, production scheduling, and inventory control tasks previously mentioned. The reason for using an additional level of multitasking (machine setup and disturbance control tasks) was to increase the processing resources demand while minimizing the possibility of monotony by having a greater variety of independent tasks rather than just increasing the event rate at the other secondary tasks (production scheduling and inventory control).

\section{Task Description}

The experiment consisted of six experimental treatments as presented in Table 7. The average duration of each treatment ranged between 50 minutes and 120 minutes. During that period of time 500 units were inspected. Out of the 500 units, 50 had no defects (blanks), 250 units had a defect (or defects) that did not exceeded the quality criterion (acceptable), and 200 units had a defect (or defects) that exceeded the criterion (rejectable). The quality criterion was 6 millimeters for the speck diameter, and 26 millimeters for the scratch length. The just noticeable difference (jnd) that each subject 
could detect was added or subtracted to the quality criterion to generate rejectable defects (quality criterion $+1 \mathrm{jnd}$ ) and acceptable defects (quality criterion - $1 \mathrm{jnd}$ ) respectively. The arrival of units to the inspection station was random with a mean time between events of 3 seconds. The subjects were instructed to execute the tasks to the best of their capabilities using a neutral payoff. There was no immediate knowledge of results. Although quality inspection was the primary task of this experiment, subjects conducted the other tasks at a performance level of at least $90 \%$.

The quality inspection task was conducted at the one task level of the Tasks factor. In the inspection task a ringing sound alerted the operator to the arrival of a unit to be inspected. The operator clicked the "Start" button to indicate the beginning of the inspection. After the inspection (up to six seconds allowed), the operator clicked the "Reject" button to reject a unit that exceeded the memorized quality criterion, or the "Accept" button to accept a unit that did not exceed the criterion (see Figure 10).

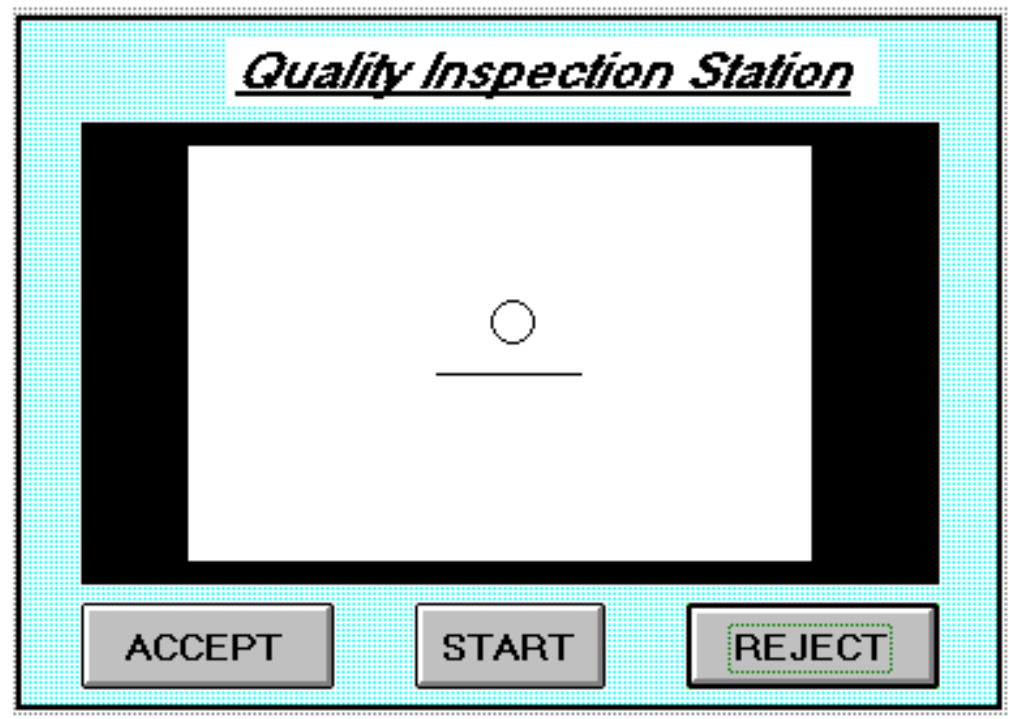

Figure 10. Quality Inspection Station screen.

In addition to the quality inspection task, the operator conducted a scheduling task and an inventory control task concurrently at the three tasks level of the Tasks factor. For 
the scheduling task the operator responded to a particular voiced message ("Scheduling") from the production scheduling and inventory control station announcing the arrival of a new order (see Figure 11). After comparing the new order quantity and due date with other orders already in the system, the operator scheduled it based on a scheduling criterion. According to this criterion the new order should be scheduled to be processed before any order with a later due date. In the case of more than one order with the same due date, the one with the smallest quantity should be scheduled first. For the inventory control task, the operator responded to a voiced message ("Inventory") from the production scheduling and inventory control station announcing the need to conduct an inventory on a specific part. The operator then counted the particular dummy parts in the bin and entered the quantity in the inventory control application of the production scheduling and inventory control station (see Figure 12). After calculating (mentally) the difference between the quantity required and the available quantity the operator placed an order for the quantity needed to satisfy the demand.

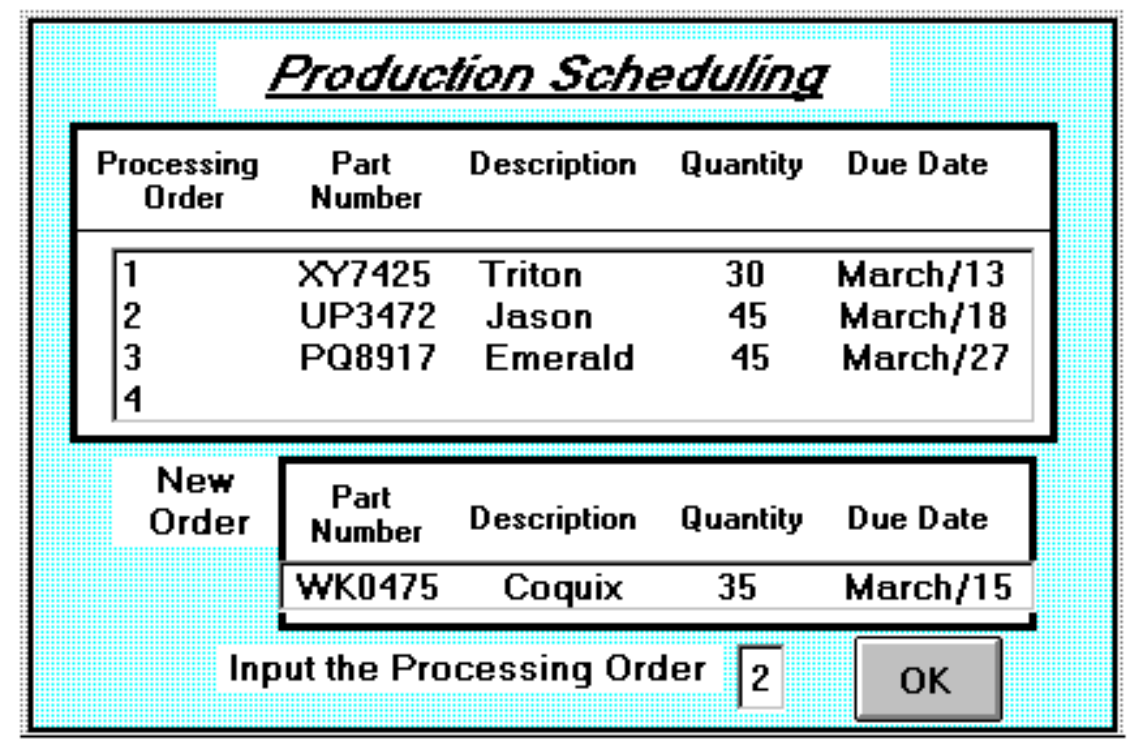

Figure 11. Scheduling screen at the Production Scheduling and Inventory Control Station. 


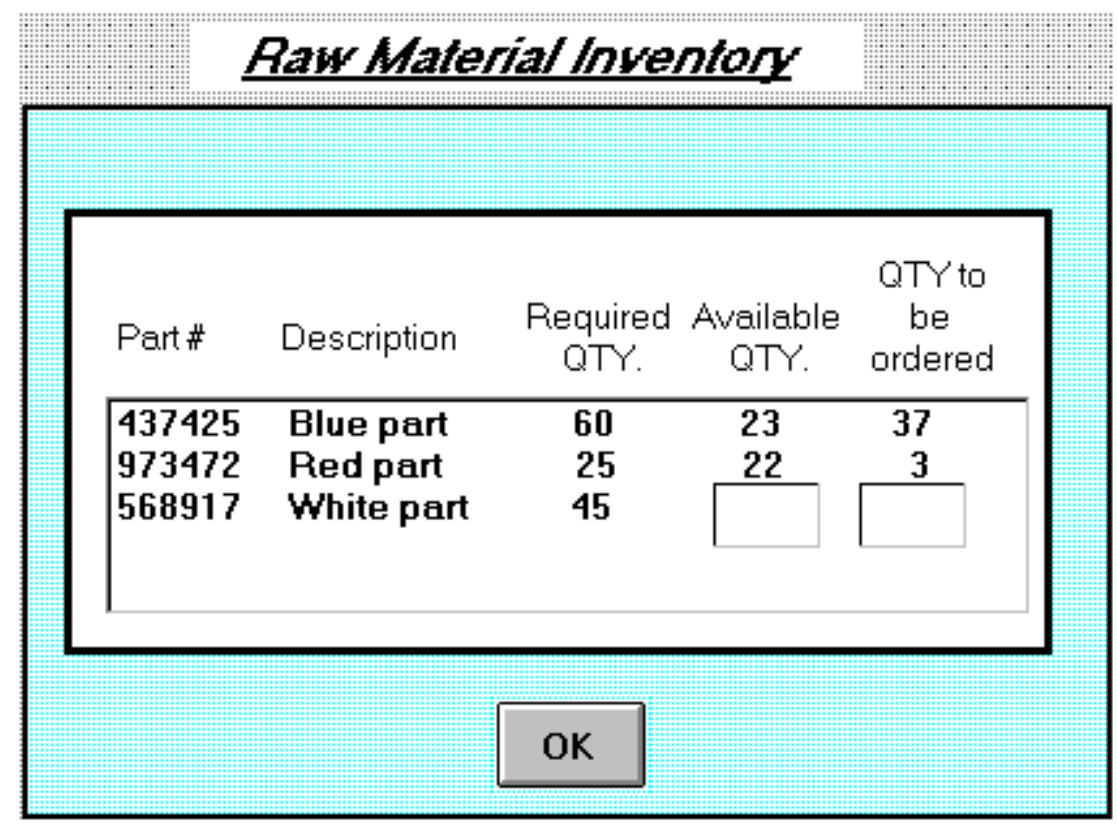

Figure 12. Inventory screen at the Production Scheduling and Inventory Control Station.

At the Five Tasks level of the Tasks factor, the operator concurrently conducted a machine setup task and a disturbance control task in addition to the quality inspection, production scheduling, and inventory control tasks previously discussed. The operator responded to a voiced message from the adjacent process station announcing the need to conduct either a setup ("Machine Setup") or a disturbance control ("Machine Problem"). For the setup task the operator entered the parameters of a particular product (from a setup card) to be processed (see Figure 13). The setup card (hard copy) was available at the adjacent process station. For the machine disturbance control task the operator read the displayed error message on the station's screen, then entered a particular alphanumeric code, available at the station (from a disturbance control codes card), to restart the process (see Figure 14). All of the additional tasks (scheduling, inventory, machine setup, and machine disturbance control) were presented randomly eighteen times each during an experimental treatment. 


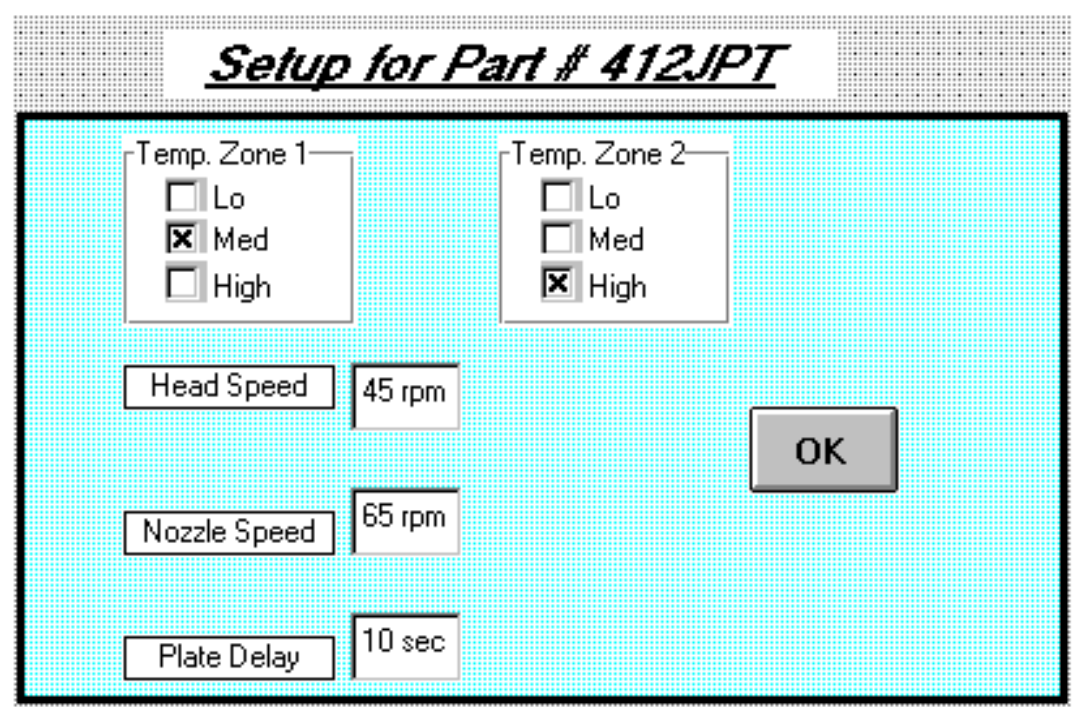

Figure 13. Setup screen at the Adjacent Process Station.

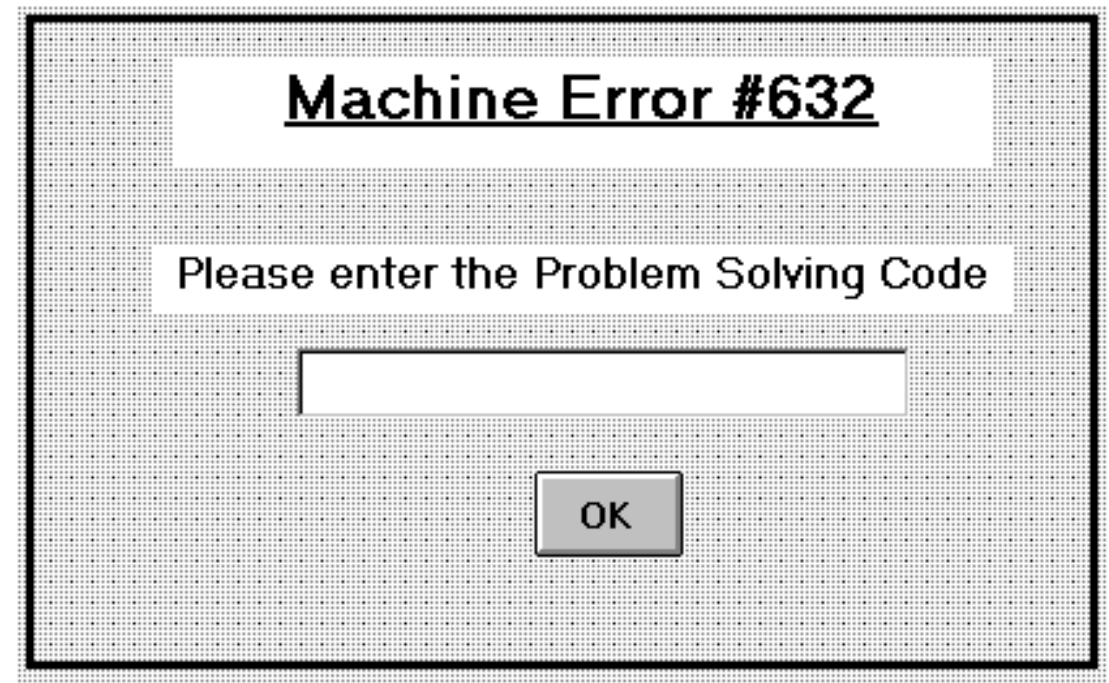

Figure 14. Disturbance control screen at the Adjacent Process Station.

\section{Dependent Variables}

The proportion of correct detection (rejection of unacceptable units, hit), the proportion of incorrect detection (rejection of acceptable units, false alarm), the time to make a decision about the part inspected, and the scores of the subjective workload 
questionnaire were recorded for each experimental treatment (Appendix H). In addition, the SDT metrics of sensitivity $\left(\mathrm{d}^{\prime}\right)$ and inspector decision making criterion or bias ( $\beta$ and c) were calculated using the observed hit and false alarm rates. The computational formulas for the SDT metrics $\left(\mathrm{d}^{\prime}, \beta\right.$, and $\left.c\right)$ and the experiment data for each subject (based on the 500 units inspected) is presented in Appendix I.

The subjective workload questionnaire consisted of twelve likert-like scaled statements divided in six major categories: 1) mental demand, 2) physical demand, 3) temporal demand, 4) performance, 5) effort, and 6) frustration level. These categories are the same subscales used in NASA Task Load Index Subjective Workload Assessment Technique (NASA-TLX). Hart and Staveland (1988) indicated that the six subscales were found to be primary sources of task loading conducive to workload. The NASATLX was not used, despite its high sensitivity to experimental manipulations of workload, to avoid the use of a reference task. The reference task is recommended to obtain subjective estimates of the importance of the six subscales (Gopher and Braune, 1984). It must share elements in common with the experimental tasks. The subjective workload level of the experimental tasks would be rated with respect to the reference task. Given the subjects' lack of experience in the industrial quality inspection task combined with the multitasking of the other independent tasks the use of a reference task might be inadequate for this experiment.

\section{Experimental Procedures}

Before going through the screening process the potential subjects received general information (written and verbal) about the experiment (Appendix A). Those who agreed to participate read and signed the informed consent form (Appendix B). At this point, the participant's vision was tested for acuity using a Baush \& Lomb Vision Tester. Those who meet the visual acuity criterion (20/20), participated in a Two Alternative Forced Choice procedure (2AFC) to determine if they could score a proportion of correct detection of at least 0.80 (Appendix C). The criterion of 0.80 correct detection is 
consistent with what has been reported for $100 \%$ quality inspection in industry (Juran 1974; Konz, Peterson, and Joshi, 1981; Schilling 1982). Written and verbal instructions were given to the subjects before the 2AFC screening test (Appendix D). Those who satisfactorily passed the screening process participated in the Constant Stimuli Method procedure to determine difference threshold (DL, for the German "Differenz Limen") (Appendix E). This psychophysical measure was used to generate the defects' intensity consistent with the just noticeable difference that each subject could detect (Appendix J). Subjects received written and verbal instructions before this procedure (Appendix F).

Before participating in the experiment the subjects received instructions (written and verbal) as well as individualized training and practice (with feedback) in the experimental rules and procedures, tasks and equipment, and the defect rejection criterion (Appendix G). Once their performance on the secondary tasks of the laboratory controlled AMS cell exceeded $90 \%$ they were scheduled for six experimental sessions (one experimental treatment per session). The $90 \%$ criterion was used to minimize any practice or learning effect during the experiment. The subjects received practice (with feedback and no time constraint, as well as without feedback and with time constraint) in the quality inspection task before participating in each experimental treatment. The subjective workload questionnaire was filled out after the subjects completed each experimental treatment.

\section{Data Analysis}

The observed proportions of correct rejection of unacceptable parts (hit), and the proportions of incorrect rejection of acceptable parts (false alarm) were first adjusted via the procedure necessary to permit the calculation of SDT $\left(\mathrm{d}^{\prime}, \beta\right.$, and $\left.c\right)$ in cases were the observed proportions equaled 0 or 1 (Snodgrass and Corwin, 1988). Snodgrass and Corwin (1988) recommended the correction of all hit and false alarm rates by adding 0.5 to each frequency and dividing by $\mathrm{N}+1$, where $\mathrm{N}$ is the number of total events 
$\left(\right.$ Hit $\left.=\frac{\# \text { correct rejection }+0.5}{\# \text { rejectable parts }+1} ; F_{-} A=\frac{\# \text { incorrect rejection }+0.5}{\# \text { acceptable parts }+1}\right)$. For consistency, they recommend applying the correction routinely, even in the absence of 0 and 1, and even when SDT measures are not calculated. This correction was also recommended for log-linear models of data expressed as counts in contingency tables (Plackett, 1974; Upton, 1978). More recently, See, Warm, Dember, and Howe (1997) reported the use of this adjustment procedure in an empirical evaluation of five parametric and nonparametric SDT metrics of response bias.

Analyses of variance (ANOVA) were done for each of the dependent variables (hit, false alarm, average time to make the decision, and the subjective workload questionnaire scores) and the SDT metrics $\left(\mathrm{d}^{\prime}, \beta\right.$, and $\left.c\right)$. The computational formulas (for $\mathrm{d}^{\prime}, B$, and $c$ ) and the subjects data (hit rate, false alarm rate, $\mathrm{d}^{\prime}, B, c$, average time, and the scores of the subjective workload questionnaire) are presented in Appendix I. 


\section{Chapter 3. RESULTS}

\section{$\underline{\text { Hit Rate }}$}

The ANOVA of the dependent variable hit is presented in Table 9. Based on the unadjusted F (p-value $=0.0251)$ and the Geisser-Greenhouse correction factor $(\mathrm{G}-\mathrm{Gp}=$ 0.0253) the effect of the interaction between Defect Type and Tasks was statistically significant.

Table 9. ANOVA summary table of hit.

\begin{tabular}{|c|c|c|c|c|c|c|}
\hline Source & df & SS & MS & F & p-value & G-Gp \\
\hline Between-Subjects & & & & & & \\
\hline Subjects (S) & 11 & 1.224766 & 0.111342 & & & ------- \\
\hline Within-Subject & & & & & & \\
\hline Defect Type (DT) & 1 & 0.002250 & 0.003101 & 0.19 & 0.668 & ------- \\
\hline DT x S & 11 & 0.127138 & 0.011558 & & & \\
\hline Tasks (Tsk) & 2 & 0.006202 & 0.003101 & 0.55 & 0.583 & - ------ \\
\hline Tsk x S & 22 & 0.123191 & 0.005600 & & & \\
\hline DT x Tsk & 2 & 0.065055 & 0.032528 & 4.38 & $0.0251 *$ & $0.0253 *$ \\
\hline DT x Tsk x S & 22 & 0.163518 & 0.007433 & & & \\
\hline Total & 71 & 1.712121 & & & & \\
\hline
\end{tabular}

* Statistically significant at $\alpha=0.05$

According to a Newman-Keuls post hoc analysis of the unconfounded comparisons of the interaction between Defect Type and Tasks, there was a statistically significant difference between inspection of parts with one type of defect (scratch or speck) while multitasking and the inspection of parts with both types of defects (scratch and speck) while multitasking (see Table 10). The hit rate when both defects were present in the inspected parts and the subject conducted one or three tasks concurrently was higher than when the same number of tasks was performed but only one type of defect was present in the inspected parts. However, when the subjects conducted five tasks and both defects were present in the inspected parts, the hit rate was lower than 
when the same number of tasks was performed but only one type of defect was present in the inspected parts. The interaction between Defect Type and Tasks is shown in Figure 15.

Table 10. Newman-Keuls analysis of the effect of the Defect Type and Task interaction on hit.

\begin{tabular}{|c|c|c|c|c|c|c|c|c|c|}
\hline \multicolumn{10}{|c|}{ Increasing Rank Order } \\
\hline & & 1 & 2 & 3 & 4 & 5 & 6 & & \\
\hline $\begin{array}{l}\text { Treatment } \\
\text { Means }\end{array}$ & & $\begin{array}{c}\mathrm{DT}_{2} \mathrm{Tsk}_{5} \\
0.736\end{array}$ & $\begin{array}{c}\mathrm{DT}_{1} \mathrm{Tsk}_{1} \\
0.753\end{array}$ & $\begin{array}{c}\mathrm{DT}_{1} \mathrm{Tsk}_{3} \\
0.753\end{array}$ & $\begin{array}{c}\mathrm{DT}_{2} \mathrm{Tsk}_{1} \\
0.784\end{array}$ & $\begin{array}{c}\mathrm{DT}_{1} \mathrm{Tsk}_{5} \\
0.806\end{array}$ & $\begin{array}{l}\mathrm{DT}_{2} \mathrm{Tsk}_{3} \\
0.826\end{array}$ & $\mathrm{r}$ & $\mathrm{CD}_{0.05}$ \\
\hline \multirow{5}{*}{$\begin{array}{l}\text { Rank } \\
\text { Order }\end{array}$} & 1 & ------- & ------- & ------- & $0.048 *$ & $0.07 *$ & $0.097 *$ & 6 & 0.032 \\
\hline & 2 & & ------- & 0 & $0.031 *$ & $0.053 *$ & ------ & 5 & 0.030 \\
\hline & 3 & & & ------- & ------- & $0.053 *$ & $0.073 *$ & 4 & 0.028 \\
\hline & 4 & & & & ------- & ------- & $0.042 *$ & 3 & 0.026 \\
\hline & 5 & & & & & ------- & ------- & 2 & 0.021 \\
\hline
\end{tabular}

* Statistically significant at $\alpha=0.05$

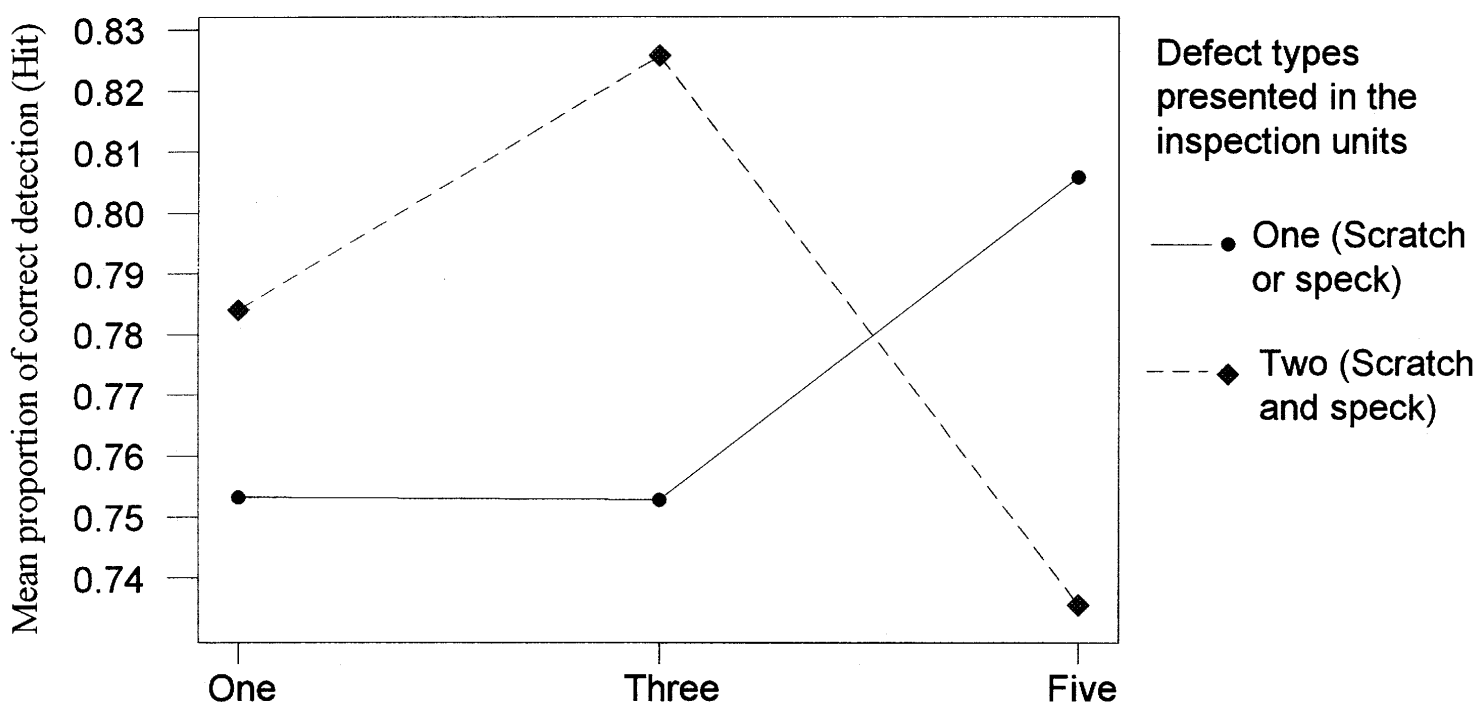

Tasks being performed

Figure 15. Mean plot of the effects of the Defect Type and Tasks interaction on hit. 


\section{False Alarm Rate}

The ANOVA of the dependent variable false alarm is presented in Table 11.

Based on the p-values of the unadjusted $\mathrm{F}$ there was no statistically significant effect.

Table 11. ANOVA summary table of false alarm.

\begin{tabular}{|c|c|c|c|c|c|c|}
\hline Source & df & SS & MS & F & p-value & G-Gp \\
\hline Between-Subjects & & & & & & \\
\hline Subjects (S) & 11 & 0.059639 & 0.005422 & & & ------- \\
\hline Within-Subject & & & & & & \\
\hline Defect Type (DT) & 1 & 0.003123 & 0.003123 & 1.97 & 0.188 & ------- \\
\hline DT x S & 11 & 0.017424 & 0.001584 & & & \\
\hline Tasks (Tsk) & 2 & 0.003492 & 0.001746 & 1.62 & 0.220 & ------- \\
\hline Tsk x S & 22 & 0.023686 & 0.001077 & & & \\
\hline DT x Tsk & 2 & 0.002142 & 0.001071 & 1.11 & 0.346 & ------- \\
\hline DT x Tsk x S & 22 & 0.021165 & 0.000962 & & & \\
\hline Total & 71 & 0.130672 & & & & \\
\hline
\end{tabular}

* Statistically significant at $\alpha=0.05$

\section{SDT metrics ( $d^{\prime}, B$, and $\left.c\right)$}

The ANOVA of the dependent variable $\mathrm{d}^{\prime}$ is presented in Table 12. Based on the p-values of the unadjusted F there was no statistically significant effect. The subjects' perceptual sensitivity (mean $\mathrm{d}^{\prime}=3.096$ ) remained constant throughout the experiment. The ANOVA of the dependent variable $B$ is presented in Table 13. Based on the p-values of the unadjusted $\mathrm{F}$ there was no statistically significant effect. The observed criterion or response bias (mean $B=19.07)$ exceeded the ideal criterion $\left(\beta_{i}=1.25\right)$ for a neutral payoff (costs for incorrect decisions $=$ rewards for correct decisions). This represents a conservative criterion adopted by the subjects. 
Table 12. ANOVA summary table of $d^{\prime}$.

\begin{tabular}{|c|c|c|c|c|c|c|}
\hline Source & df & SS & MS & F & p-value & G-Gp \\
\hline Between-Subjects & & & & & & \\
\hline Subjects (S) & 11 & 6.9891 & 0.6354 & & & ------- \\
\hline Within-Subject & & & & & & \\
\hline Defect Type (DT) & 1 & 0.0045 & 0.0045 & 0.01 & 0.905 & ------- \\
\hline DT x S & 11 & 3.3294 & 0.3027 & & & \\
\hline Tasks (Tsk) & 2 & 0.2613 & 0.1307 & 0.75 & 0.482 & ------ \\
\hline Tsk x S & 22 & 3.8095 & 0.1732 & & & \\
\hline DT x Tsk & 2 & 0.1117 & 0.0559 & 0.23 & 0.793 & ------ \\
\hline DT x Tsk x S & 22 & 5.2498 & 0.2386 & & & \\
\hline Total & 71 & 19.7553 & & & & \\
\hline
\end{tabular}

* Statistically significant at $\alpha=0.05$

Table 13. ANOVA summary table of $\beta$.

\begin{tabular}{|c|c|c|c|c|c|c|}
\hline Source & df & SS & MS & F & p-value & G-Gp \\
\hline Between-Subjects & & & & & & \\
\hline Subjects (S) & 11 & 12249.2 & 1113.6 & & & ------- \\
\hline Within-Subject & & & & & & \\
\hline Defect Type (DT) & 1 & 322.7 & 322.7 & 0.70 & 0.420 & ------- \\
\hline DT x S & 11 & 5046.3 & 458.8 & & & \\
\hline Tasks (Tsk) & 2 & 27.7 & 13.8 & 0.06 & 0.942 & ------ \\
\hline Tsk x S & 22 & 5074.2 & 230.6 & & & \\
\hline DT x Tsk & 2 & 1861.8 & 930.9 & 3.31 & 0.055 & ------- \\
\hline DT x Tsk x S & 22 & 6185.8 & 281.2 & & & \\
\hline Total & 71 & 30767.6 & & & & \\
\hline
\end{tabular}

* Statistically significant at $\alpha=0.05$

The ANOVA of the dependent variable $c$ is presented in Table 14. Based on the unadjusted F ( $\mathrm{p}$-value $=0.0448)$ and the Geisser-Greenhouse correction factor $(\mathrm{G}-\mathrm{Gp}=$ 0.0491) the effect of the interaction between Defect Type and Tasks was statistically significant. 
Table 14. ANOVA summary table of $c$.

\begin{tabular}{|c|c|c|c|c|c|c|}
\hline Source & df & SS & MS & F & p-value & G-Gp \\
\hline Between-Subjects & & & & & & \\
\hline Subjects (S) & 11 & 13.2123 & 1.2011 & & & ------- \\
\hline Within-Subject & & & & & & \\
\hline Defect Type (DT) & 1 & 0.0278 & 0.0278 & 0.14 & 0.718 & ------- \\
\hline DT x S & 11 & 2.2165 & 0.2015 & & & \\
\hline Tasks (Tsk) & 2 & 0.1626 & 0.0813 & 0.88 & 0.429 & ------- \\
\hline Tsk x S & 22 & 2.0309 & 0.0923 & & & \\
\hline DT x Tsk & 2 & 0.8429 & 0.4215 & 3.59 & $0.0448 *$ & $0.0491 *$ \\
\hline DT x Tsk x S & 22 & 2.5840 & 0.1175 & & & \\
\hline Total & 71 & 21.0770 & & & & \\
\hline
\end{tabular}

* Statistically significant at $\alpha=0.05$

According to a Newman-Keuls post hoc analysis of the unconfounded comparisons of the interaction between Defect Type and Tasks, there was a statistically significant difference in response bias $(c)$ between inspection of parts with one type of defect (scratch or speck) while multitasking and the inspection of parts with both types of defects (scratch and speck) while multitasking (see Table 15). The criterion or response bias when both defects were present in the inspected parts and the subject conducted one or three tasks concurrently was lower than when the same number of tasks was performed but only one type of defect was present in the inspected parts. However, when the subjects conducted five tasks and both defects were present in the inspected parts, the response bias was higher than when the same number of tasks was performed but only one type of defect was present in the inspected parts. The interaction between Defect Type and Tasks is shown in Figure 16. The mean $c$ values throughout the levels of the interaction exceeded the point of completely neutral bias $\left(c_{\mathrm{N}}=0\right)$. This represents a conservative criterion adopted by the subjects which is consistent with the results of the less sensitive response bias metric $\beta$. 
Table 15. Newman-Keuls analysis of the effect of the Defect Type and Task interaction on $c$.

\begin{tabular}{|c|c|c|c|c|c|c|c|c|c|}
\hline \multicolumn{10}{|c|}{ Increasing Rank Order } \\
\hline & & 1 & 2 & 3 & 4 & 5 & 6 & & \\
\hline $\begin{array}{l}\text { Treatment } \\
\text { Means }\end{array}$ & & $\begin{array}{c}\mathrm{DT}_{2} \mathrm{Tsk}_{3} \\
0.476\end{array}$ & $\begin{array}{c}\mathrm{DT}_{1} \mathrm{Tsk}_{5} \\
0.524\end{array}$ & $\begin{array}{c}\mathrm{DT}_{2} \mathrm{Tsk}_{1} \\
0.663\end{array}$ & $\begin{array}{c}\mathrm{DT}_{1} \mathrm{Tsk}_{3} \\
0.734\end{array}$ & $\begin{array}{c}\mathrm{DT}_{1} \mathrm{Tsk}_{1} \\
0.778\end{array}$ & $\begin{array}{l}\mathrm{DT}_{2} \mathrm{Tsk}_{5} \\
0.826\end{array}$ & $r$ & $\mathrm{CD}_{0.05}$ \\
\hline \multirow{5}{*}{$\begin{array}{l}\text { Rank } \\
\text { Order }\end{array}$} & 1 & ------- & ------- & $0.187 *$ & $0.258^{*}$ & ------- & $0.303^{*}$ & 6 & 0.1260 \\
\hline & 2 & & ------- & $\begin{array}{l}------ \\
\end{array}$ & $0.210^{*}$ & $0.254 *$ & $0.255^{*}$ & 5 & 0.1200 \\
\hline & 3 & & & ------- & ------- & $0.115^{*}$ & $0.116^{*}$ & 4 & 0.1123 \\
\hline & 4 & & & & $\begin{array}{ll}------- \\
\end{array}$ & 0.044 & $\begin{array}{ll}------- \\
\end{array}$ & 3 & 0.1014 \\
\hline & 5 & & & & & ------- & ------- & 2 & 0.0838 \\
\hline
\end{tabular}

* Statistically significant at $\alpha=0.05$

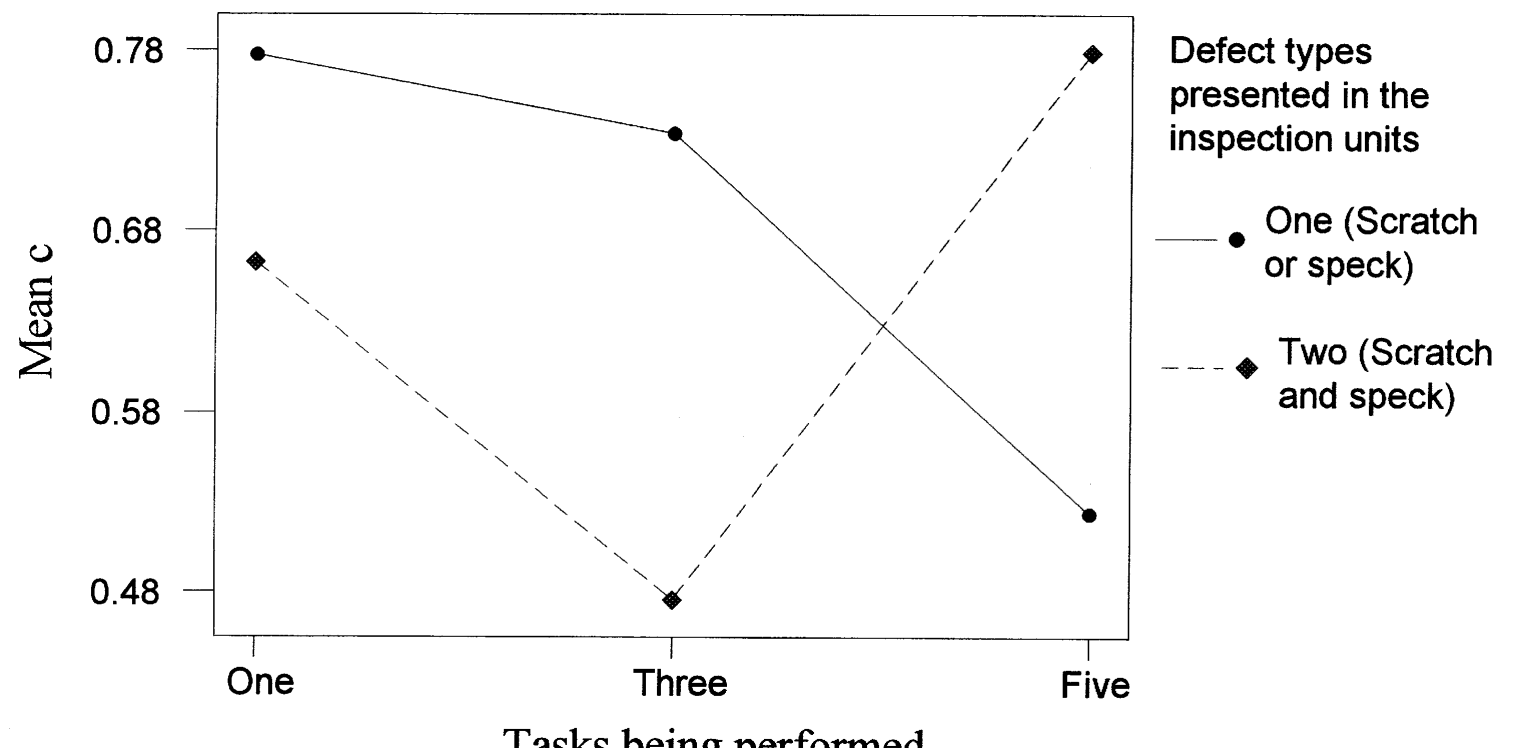

Figure 16. Mean plot of the effects of the Defect Type and Tasks interaction on $c$.

\section{$\underline{\text { Average Time }}$}

The ANOVA of the dependent variable average time to make a decision to accept or reject the inspected part is presented in Table 16. Based on the p-values of the 
unadjusted $F$ and the Geisser-Greenhouse correction factor $(\mathrm{G}-\mathrm{Gp})$ the effect of the Defect Type $\left(\mathrm{F}_{\mathrm{p} \text {-value }}=0.01, \mathrm{G}-\mathrm{Gp}=0.01\right)$ and Tasks $\left(\mathrm{F}_{\mathrm{p} \text {-value }}=0.029, \mathrm{G}-\mathrm{Gp}=0.048\right)$ were statistically significant. It took more time to inspect parts containing both types of defect than parts containing only one type (see Figure 17). According to a NewmanKeuls post hoc analysis, the average time to make a decision to accept or reject the inspected part was significantly less when the subjects were multitasking than when they were only performing the quality inspection task (see Table 17 and Figure 17).

Table 16. ANOVA summary table of average time to make a decision.

\begin{tabular}{|c|c|c|c|c|c|c|}
\hline Source & df & SS & MS & F & p-value & G-Gp \\
\hline Between-Subjects & & & & & & \\
\hline Subjects (S) & 11 & 1.48670 & 0.13515 & & & ------ \\
\hline Within-Subject & & & & & & \\
\hline Defect Type (DT) & 1 & 0.54080 & 0.54080 & 9.60 & $0.01 *$ & $0.01 *$ \\
\hline DT x S & 11 & 0.61957 & 0.05632 & & & \\
\hline Tasks (Tsk) & 2 & 0.19603 & 0.09802 & 4.17 & $0.029 *$ & $0.048 *$ \\
\hline Tsk x S & 22 & 0.51757 & 0.02353 & & & \\
\hline DT x Tsk & 2 & 0.01583 & 0.00792 & 0.12 & 0.890 & ------ \\
\hline DT x Tsk x S & 22 & 1.48910 & 0.06769 & & & \\
\hline Total & 71 & 4.86560 & & & & \\
\hline
\end{tabular}

* Statistically significant at $\alpha=0.05$ 


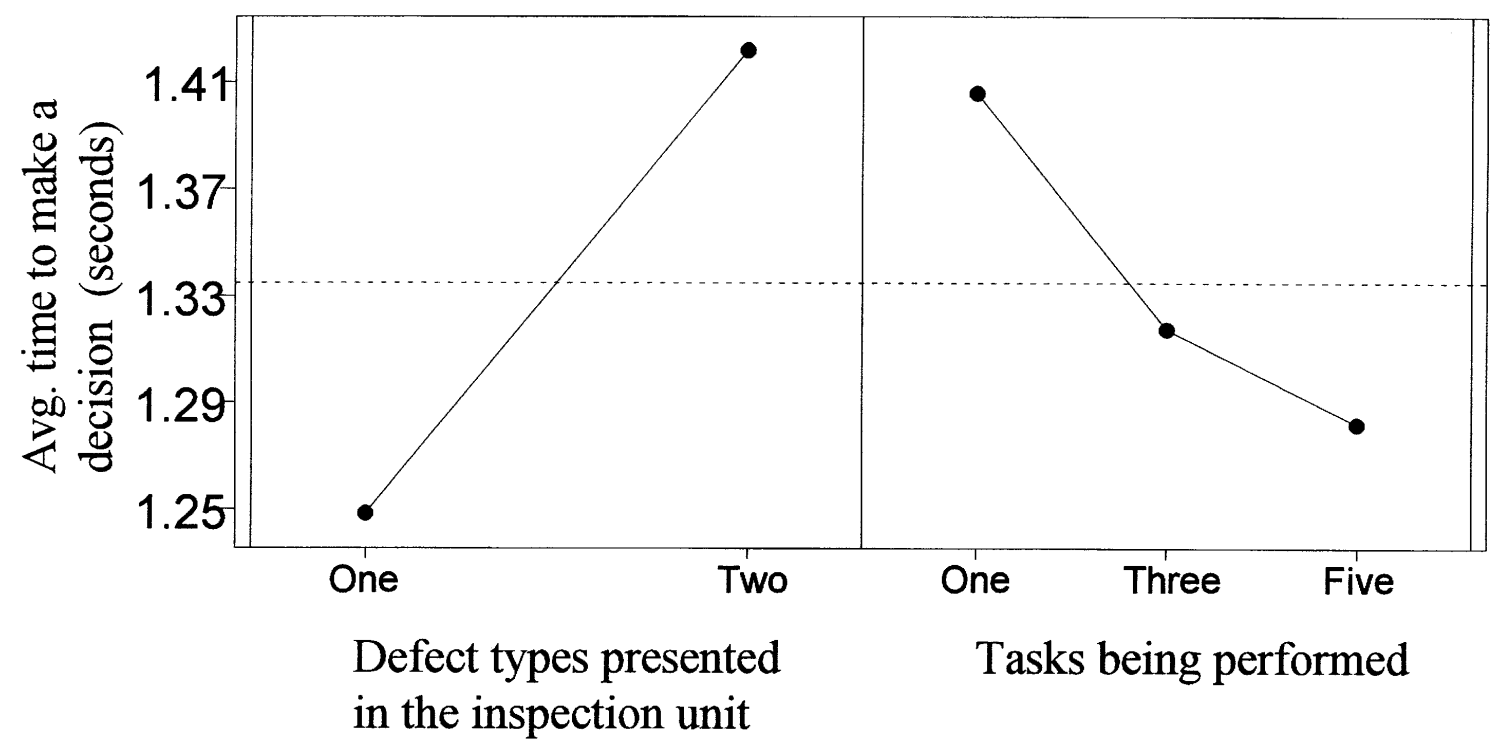

Figure 17. Mean plot of Defect Type and Tasks effects on the average time to make a decision.

Table 17. Newman-Keuls analysis of the effect of Tasks on the average time to make a decision.

\begin{tabular}{|l|c|c|c|c|c|c|}
\hline \multicolumn{7}{|c|}{ Increasing Rank Order } \\
\hline \multicolumn{2}{|c|}{} & 1 & 2 & 3 & \multicolumn{2}{l|}{ CD $_{0.05}$} \\
\hline Treatment & & Tsk $_{5}$ & Tsk $_{3}$ & Tsk $_{1}$ & $\mathrm{r}$ & \\
Means & & 1.282 & 1.317 & 1.406 & & \\
\hline Rank & 1 & ------- & 0.035 & $0.124 *$ & 3 & 0.045 \\
\cline { 2 - 7 } Order & 2 & & ------ & $0.089 *$ & 2 & 0.038 \\
\hline
\end{tabular}

* Statistically significant at $\alpha=0.05$

\section{Subjective Workload Questionnaire Scores}

The ANOVA for the scores of the item number six (Temporal Demand) in the subjective workload questionnaire was the only one that showed a statistically significant effect (see Table 18). Based on the p-values of the unadjusted F and the GeisserGreenhouse correction factor $(\mathrm{G}-\mathrm{Gp})$, the effects of Defect Type $\left(\mathrm{F}_{\mathrm{p} \text {-value }}=0.037, \mathrm{G}-\mathrm{Gp}=\right.$ $0.037)$ and Tasks $\left(\mathrm{F}_{\mathrm{p} \text {-value }}=0.0001, \mathrm{G}-\mathrm{Gp}=0.0014\right)$ were statistically significant. 
Subjects perceived the temporal demand of inspecting parts containing only one types of defect to be higher than inspecting parts containing both type of defect (see Figure 18). According to a Newman-Keuls post hoc analysis, the subject perceived the temporal demand to be higher as the number of tasks to be performed increased (see Table 19 and Figure 18). Based on the mean score of the items in the subjective workload questionnaire (that showed no statistically significant differences) it can be stated that: 1) subjects perceived the mental and physical demand of all the experimental treatments to be minimum, and 2) subjects perceived that they were able to accomplish the experimental tasks satisfactorily with a minimum mental and physical effort.

Table 18. ANOVA summary table of temporal demand.

\begin{tabular}{|c|c|c|c|c|c|c|}
\hline Source & df & SS & MS & F & p-value & G-Gp \\
\hline Between-Subjects & & & & & & \\
\hline Subjects (S) & 11 & 68.0167 & 6.1833 & & & ------ \\
\hline Within-Subject & & & & & & \\
\hline Defect Type (DT) & 1 & 3.2089 & 3.2089 & 5.61 & $0.037 *$ & $0.037^{*}$ \\
\hline DT x S & 11 & 6.2944 & 0.5722 & & & \\
\hline Tasks (Tsk) & 2 & 34.6558 & 17.3279 & 14.71 & $0.0001^{*}$ & $0.0014^{*}$ \\
\hline Tsk x S & 22 & 25.9075 & 1.1776 & & & \\
\hline DT x Tsk & 2 & 0.0469 & 0.0235 & 0.03 & 0.974 & ------- \\
\hline DT x Tsk x S & 22 & 19.9097 & 0.9050 & & & \\
\hline Total & 71 & 158.04 & & & & \\
\hline
\end{tabular}

* Statistically significant at $\alpha=0.05$ 


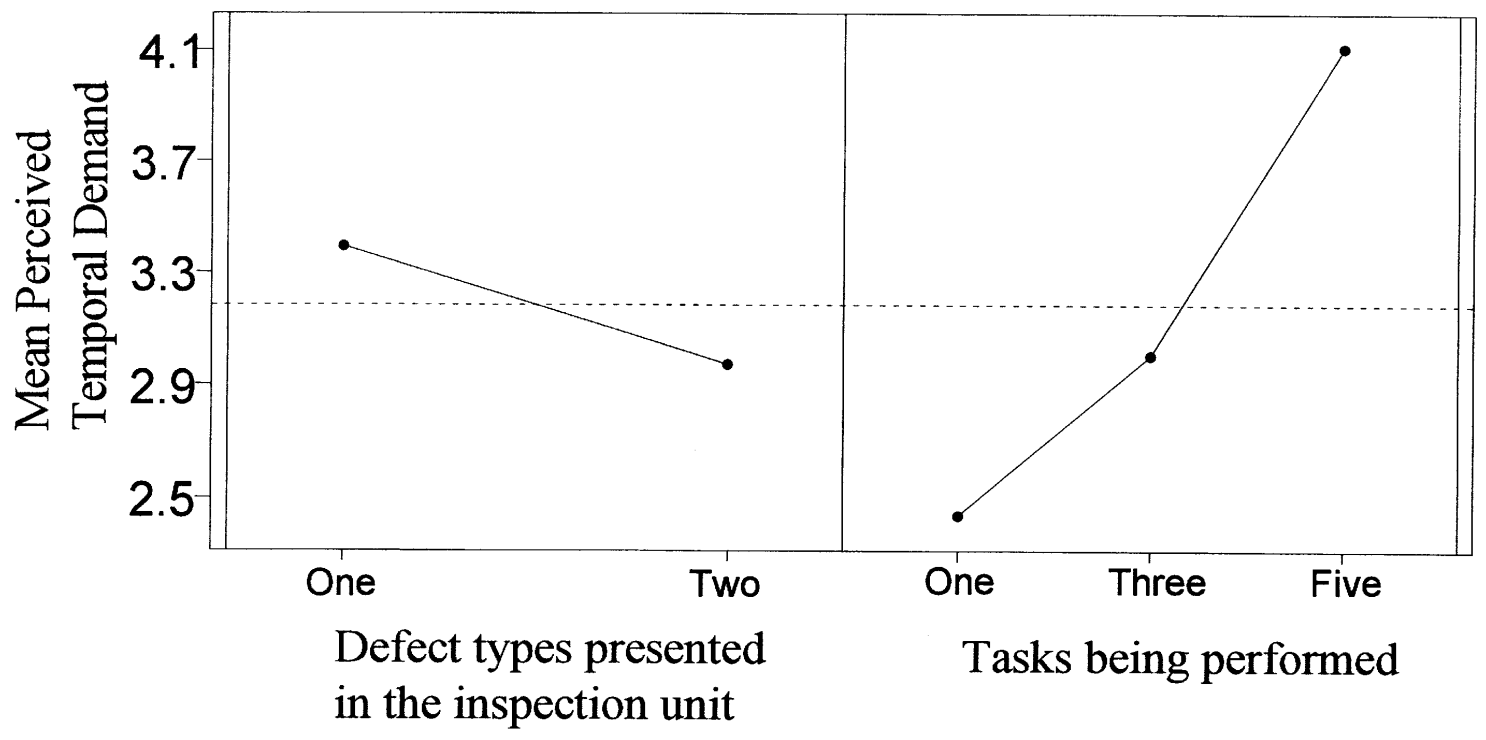

Figure 18. Mean plot of Defect Type and Tasks effects on the temporal demand.

Table 19. Newman-Keuls analysis of the effect of Tasks on the temporal demand.

\begin{tabular}{|l|c|c|c|c|c|c|}
\hline \multicolumn{7}{|c|}{ Increasing Rank Order } \\
\hline \multicolumn{2}{|c|}{} & 1 & 2 & 3 & & \\
\hline Treatment & & Tsk $_{5}$ & Tsk $_{3}$ & Tsk $_{1}$ & $\mathrm{r}$ & $\mathrm{CD}_{0.05}$ \\
Means & & 2.438 & 3.004 & 4.108 & & \\
\hline Rank & 1 & ------- & $0.566 *$ & $1.67 *$ & 3 & 0.321 \\
\cline { 2 - 8 } Order & 2 & & ------ & $1.104 *$ & 2 & 0.265 \\
\hline
\end{tabular}

* Statistically significant at $\alpha=0.05$ 


\section{Chapter 4. DISCUSSION}

The results obtained from this experiment support the assertion that the characterization of the operator's performance in the quality inspection task while conducting multitasking in an AMS is not strictly bounded by the classical decision theory paradigm. Processing resources and memory load concepts need to be considered in order to obtain a better understanding of the operator's performance in quality inspection. This position will be evident as the three hypotheses that motivated this research are evaluated.

\section{Hypothesis 1}

Hypothesis 1 stated that the operator's decision making component of the quality inspection task in AMS would be significantly affected by the appearance of different types of defects in the units being produced. The nonsignificant differences on hit, false alarm, and the SDT metrics $\left(\mathrm{d}^{\prime}, \beta\right.$, and $c$ ) as a function of Defect Type failed to support this hypothesis. This finding is consistent with those reported by Craig et al. (1977) and Craig (1979) in which they concluded that the added complexity of looking for more than one kind of signal (two types) has no adverse effect on vigilance task performance.

Even though the participants were instructed to use a neutral payoff they maintained a conservative response criterion (strict payoff) throughout the experiment. This resulted in the operator (consciously or unconsciously) trading off hits in order to avoid false alarms. The strongest evidence to support the subjects' conservative behavior is that their response bias (mean $\beta=19.06$, mean $c=0.659$ ) exceeded the ideal criterion $\left(\beta_{\mathrm{i}}=1.25, c_{\mathrm{N}}=0\right)$ despite the fact that their perceptual sensitivity (mean $\left.\mathrm{d}^{\prime}=3.096\right)$ was high. These results seem to suggest the ineffectiveness of using instructions as the only instrument to control the payoff adopted by the subjects.

The increase in load imposed by the inspection of more than one defect (two different types) in the same unit was not enough to reduce the monotony of the task nor to 
improve the performance in terms of detection. Subjects perceived the inspection task to be boring. Most of them expressed a preference for performing additional tasks because, as some of them indicated in the comments section of the questionnaires or directly to the experimenter, "it helps to break the monotony of the quality inspection." Subjects complained about the temporal uncertainty of the quality inspection task. They would have liked to control the pace of the task, or as some of them indicated, "I like performing additional tasks because it makes the quality inspection time pass quickly." Apparently, the less they worked the more bored they felt. This can be supported by the fact that the perceived temporal demand of inspecting parts containing both defect types was significantly less than when inspecting parts containing only one defect type at a time. This is in spite of the fact that the average time to make a decision when both defects were presented in the parts was significantly greater than when only one type of defect was presented.

The finding that operator performance was not adversely affected by more than one defect type in the same part is important for the quality inspection task in real world AMS. However, it is important to realize that it is possible to have more than two defect types in units inspected in real manufacturing environments. Even if the maximum number of defect types per inspected unit is two, it should be taken into consideration that the average proportion of correct detection (hit $=0.776$ ), although consistent with what has been reported for 100\% industrial quality inspection (Juran, 1974; Konz, Peterson, and Joshi, 1981; Schilling, 1982), may not be acceptable for a World Class Manufacturing organization.

\section{Hypothesis 2}

Hypothesis 2 stated that the operator's decision making component of the quality inspection task in AMS would be significantly affected by multitasking. The nonsignificant differences obtained on hit, false alarm, and the SDT metrics $\left(\mathrm{d}^{\prime}, \beta\right.$, and $\left.c\right)$ as a function of Tasks failed to support this hypothesis. Once again (as in the Defect 
Type factor) the operators maintained a conservative response bias despite having a high perceptual sensitivity, as the number of tasks performed ranged between one and five.

The additional load imposed by multitasking seems to have a significant reducing effect in the average time to make a decision about the inspected part. But, opposite to the effect of the Defect Type factor (where the perceived temporal demand decreased as the Defect Type increased), the perceived temporal demand significantly increased as the load imposed by multitasking increased. The effect of multitasking on the average time to make a decision about the inspected part is consistent with the inverted- $U$ theory, the left side in particular (Wiener et al., 1984; Craig, 1984; Poulton, 1977). An increase in load imposed by multitasking improved the performance in terms of response time at the quality inspection task. Nevertheless, the increase in load of the Tasks factor alone was not enough to significantly affect the average proportion of correct detection.

The finding that the operator's decision making performance in the quality inspection task was not affected by multitasking (up to five tasks) supports the task allocation practices in AMS in which the operator plays a supervisory control role. A major implication of this finding is the need to assess and control the operator's payoff before the actual task is conducted (off-line). This could be beneficial to prevent operators from maintaining the wrong response criterion throughout the actual quality inspection task (on-line) while multitasking in AMS.

\section{$\underline{\text { Hypothesis } 3}$}

Hypothesis 3 stated that the operator's decision making component of the quality inspection task in AMS would be significantly affected by the interaction between multitasking and the number of different types of defects in the units being inspected. This hypothesis is primarily supported by the statistically significant difference in hits and the SDT metric for response bias $c$. The significant effect of the interaction on the average proportion of correct detection provides some support for both sides of the inverted-U function (McGrath, 1965; Wiener et al., 1984). 
The increase in load imposed by multitasking of three tasks and the memorized criterion for the quality inspection task of parts containing two defect types at a time compared to just the inspection of parts containing two defect types at a time (no multitasking) caused a significant increase in average proportion of correct detection (from hit $=0.784$ to hit $=0.826$ ). The significant decrease in response bias (from $c=$ 0.663 to $c=0.476$ ) observed for this case suggest that as the number of tasks increased from one to three the subjects adopted a less conservative criterion. In terms of the average proportion of correct detection, this can also be interpreted as an example of the left-hand side of the inverted-U (the task performance level being improved by increasing the load). On the other hand, the load imposed by increasing the number of tasks from three to five and the memorized quality criterion for the quality inspection task of parts containing two defect types caused a significant drop in the average proportion of correct detection (from hit $=0.826$ to hit $=0.736$ ). As expected a significant increase in response bias (from $c=0.476$ to $c=0.826$ ) was observed for this case suggesting that as the number of tasks increased from three to five the subjects adopted a more conservative criterion. In terms of the average proportion of correct detection, this can also be interpreted as an example of the right-hand side of the inverted-U (the task performance level being degraded by overload).

For the case of the quality inspection of parts containing only one defect type at a time there was no significant change on the average proportion of correct detection (hit = 0.753 ) nor on the response criterion when the number of tasks conducted by the operator increased from one to three. The only significant increase in average proportion of correct detection (from hit $=0.753$ to hit $=0.806$ ) occurred when the operator was conducting all five tasks. The significant decrease in response bias (from $c=0.734$ to $c=$ 0.524) observed for this case suggest that as the number of tasks increased from three to five the subjects adopted a less conservative criterion. Apparently an overload effect was not evident for the quality inspection of parts containing only one defect type because, as previously discussed, the memory load imposed by this particular condition seemed to be less than for the case of two defects at a time. This is supported by the fact that the 
highest average proportion of correct detection for the inspection of parts with one defect type occurred when the operator was multitasking five tasks (hit $=0.806)$ while the lowest average proportion of correct detection overall $(\mathrm{hit}=0.736)$ was observed when the operator was inspecting parts with both defect types and multitasking five tasks.

Although a conservative response bias $\left(c>c_{\mathrm{N}}\right)$ was observed at all the levels of the interaction between Defect Type and Tasks there were statistically significant different degrees of conservative criterion. If the interaction has the same effect in an operator with a neutral payoff $\left(c_{N}=0\right)$ it might be possible to observe the operator adopting a conservative criterion $\left(c>c_{\mathrm{N}}\right)$ or a lax criterion $\left(c<c_{\mathrm{N}}\right)$ as a function of an increase in load imposed by multitasking and the memorized criterion for the quality inspection.

The finding that the operator's decision making performance in quality inspection was significantly affected by the interaction between the Defect Type and Task factors demonstrates that the quality inspection task with working memory load demands a continuous supply of processing resources, and is susceptible to interference from concurrent tasks (Parasuraman 1979; Wickens, 1992). This supports the importance of adequate task allocation in AMS. Doing so will be instrumental to maximizing the utilization of the human operator while minimizing performance problems. 


\section{Chapter 5. Conclusions and Future Research}

This research was intended to gather information about factors contributing to the characterization of the operator's performance in the quality inspection task while multitasking in an AMS. The ineffectiveness of using instructions as the only instrument to control the payoff adopted by the subjects might be considered as an external validity limitation of this research. Given the strict payoff adopted by the subjects throughout the experiment, the findings previously discussed might be interpreted as valid primarily for operators with a conservative criterion.

Despite the limitations of a laboratory simulated AMS with subjects who were not necessarily experiencing the daily pressures typical of many manufacturing environments, the findings of this research are beneficial to the design of AMS. The major implication derived from these research findings is that a quality inspection task which depends on memorized criterion will create a mental load which needs to be considered when allocating multiple tasks to an operator in an AMS. The performance of the operator in the quality inspection task while multitasking in an AMS will be determined not only by the number of different types of defect that can be presented at a time in the inspected parts, but also by the mental processing resources required to meet the demand imposed by the multiple independent tasks and the memorized quality criterion. The best performance will be obtained when the additional tasks' load minimizes the monotony of the quality inspection task without interfering with the processing resources needed for the memorized quality criterion. However, it is worth mentioning that although the best performance in terms of average proportion of correct detection exceeded the commonly accepted 0.80 for 100\% quality inspection (Juran, 1974; Konz, Peterson, and Joshi, 1981; Schilling, 1982), there is room for improvement.

Given the limitation of the study presented herein it is evident that more research on the effect of multitasking on quality inspection in AMS should be conducted using more effective methods, other than instructions, to control the operator's adopted payoff. Perhaps a payoff system that encourages the operator to adopt the criterion of interest 
(lax, neutral, or strict) will increase the external validity of this type of research. Further research to determine the effect of different fraction of defectives, and knowledge of results in the operator's performance in the quality inspection task while multitasking in an AMS are necessary. The results of such research should be compared to the findings of this research, and those of more traditional laboratory research with simple vigilance tasks and no multitasking. Based on the experience from this research the use of SDT is recommended for future research oriented to determine the effect of multitasking on the decision making performance in complex monitoring tasks. In addition to be instrumental in the assessment of the operators' adopted payoff throughout this study, the SDT extensive research body was helpful for the interpretation of the results. Finally, a confirmation study is recommended to determine the generalizability of the results obtained in this laboratory experiment to real world AMS. 


\section{REFERENCES}

Adams, M. J., Tenny, Y. J., and Pew, R. W. (1991). Strategic workload and the cognitive management of advanced multi-task systems. Dayton: CSERIAC.

Alluisi, E. A., Coates, G. D., and Morgan, B. B. (1977). Effects of temporal stressors on vigilance and information processing. In R. R. Mackie (Ed.), Vigilance: Theory, operational performance, and physiological correlated (pp.361-421). New York: Plenum.

Ammons, J. C., Govindaraj, T., and Mitchell C.M. (1988). A supervisory control paradigm for real time control of flexible manufacturing systems. Annals of Operations Research, 15, 313-335.

Banks, J. (1989). Principles of Quality Control. New York: Wiley.

Bainbridge, L. (1982). Ironies of automation. In Proceedings of Conference on Analysis, Design and Evaluation of Man-Machine Systems (pp. 129-135). BadenBaden, West Germany.

Bennet, G. K. (1975). Inspection error: its influence on quality control systems. In Drury, C. G. and Fox, J. G. (Eds.), Human reliability in quality control (pp. 1-10). New York: Taylor \& Francis.

Berniker, E. (1990). Issues and challenges to sociotechnical systems design of advanced manufacturing systems. In Karwowski, W. and Rahimi, M. (Eds.), Ergonomics of hybrid automated systems II (pp. 3-9). Amsterdan: Elsevier.

Bessant, J., Levy, P., Ley, C., Smith, S. and Tranfield, D. (1992). Organization design for factory 2000. International Journal of Human Factors in Manufacturing, 2(2), 95-125.

Bi, S. and Salvendy, G. (1994). Analytical modeling and experimental study of human workload in scheduling of advanced manufacturing systems. International Journal of Human Factors in Manufacturing, 4(2), 205-234. 
Bloomfield, J. R. (1975). Theoretical approaches to visual search. In Drury, C. G. and Fox, J. G. (Eds.), Human reliability in quality control (pp. 19-29). New York: Taylor \& Francis.

Brödner, P. (1991). Design of work and technology in manufacturing. International Journal of Human Factors in Manufacturing, 1(1), 1-16.

Business Week, 16 March 1987, 102-110. “General Motors: what went wrong”.

Chapman, D. E. and Sinclair, M. A. (1975). Ergonomics in inspection tasks in the food industry. In Drury, C. G. and Fox, J. G. (Eds.), Human reliability in quality control (pp. 231-251). New York: Taylor \& Francis.

Colquhoun, W. P., and Edwards, R. S. (1970). Practice effects on a visual vigilance task with and without search. Human Factors, 12(4), 537-545.

Corbett, J. M. (1987). Ergonomics in the development of human-centered AMT. Applied Ergonomics, 19, 35-39.

Craig, A. (1979). Vigilance for two kinds of signal with unequal probabilities of occurrence. Human Factors, 21(6), 647-653.

Craig, A. and Colquhoun, W. P. (1975). Vigilance: a review. In Drury, C. G. and Fox, J. G. (Eds.), Human reliability in quality control (pp. 71-87). New York: Taylor \& Francis.

Craig, A. and Colquhoun, W. P. (1977). Vigilance effects in complex inspection. In R. R. Mackie (Ed.) Vigilance: Theory, operational performance, and physiological correlated (pp.239-262). New York: Plenum.

Czaja, S.J. and Drury, C.G. (1981). Training programs for inspection. Human Factors, 25(4), 391-399.

Damos, D. L. (1991). Multiple-task performance. London: Taylor \& Francis.

Davies, D. D. (1986). Managing technological innovation. San Francisco: JosseyBass.

Davidow, W. H., and Malone, M. S. (1992). The virtual corporation. New York: Harper Collins. 
Drury, C.G. (1975). Inspection of sheet materials - model and data. Human Factors, $17(3), 257-265$.

Drury, C. G. and Fox, J. G. (1975). The imperfect inspector. In Drury, C. G. and Fox, J. G., (Eds.), Human reliability in quality control (pp. 11-16). New York: Taylor \& Francis.

Drury, C. G. and Fox, J. G. (1975b). Human reliability in quality control. New York: Taylor \& Francis.

Drury, C.G. and Addison, J.L. (1973). An industrial study of the effects of feedback and fault density on inspection performance. Ergonomics, 16, 159-169.

Drury, C.G., and Sinclair, M.A. (1983). Human and machine performance in an inspection task. Human Factors, 25 (4), 391-399.

Drury, C.G. (1992). Inspection performance. In Salvendy, G. (Ed.), Handbook of Industrial Engineering (pp. 2282-2314). New York: Wiley.

Drury, C.G. (1992b). Product design for inspectability: a systematic procedure. In Helander, M., and Nagamachi, M. (Eds.), Design for manufacturability (pp. 204216). London: Taylor \& Francis.

Drury, C.G., and Prabhu, P. V. (1994). Human factors in test and inspection. In Salvendy, G. and Karwowski, W. (Eds.), Design of work and development of personnel in advanced manufacturing (pp. 355-401). New York: John Wiley \& Sons.

Embrey, D. E. (1975) Training the inspector's sensitivity and response strategy. In Drury, C. G. and Fox, J. G. (Eds.), Human reliability in quality control (pp.123131). New York: Taylor \& Francis.

Fox, J.G., and Halsegrave, C.M. (1969). Industrial inspection efficiency and the probability of a defect occurring. Ergonomics, 12, 713-721.

Gescheider, G. A. (1985). Psychophysics: method, theory, and application. Hillsdale: Lawrence Erlbaum Associates.

Gopher, D. and Braune, R. (1984). On the psychophysiscs of workload: Why bother with subjective measures? Human Factors, 26, 519-532. 
Gramopadhye, A. K., Drury, C. G., Sharit, J., and Sudit, M. (1992). A framework for function allocation in inspection. In Brödner, P. and Karwowski, W. (Eds.). Ergonomics of hybrid automated systems III (pp. 249-257). Amsterdam: Elsevier. Green, D.M., and Swets, J.A., (1966). Signal detection theory and psychophysics. New York: Wiley.

Guralnick, M. J. (1972). Observing responses and decision process in vigilance. Journal of Experimental Psychology, 93(2), 239-244.

Hart, S.G. and Straveland, L.E. (1988). Development of NASA-TLX (Task Load Index): Results of experimental and theorethical research. In Hancock, P.A. and Meshkati, N.(Eds.), Human mental workload (pp.139-183). Amsterdam: NorthHolland

Hou, T., Lin, L. and Drury, C.G. (1993). An empirical study of hybrid inspection systems and allocation of inspection functions. International Journal of Human Factors in Manufacturing, 3(4), 351-367.

Howarth, C. I., and Bloomfield, J.R. (1971). A rational equation for predicting search times in simple inspection tasks. Psychonomic Science, 17, 225-226.

Juran, J.M. (1974). Quality control handbook. New York: McGraw-Hill.

Juran, J.M. and Gryna, F.M. (1980). Quality planning and analysis. New York: McGraw-Hill.

Kahneman, D. (1973). Attention and effort. Englewood Cliffs: Prentice-Hall.

Karwowski, W. and Salvendy, G. (1991). Preface. International Journal of Human Factors in Manufacturing, 1(1), iii.

Karwowski, W., Salvendy, G., Badham, R., Brödner, P., Clegg, C., Hwang, S.L., Iwasawa, J., Kidd, P.T., Kobayashi, N., Koubek, R., LaMarsh, J., Nagamachi, M., Naniwada, M., Salzman, H., Seppala, P., Schallock, B., Sheridan, T., Warschat, J. (1994). Integrating people, organization, and technology in advanced manufacturing: a position paper based on the joint view of industrial managers, engineers, consultants, and researchers. International Journal of Human Factors in Manufacturing, 4(1), 1-19. 
Konz, S. (1995). Work design: Industrial ergonomics. Scottsdale: Publishing Horizons.

Konz, S., Peterson, G. and Joshi, A. (1981). Reducing inspector errors. Quality Progress, 14(7), 24-26.

Kuivanen, R. (1996). Disturbance control in flexible manufacturing. International Journal of Human Factors in Manufacturing, 6(1), 41-56.

Macmillan, N. A., and Creelman, C. D. (1991). Detection theory: A user's guide. Cambridge: Cambridge University Press.

Mackworth, J. F. (1964). The effect of true and false knowledge of results on the detectability of signals in a vigilance task. Canadian Journal of Psychology, 18(1), 106-117.

Mackworth, J. F. (1965). The effect of amphetamine on the detectability of signals in a vigilance task. Canadian Journal of Psychology, 19(1), 104-109.

McCloy, T., Derrick, W., and Wickens, C. (1983). Workload assessment metrics What happens when they dissociate? In Proceedings of the Aerospace Behavioral Engineering Technology Second Conference. Warrendale, PA.

McGrath, J. J. (1965). Performance sharing in an audiovisual vigilance task. Human Factors, 7, 141-153.

Megaw, E. D. and Richardson, J. (1979). Eye movements and industrial inspectors. Applied Ergonomics, 10 (2), 145-154.

Mize, J. H. (1988). Success factors for advanced manufacturing systems. In Blache, K. M. (Ed.), Success factors for implementing change: A manufacturing viewpoint (pp. 19-27). Dearborn: SME.

Monden, Y. (1993). Toyota production system. Norcross: IIE.

Moray, N., Dessouky, M. I., Kijowski, B. A., and Adapathya, R. (1990). Strategic behavior, workload and performance in task scheduling (Report No. EPRL-90-06). University of Illinois at Urbana.

Morawski, T., Drury, C. G., and Karwan, M. H. (1980). Predicting search performance for multiple targets. Human Factors, 22(4), 707-718. 
Nakamura, N. and Salvendy, G. (1994). Human planner and scheduler. In Salvendy, G. and Karwowski, W. (Eds.), Design of work and development of personnel in advanced manufacturing (pp. 331-354). New York: John Wiley \& Sons.

Niebel, B.W. (1993). Motion and time study. Boston: Irwin.

Parasuraman, R. (1979). Memory load and event rate control sensitivity decrements in sustained attention. Science, 205, 925-927.

Parasuraman, R., Warm, J. S., and Dember, W. N. (1987). Vigilance: Taxonomy and utility. In L. S. Mark, J. S. Warm, and R. L. Huston (Eds.), Ergonomics and human factors (pp. 11-31). New York: Springer-Verlag.

Pinochet, A., Matsubara, Y., and Nagamachi, M. (1996). Construction of a knowledge-based system for diagnosing the sociotechnical integration in advanced manufacturing technologies. International Journal of Human Factors in Manufacturing, 6(4), 323-349.

Poulton, E. C. (1977). Arousing stresses increase vigilance. In R. R. Mackie (Ed.) Vigilance: Theory, operational performance, and physiological correlated (pp. 423-459). New York: Plenum.

Rasmussen, J. (1983). Skills, rules, and knowledge: signals, signs, and symbols, and other distinctions in human performance models. IEEE Transactions on systems, man, and cybernetics, 13(3), 257-266.

Rasmussen, J. (1986). Information processing and human-machine interaction; an approach to cognitive engineering. New York: North-Holland.

Salvendy, G. (1992). What we know and what we should know about human factors in CIM: A strategy for implementation and research \& development. In Nagamachi, M. (Ed.), An international joint research on construction of advanced manufacturing technology integrated human and computer. Report for Toyota Foundation. Tokyo.

Sanders, M. S. and McCormick, E. J. (1993). Human factors in engineering and design. New York: Mcgraw-Hill. 
Schilling, E. G. (1982). Acceptance sampling in quality control. New York: Marcel Dekker.

Schoonard, J. W., Gould, J. D., and Miller, L. A. (1973). Studies of visual inspection. Ergonomics, 16(3), 365-379.

Schonberger, R.J. (1986). World class manufacturing. New York: Macmillan.

Schott, E. and Wilkinson, B. (1989). FMC and JIT: the odd couple? Production Engineer, 68(4), 39-41.

See, J. E., Warm, J. S., Dember, W. N., and Howe, S. R. (1997). Vigilance and signal detection theory: An empirical evaluation of five measures of response bias. Human Factors, 39(1), 14-29.

Sheridan, T. B. and Johansen, G. (1976). Monitoring behavior and supervisory control. New York: Plenum.

Sheridan, T. B. (1997). Supervisory control. In Salvendy, G. (Ed.), Handbook of human factors (2nd ed.) (pp. 1295-1327). New York: John Wiley \& Sons.

Sheridan, T. B. (1994). Human supervisory control. In Salvendy, G. and Karwowski, W. (Eds.), Design of work and development of personnel in advanced manufacturing (pp.79-102). New York: John Wiley \& Sons.

Shingo, S. (1986). Zero quality control: Source inspection and the poka-yoke system. Portland: Productivity Press.

Smith, L.A. and Barany, J.W. (1970). An elementary model of human performance on paced visual inspection tasks. AIIE Transactions, II (4), 298-307.

Snodgrass, J. G. and Corwin, J. (1988). Pragmatics of measuring recognition memory: Applications to dementia and amnesia. Journal of Experimental Psychology: General, 117, 34-50.

Suri, R., and Whitney, C.K. (1984). Decision support requirements in flexible manufacturing systems. Journal of Manufacturing Systems, 3, 61-69.

Swets, J.A. (1977). Signal detection theory applied to vigilance. In Mackie, R. R. (Ed.) Vigilance: theory, operational performance and physiological correlates (pp. 705-718). New York: Plenum. 
Swets, J.A., Tanner, W.P., and Birdsall, T.G. (1964). Decision processes in perception. In Swets, J.A., Tanner, W.P., and Birdsall, T.G. (Eds.), Signal detection recognition by human observers: Contemporary readings (pp. 1-57). New York: Wiley.

Talavage, J. and Hannam, R.G. (1992). Flexible manufacturing systems and cellular manufacturing. In Salvendy, G. (Ed.), Handbook of industrial engineering (pp. 612-646). New York: Wiley, 1992.

Thapa, V. B. , Gramopadhye, A. K., and Melloy, B. (1996). Evaluation of different training strategies to improve decision-making performance in inspection. International Journal of Human Factors in Manufacturing, 6(3), 243-261.

Turner, W.C., Mize, J.H., Case, K.E., and Nazemetz, J.W. (1993). Introduction to industrial and systems engineering. Englewood: Prentice Hall.

The Wall Street Journal, 13 May 1986, 1. “Tricky technology: American car makers discover 'Factory of the future' is headache just now".

Unterweger, P. (1988). The human factor in the factory of the future. In Blache, K. M. (Ed.), Success factors for implementing change: A manufacturing viewpoint (pp. 7-18). Michigan: SME.

Wallack, P. M., and Adams, S. K. (1969). The utility of signal detection theory in the analysis of industrial inspector accuracy. AIIE Transactions, 1(1), 33-44.

Wang, M.J. and Drury, C. G. (1989). A method of evaluating inspector's performance differences and job requirements. Applied Ergonomics, 20 (3), 181-190.

Wiener, E. L. (1975). Individual and group differences in inspection. In Drury, C. G. and Fox, J. G. (Eds.), Human reliability in quality control (pp. 101-122). New York: Taylor \& Francis.

Wiener, E. L. (1975). On simultaneous monitoring and tracking. Journal of Applied Psychology, 60, 353-363.

Wiener, E. L., Curry, R. E., and Faustina, M. L. (1984). Vigilance and task load: In search of the inverted U. Human Factors, 26(2), 215-222. 
Wickens, C.D. (1984). Processing resources in attention. In Parasuraman, R. and Davies, R. (Eds.), Varieties of attention (pp. 63-101). New York: Academic Press. Wickens, C.D. (1991). Processing resources and attention. In Damos, D. L. (Ed.), Multiple-task performance (pp.3-34). London: Taylor \& Francis.

Wickens, C.D. (1992). Engineering psychology and human performance. New York: Harper Collins.

Williges, R.C. (1969). Within-session criterion changes compared to an ideal observer criterion in a visual monitoring task. Journal of Experimental Psychology, 81, 6166.

Williges, R.C. (1971). The role of payoffs and signal ratios in criterion changes during a monitoring task. Human Factors, 13 (3), 261-267.

Williges, R.C. (1973). Manipulating the response criterion in visual monitoring. Human Factors, 15 (2), 179-185.

Williges, R.C. and North, R.A. (1972). Knowledge of results and decision making performance in visual monitoring. Organizational Behavior and Human Performance, 8, 44-57.

Wilson, J.R. (1991). Personal perspective: critical human factors contributions in modern manufacturing. International Journal of Human Factors in Manufacturing, 1(3), 281-297.

Wilson, J.R. (1992). Human resource issues in manufacturing systems: the effects of JIT/TQM initiatives. In Helander, M., and Nagamachi, M. (Eds.), Design for manufacturability (pp. 269-280). London: Taylor \& Francis.

Wobbe, W. (1992). Advanced manufacturing and anthropocentric production systems in the European community. In Brödner, P. and Karwowski, W. (Eds.). Ergonomics of Hybrid Automated Systems III (pp. 1-8). Amsterdam: Elsevier.

Wood, W. T. (1982). The use of machine aids in dynamic multi-task environments: A comparison of an optimal model to human behavior. Unpublished master's thesis, Massachusetts Institute of Technology, Cambridge. 
Zairi, M. (1992). Towards an effective implementation of CIM: the role of shopfloor data collection systems. In Brödner, P. and Karwowski, W. (Eds.), Ergonomics of hybrid automated systems III (pp. 223-235). Amsterdan: Elsevier.

Zunzanyika, X. K. and Drury, C. G. (1975). Effects of information on industrial inspection performance. In Drury, C. G. and Fox, J. G. (Eds.), Human reliability in quality control (pp. 189-195). New York: Taylor \& Francis. 


\section{APPENDIX A}

\section{General Information: The Effects of Multitasking on Quality Inspection in AMS}

The purpose of the experiment in which you have been asked to participate is to determine if the human operator's performance in a quality inspection task is affected by multitasking (concurrently conducting multiple independent tasks) in Advanced Manufacturing Systems (AMS). The general information presented in this sheet is intended to help you decide whether you wish to participate in this experiment. If you do, you will be asked to fill out an informed consent form. At this point a screening procedure will be conducted to determine if your visual detection characteristics match those required for this experiment. First, your vision will be tested for acuity using a Baush \& Lomb Vision Tester. If you meet the visual acuity criterion, a psychophysical test, known as the Forced Choice Procedure (detecting differences in images on a computer screen), will be conducted to determine your visual capability to detect quality defects. Before each test you will receive written instructions and an interactive demonstration. You will be compensated for your time whether or not you are selected as a participant. The screening procedure has an approximate duration of twenty minutes.

At this point, if you have been selected as a participant, your visual perception sensitivity characteristics will be determined via a psychophysical procedure known as the constant stimuli method (detecting differences in images on a computer screen). The constant stimuli method procedure has a duration of approximately one hour. After this procedure you will receive training and practice in the experimental rules and procedures, tasks and equipment, and the defect rejection criterion. The training and practice activities have an approximate duration of forty minutes. After satisfactorily completing the training and practice session, six experimental sessions of approximately two hours each will be scheduled for six different days. During the experimental sessions you will be instructed to perform as an operator in a laboratory controlled manufacturing cell performing up to five independent task:

1) quality inspection: compare a part presented on a computer screen to a memorized criterion and decide whether to accept or reject the part.

2) production scheduling: schedule a production order presented on a computer screen based on a scheduling criterion.

3 ) inventory control: conduct an inventory on a specific part and place an order for the quantity required to meet the part demand presented on a computer screen.

4) machine setup: enter the parameters of a setup needed to produce a part on a computer screen.

5) machine disturbance control: enter an alphanumeric code on a computer to solve a machine problem presented on a computer screen. Written instructions and an interactive demonstration will be provided before each experimental session. 
The monetary compensation is $\$ 5$ per hour. You will be paid in cash at the end of each session. Total time commitment will be 14 hours, consisting of 7 sessions of 2 hours each, with total pay up to $\$ 70$. Please ask the experimenter now if you have any questions based on this general description of the experiment. Otherwise, request and complete the informed consent form if you wish to participate in this research. 


\title{
APPENDIX B
}

\section{VIRGINIA POLYTECHNIC INSTITUTE AND STATE UNIVERSITY}

\author{
Informed Consent for Participants of Investigative Projects
}

\author{
Title of Project: The Effects of Multitasking on Quality Inspection in AMS \\ Investigator: José A. Pesante-Santana \\ Faculty Advisor: Dr. Robert C. Williges
}

\section{The Purpose of this Research}

There are still a surprising number of parts in AMS that can only be inspected by means of human visual sensory detection. Even when the quality inspection search component has been automated, human operators must make a final decision on the acceptability of a manufactured part. In many cases, this judgment must be made on the basis of a comparison with a memorized criterion for acceptable parts. The purpose of this experiment is to determine if the human operator's performance in a quality inspection task is affected by multitasking (concurrently conducting multiple independent tasks) in AMS.

\section{Procedures}

This research is comprised of two phases: 1) the training and practice phase, 2) the experimental treatments phase. The training and practice phase will begin by determining some of your visual perception sensitivity characteristics via a psychophysical procedure, known as the constant stimuli method. You will receive written instructions and an interactive demonstration before this procedure. During the rest of this phase you will receive training (written instructions and an interactive demonstration) and practice in the experimental rules and procedures, tasks and equipment, and the defect rejection criterion. This session has an approximate duration of three hours. After satisfactorily completing the training and practice session, the second phase of the research will be scheduled. This phase consists of six experimental sessions of approximately two hours each (so total time commitment will be 14 hours, consisting of 7 sessions of 2 hours each). Written instructions and an interactive demonstration will be provided before each experimental session. Your participation in both phases of the research will be monitored from a video cube station outside the experimental room. However, it will not be videotaped.

During the second phase you will participate in six experimental treatments in a laboratory controlled manufacturing cell. The number of defects in the manufactured parts and the number of tasks to be conducted will be the two factors that will be varied 
over the six treatments. There are up to five independent tasks to be conducted in the manufacturing cell:

1) quality inspection: compare a part presented on a computer screen to a memorized criterion and decide whether to accept or reject the part.

2) production scheduling: schedule a production order presented on a computer screen based on a scheduling criterion.

3) inventory control: conduct an inventory on a specific part and place an order for the quantity required to meet the part demand presented on a computer screen.

4) machine setup: enter the parameters of a setup needed to produce a part on a computer screen.

5) machine disturbance control: enter an alphanumeric code on a computer to solve a machine problem presented on a computer screen.

Of these tasks, quality inspection will be conducted at every experimental treatment. The six experimental treatments will be scheduled in six sessions (one experimental treatment per session).

\section{Benefits of this Research}

Throughout the evolution of manufacturing, human sensory (visual) detection capabilities have been a vital, but often ignored, component of the quality inspection task. Despite all the significant technological developments in manufacturing, human sensory detection capabilities are still essential for the decision making component of the quality inspection task. Your participation in this research will provide significant information leading to a better understanding and characterization of the operator's performance in a quality inspection task while multitasking in AMS. The contribution of such characterization to present and future manufacturing systems is significant information that can be used for the design and allocation of the tasks in a way that maximizes the human operator's performance.

No promise or guarantee of benefits have been made to encourage you to participate. You may receive a summary of the research results when completed.

\section{Extent of Anonymity and Confidentiality}

The information collected in this experiment will be treated with confidentiality. At all times your name will be separated from your data and a coding scheme will be used to identify your data by subject number, gender, and treatment (e.g., S2-F-T3). The images provided by two video cameras inside the laboratory controlled manufacturing cell will be used to monitor your participation in the research. However, it will not be videotaped. 


\section{Compensation}

If you decide to participate in this research you will be paid $\$ 5$ per hour (cash) at the end of each session.

\section{Freedom to Withdraw}

You are free to withdraw from this study at any time without penalty. If you choose to withdraw, you will be compensated for the portion of time that you completed.

\section{Approval of Research}

This research has been approved, as required, by the Institutional Review Board for Research Involving Human Subjects at Virginia Polytechnic Institute and State University, and by the Department of Industrial and Systems Engineering.

\section{Subject's Responsibilities}

I voluntarily agree to participate in this study and execute all the research tasks at every phase of the research (training, practice, and experimental treatments) to the best of my capabilities. 


\section{Subject's Permission}

I have read and understand the Informed Consent and conditions of this project. I have had all my questions answered. I hereby acknowledge the above and give my voluntary consent for participation in this project.

If I participate, I may withdraw at any time without penalty. I agree to abide by the rules of this project.

\begin{tabular}{cc}
\hline Name & \\
& Date
\end{tabular}

Should I have questions about this research or its conduct, I may contact:

José A. Pesante-Santana

231-3193

Investigator

Dr. Robert C. Williges

$231-6270$

Faculty Advisor

H.T. Hurd

$231-5281$

Chair, IRB

Research Division 


\section{APPENDIX C}

\section{The Forced Choice Procedure}

The two-alternative forced-choice (2AFC) procedure was used to derive a measure of each subject's sensitivity (visual capability to detect quality defects). This sensitivity measure was independent of the subject's criterion (Green and Swets, 1966). For this procedure each subject was given a series of 102 presentations. Each presentation contained twelve items of the same type (lines or dots) equally divided in two groups. The subject's task was to detect the group that contained one item with an intensity (length or diameter) different to the other parts in the group (defect). The position of the rejectable defect was counterbalanced to control the effect of space error. The order of the presentations was randomized.

The sensitivity value was obtained from the proportion of correct detection of the rejectable defect. In order to be selected for the experiment the subjects needed to score a proportion of correct detection of at least 0.80 for both type of defects. The criterion of 0.80 is consistent with what has been commonly accepted for industrial quality inspection (Juran, 1974; Konz, Peterson, and Joshi, 1981; Schilling, 1982).

Visual Basic 4.0 was used to generate the computer-based 2AFC procedure code. The procedure was conducted in a 486-DX computer with a high resolution monitor located in a standing work table. 


\section{APPENDIX D}

\section{Instructions for the Two Alternatives Forced Choice Procedure}

Imagine that you are an industrial quality inspector in charge of a process in which you have to identify one of two batches containing a defective part (see Figure A). Each batch will consist of six items of equal length (in the case of lines) or equal diameter (in the case of circles). The batch containing an item different from the remaining five items should be identified as defective. All you need to do in order to identify the defective batch on each presentation is to click the DEFECTIVE button below the particular batch. You should continue the quality inspection task until the message End of Task appears on the screen.

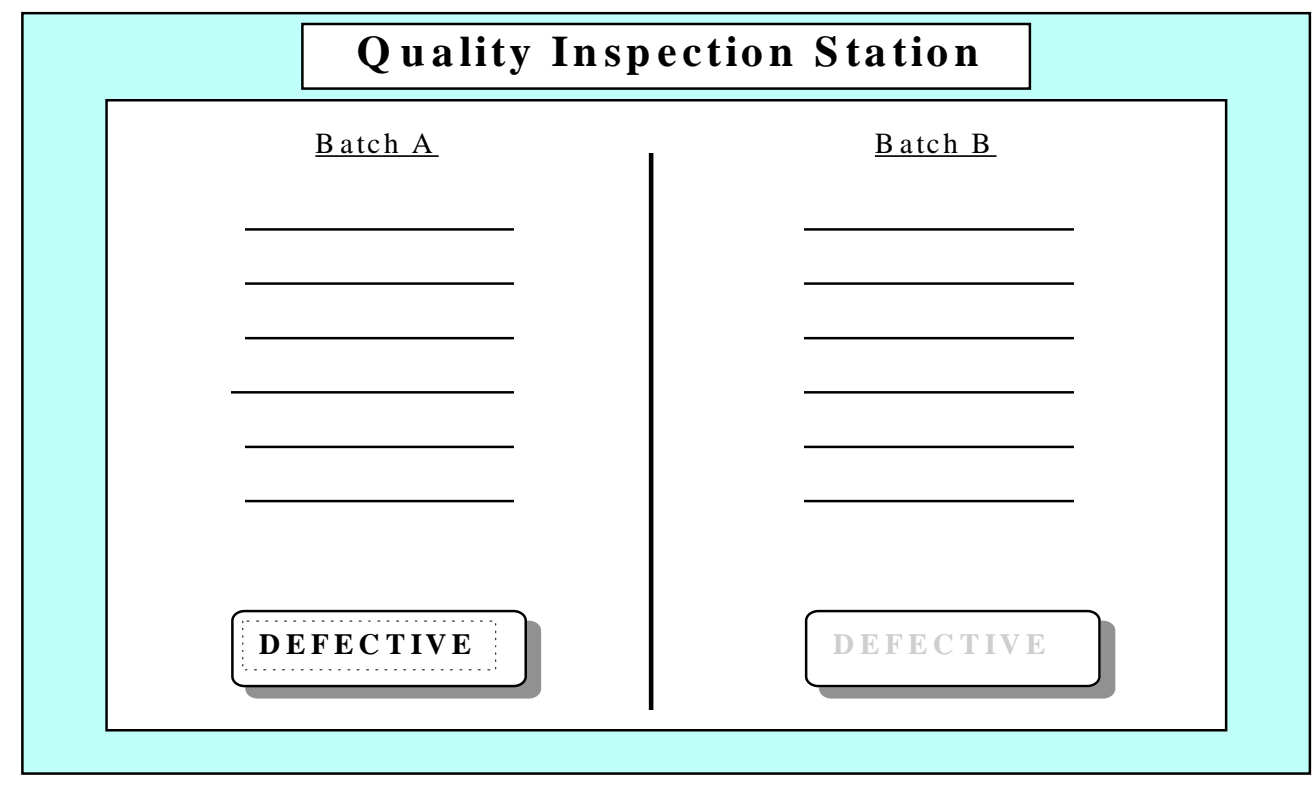

Figure A Screen image of the Forced Choice screening procedure. 


\section{APPENDIX E}

\section{The Constant Stimuli Method Procedure to Determine Difference Threshold}

The constant stimuli method procedure was used to determine the difference threshold (DL, for the German "Differenz Limen") or just noticeable difference that each subject could detect. To determine the DL, the stimuli (defect) of interest were presented in pairs, with one stimuli called the standard stimulus $(\mathrm{St})$ and the other called the comparison stimulus (Co). Seven comparison stimuli were used with intensity above and below the St (an equal number of each). A total of 100 stimuli pair presentations were conducted for each stimuli used in the experiment. The order of Co and St on the pair was counterbalanced to control the effect of space error. Whether the subject judged the Co to be greater than St was recorded and plotted for each presentation.

A least square regression model was built using the seven stimuli and their respective proportion of "greater than" answers. As recommended by Gescheider (1985), the DL was obtained from the difference in intensity between the points where $25 \%$ of the time and $75 \%$ of the time the subject's response was "greater than" (Appendix J). The psychometric function (ogive) obtained by plotting the seven stimuli (x-axis) and their respective proportion of "greater than" answers (y-axis) was used to supplement the estimation of the DL.

Visual Basic 4.0 was used to generate the computer-based 2AFC procedure code. The procedure was conducted in a 486-DX computer with a high resolution monitor located in a standing work table. 


\section{APPENDIX F}

\section{Instructions for the Constant Stimuli Method Procedure to Determine Difference}

\section{Threshold (DL)}

Imagine that you are an industrial quality inspector in charge of a process in which you have to determine if one item is greater than another item (in terms of length for lines, or in terms of diameter for circles). All you need to do is to click the YES or the

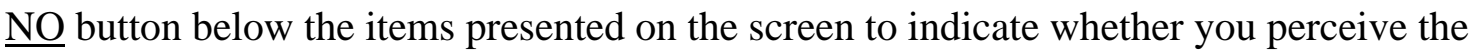
item in question to be greater than the other item being presented in the computer screen (see Figure A). A bell sound will alert you to the arrival of a new set of items to be inspected on the computer screen. You should continue the quality inspection task until the message End of Task appears on the screen.

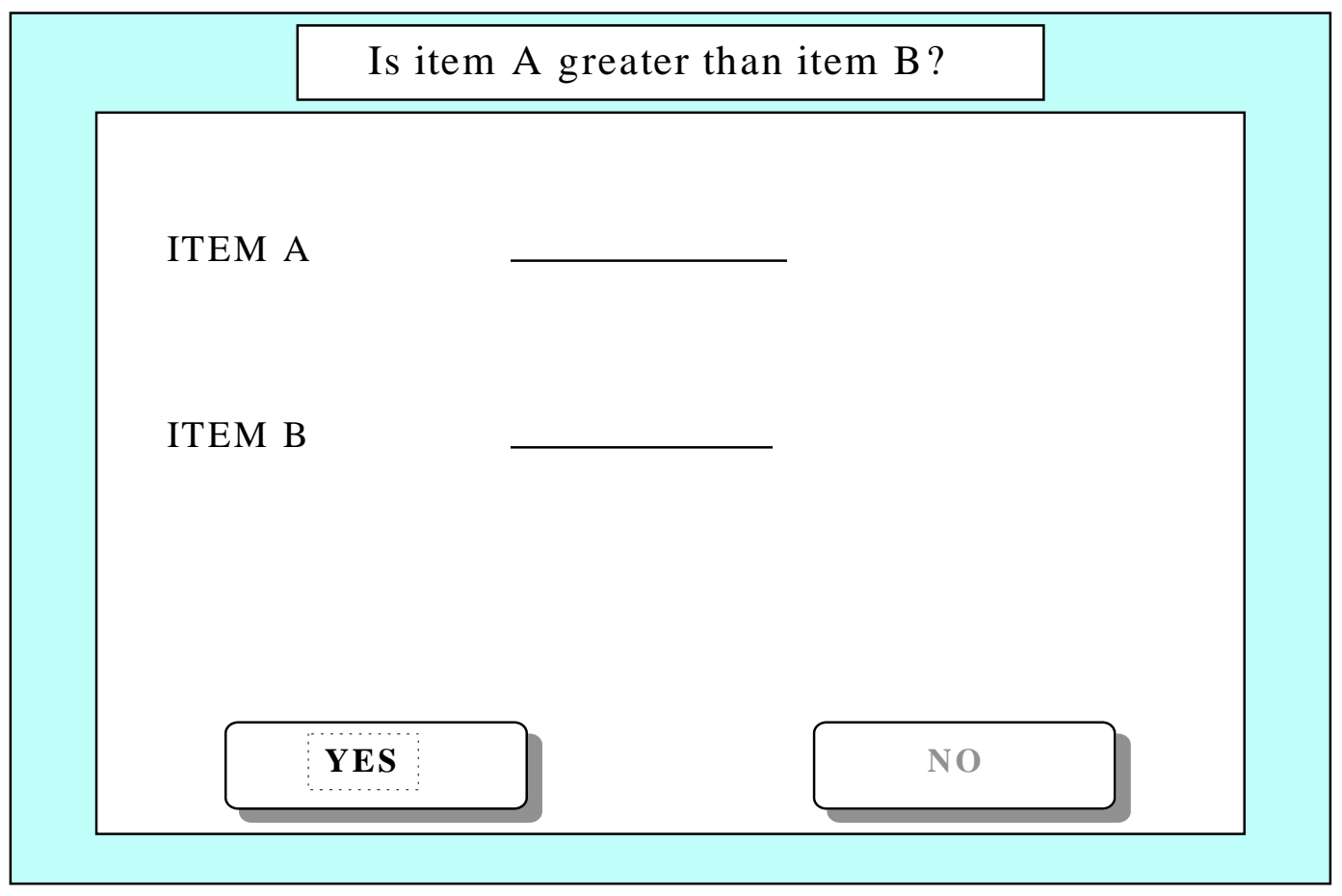

Figure A Screen image of the Constant Stimuli Method procedure for DL. 


\section{APPENDIX G}

\section{Instructions for the Experimental Treatments}

\section{Instructions for the Quality Inspection Task}

Imagine that you are an operator in an Advanced Manufacturing System (AMS). Your main function is to inspect the quality of the units presented on the computer monitor of the station. After hearing a ringing sound and seeing the red sign on the computer screen announcing the arrival of a new part to be inspected you are expected to conduct the following steps:

1) Click on the "Start" button once you are in front of the computer monitor and ready to begin the inspection.

2) If the unit has a defect compare its length (for the Scratch) or its diameter (for the Speck) to the memorized Quality Specifications.

a. If the unit's dimension (length or diameter) just inspected exceeds the memorized quality criterion, then reject the unit (click the "Reject" button).

b. If the unit's dimension (length or diameter) just inspected does not exceed the memorized quality criterion, then accept the unit (click the "Accept" button).

* Defects will always be located at the center of the part.

** Whenever both defects (Scratch and Speck) are present in the same unit compare both with their respective memorized quality criterion and reject the unit (click the "Reject" button) if at least one of the defect's dimensions exceeds the criterion. Otherwise accept the unit (click the "Accept" button). In other words, only accept the unit if both defects are acceptable.

*** Notice that your decision will be right whenever you reject a rejectable unit or accept an acceptable one. Your decision will be erroneous whenever you accept a rejectable unit or reject an acceptable one

3) If there is no defect in the unit being inspected, then accept the unit (click the "Accept" button).

4) If there is no other task waiting for your intervention, then wait at the Quality Inspection Station until the next part arrives to be inspected.

5) Always finish the inspection of the unit presented in the computer monitor before you begin another task. Remember that if you do not enter your decision about the part you are inspecting within the allowable time (six seconds after the "Start" button was clicked), then the part will move on to another process without having been inspected. 
6) If a part arrives to be inspected while you are conducting another task, it will stay in the quality station until you click the "Start" button. The six seconds allowed to inspect the part only begins after you click the "Start" button.
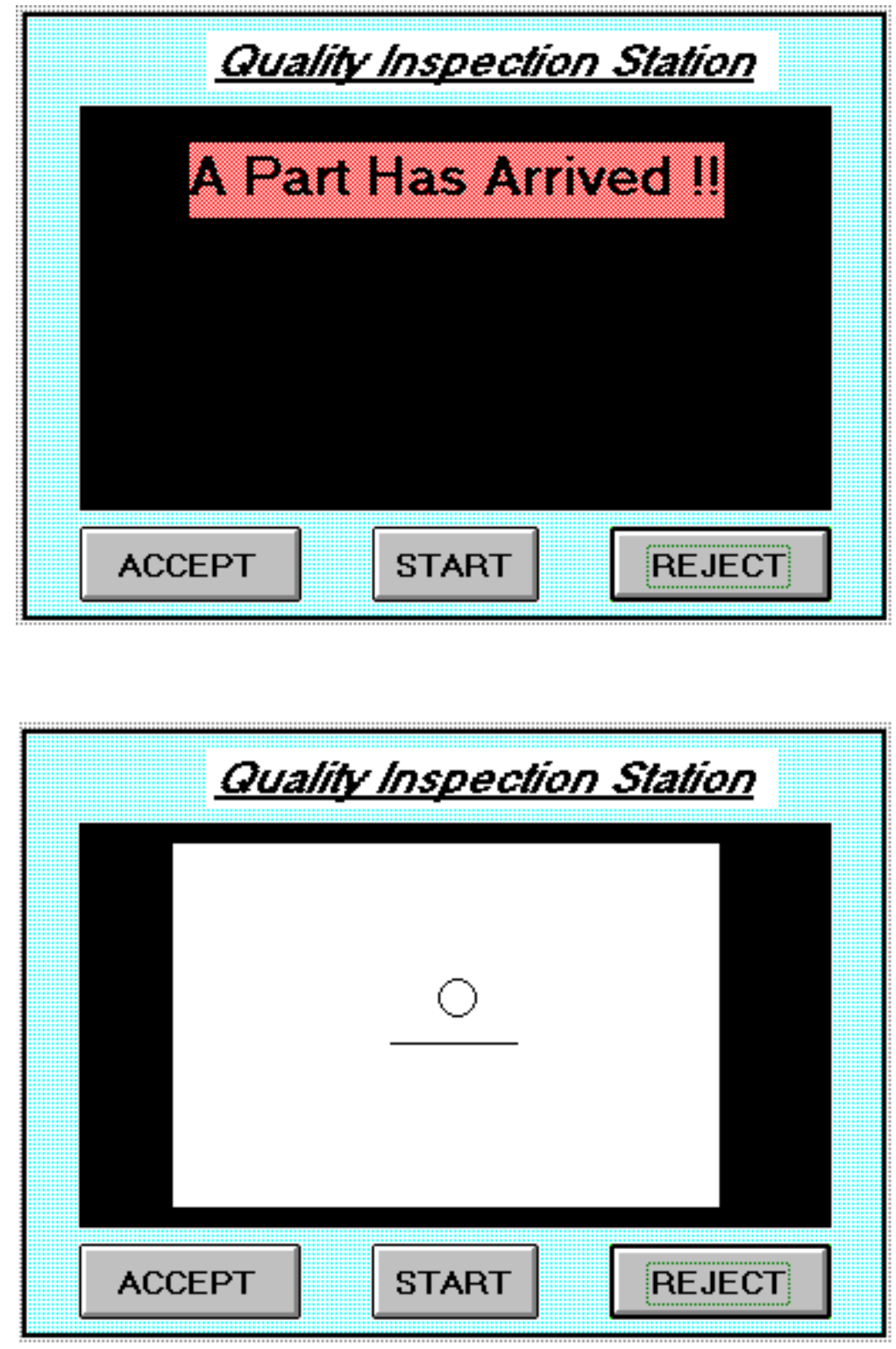


\section{Instructions for the Production Scheduling Task}

Whenever you hear a "Scheduling" message you are expected to do the following:

1) Go to the Production Scheduling and Inventory Station as soon as possible (after finishing the task you may be conducting). Remember, do not leave the quality inspection without entering your decision of "Accept" or "Reject" for the part being inspected.

2) Enter the number in which the new production order (at the bottom of the screen) should be scheduled to be processed, using the following criterion:

a. A new order should be scheduled to be processed before any order with a later due date.

b. In the case of more than one order with the same due date, the one with the smallest quantity should be scheduled first.

3) After entering the scheduling number for the order, click the "OK" button.

4) Return to the Quality Control Station if there is no error in the transaction just completed and/or there is no other task (machine setup or disturbance control) waiting for your intervention.

5) If there is an error in the transaction just completed, repeat the task from step 2.

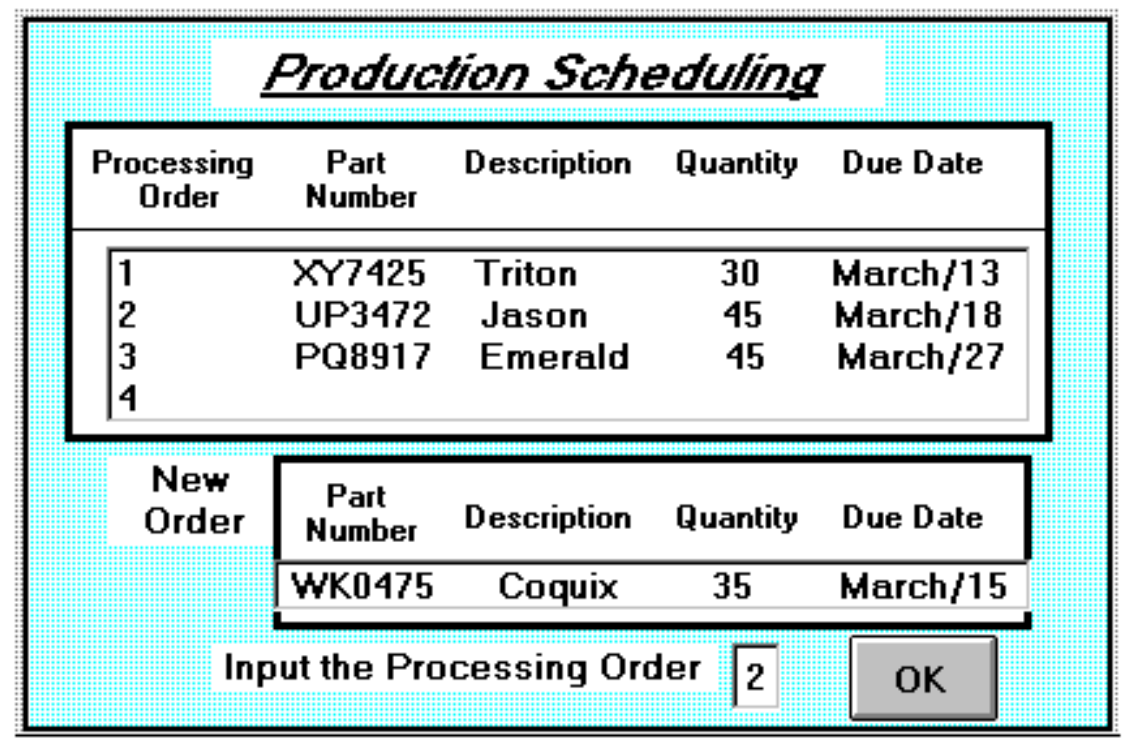




\section{Instructions for the Inventory Task}

Whenever you hear a "Inventory" message you are expected to do the following:

1) Go to the Production Scheduling and Inventory Station as soon as possible (after finishing the task you may be conducting). Remember, do not leave the quality inspection without entering your decision of "Accept" or "Reject" for the part being inspected.

2) Identify the specific part requested to be inventoried in the inventory control screen (at the bottom of the screen).

3) Count the number of parts in the correct bin and enter the quantity in the inventory control screen (“Available QTY" field).

4) Mentally calculate the quantity required to complete the order, enter the amount of units needed to complete the required order, and click the "OK" button.

5) Return to the Quality Control Station if there is no error in the transaction just completed and/or there is no other task (machine setup or disturbance control) waiting for your intervention.

6) If there is an error in the transaction just completed, repeat the task from step 2.

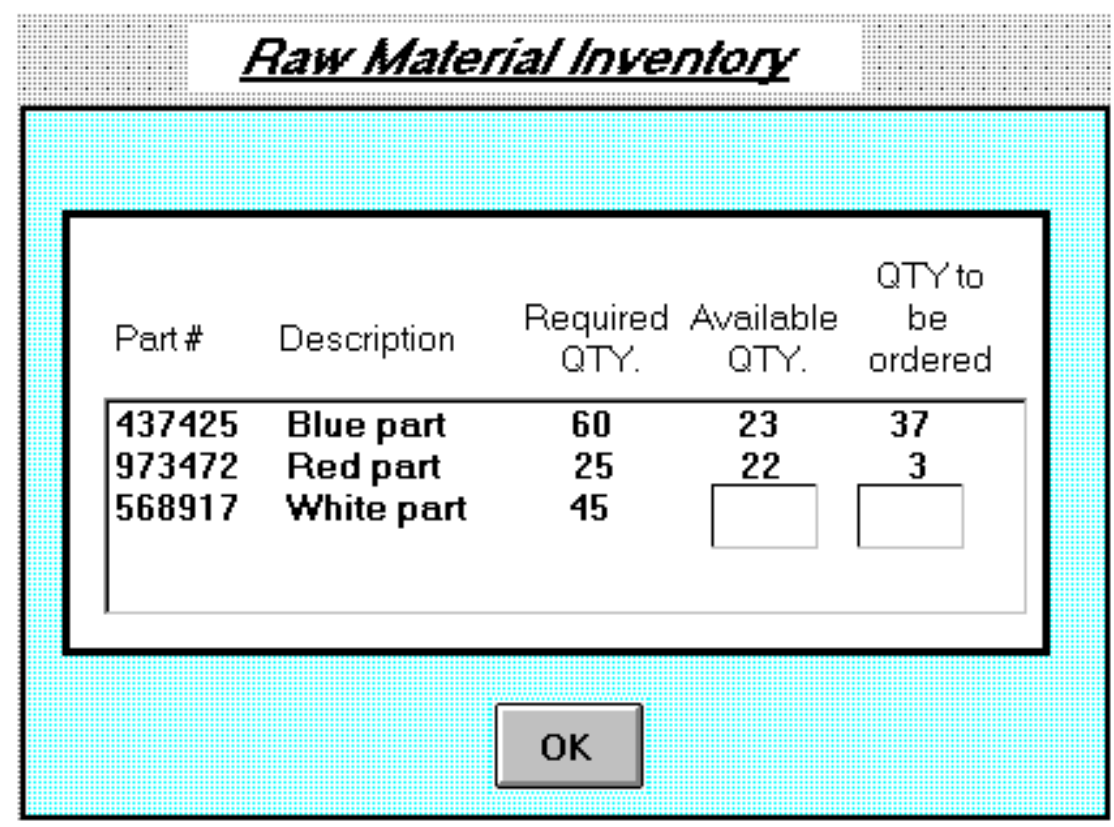




\section{Instructions for the Machine Setup Task}

following:

Whenever you hear a "Machine Setup" message you are expected to do the

1) Go to the Adjacent Process Station as soon as possible (after finishing the task you may be conducting). Remember, do not leave the quality inspection without entering your decision of "Accept" or "Reject" for the part being inspected.

2) Identify the specific part number for which the setup has to be entered and find the values for the setup in the setup card available at the station.

3) Enter the values for the setup requested in the setup screen.

4) After entering the setup click the "OK" button.

5) Return to the Quality Control Station if there is no error in the transaction just completed and/or there is no other task (production scheduling or inventory) waiting for your intervention.

6) If there is an error in the transaction just completed, repeat the task from step 2.

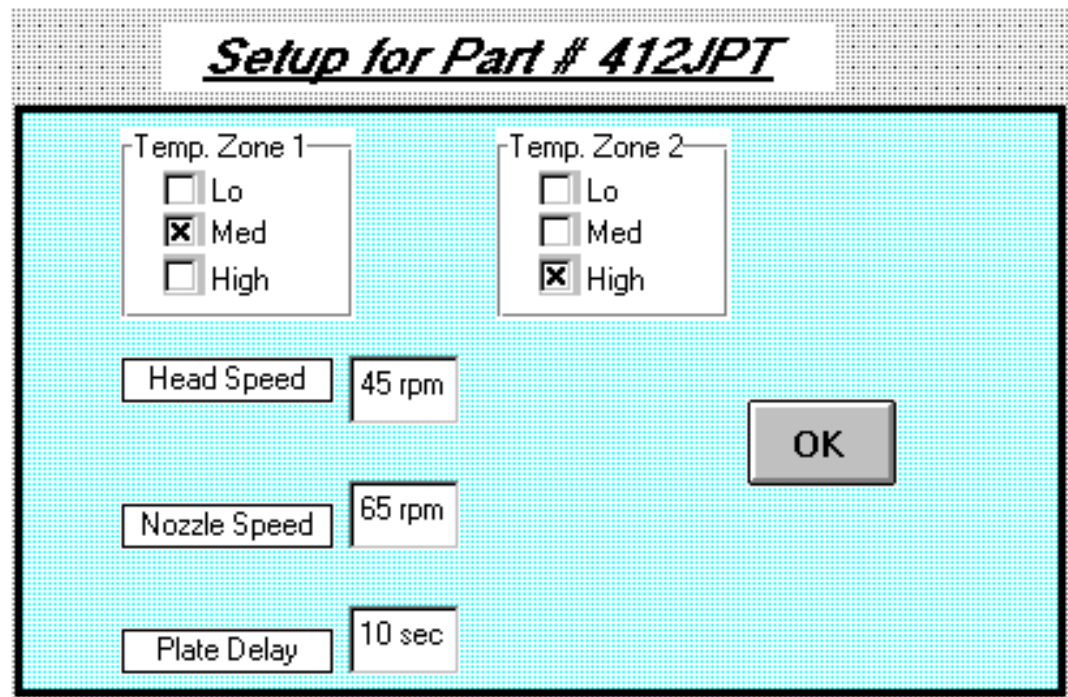




\section{Instructions for the Machine Disturbance Control Task}

following:

Whenever you hear a "Machine Problem" message you are expected to do the

1) Go to the Adjacent Process Station as soon as possible (after finishing the task you may be conducting). Remember, do not leave the quality inspection without entering your decision of "Accept" or "Reject" for the part being inspected.

2) Identify the machine problem number and find the alphanumeric code (from the disturbance control codes card available at the station) needed to solve the machine problem.

3) Enter the alphanumeric code in the station and click the "OK" button.

4) Return to the Quality Control Station if there is no error in the transaction just completed and/or there is no other task (production scheduling or inventory) waiting for your intervention.

5) If there is an error in the transaction just completed, repeat the task from step 2.

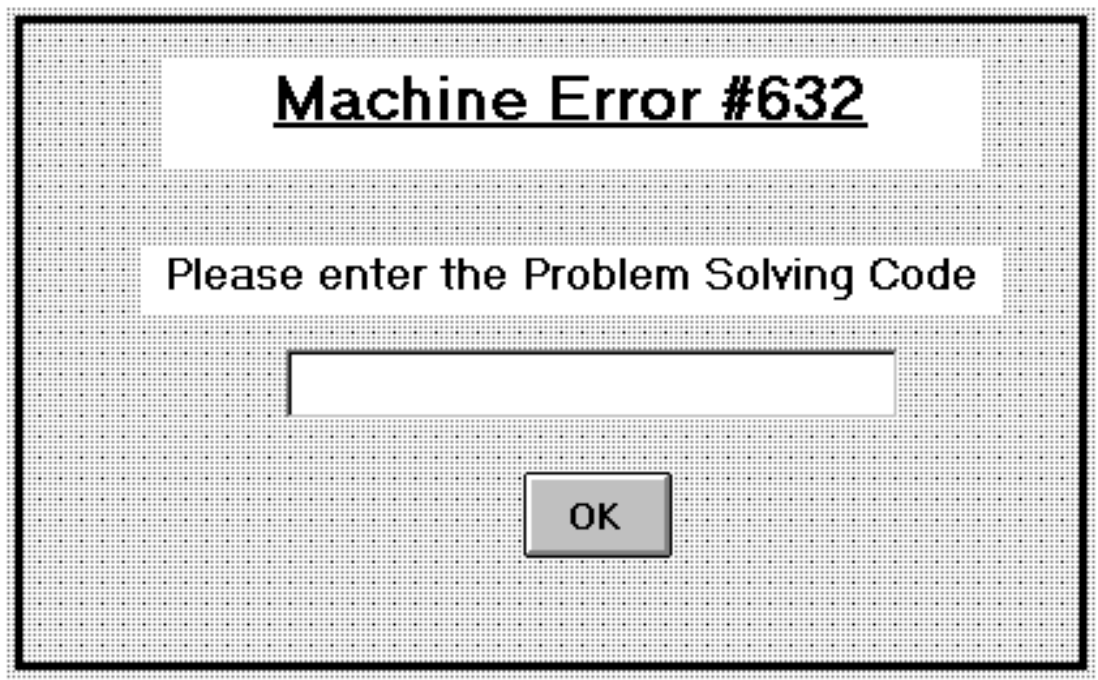




\section{Overview of the Instructions for the Experiment}

Imagine that you are an operator in an Advanced Manufacturing System (AMS). Although your main function is always to perform the quality inspection task as instructed in the training session, there might be occasions (experimental treatments) in which you will have to concurrently execute other tasks (such as production scheduling, inventory control, machine setup, and/or machine disturbance control) in addition to your main task. Even though quality inspection is your primary task, it is expected that you will perform any additional tasks to the best of your abilities (as trained and practiced in the training session). There will be only one experimental treatment per scheduled session. The following information will remind you of the main steps (previously learned and practiced in the training session) that you have to follow in the experiment.

1) There will be two types of defects (Scratch and Speck). Their presence will vary base on the experimental treatments. In some experimental treatments only one type of defect might appear on an inspection unit, while in other treatments both type of defects might appear on the same inspection unit. You will be informed before each session which one of the two possible cases will you be dealing with during the experimental treatment. In the inspection task a ringing sound will alert you to the arrival of a unit to be inspected. You will click the "Start" button to indicate the beginning of the inspection. Six seconds will be allowed for the inspection. You will click the "Reject" button to reject a unit that exceeds the memorized quality criterion (learned and practiced in the training session) or the "Accept" button to accept a unit that does not exceed the criterion. Your decision will be right whenever you reject a rejectable unit or accept an acceptable one. Your decision will be erroneous whenever you accept a rejectable unit or reject an acceptable one.

2) An "Inventory" or a "Scheduling" message from the production scheduling and inventory control station will let you know when you need to conduct a scheduling task or an inventory control task (in addition to the quality inspection task). If the scheduling screen appears on the station monitor with a new order, you will compare its quantity and due date with the other orders already in the system, then you will schedule it based on a scheduling criterion. According to this criterion the new order should be scheduled to be processed before any order with a later due date. In the case of more than one order with the same due date, the one with the smallest quantity should be scheduled first. After making your decision, you should input the processing order in the screen and click the "OK" button. For the inventory control task, you will identify the specific part requested to be inventoried in the inventory control screen. Then you will count the number of parts in the bin and enter the quantity in the inventory control application screen. You will place an order for any part which is below the quantity required for production and click the 
"OK" button. Return to the quality control station if there is no other task (machine setup or disturbance control) waiting for your intervention.

3) A "Machine Problem" or a "Machine Setup" message from the adjacent process station will let you know when you need to conduct a machine setup task or a machine disturbance control task (in addition to the quality inspection, production scheduling, and inventory control tasks). For the setup task you will enter the parameters of a particular product (from the setup card available at the station) requested in the setup screen of the adjacent process station. For the disturbance control task you will read the displayed error message in the adjacent process station's screen and enter a particular alphanumeric code (from the disturbance control codes card available at the station) to restart the process. Return to the quality control station if there is no other task (production scheduling or inventory) waiting for your intervention.

4) You are required to complete every task. The production scheduling and inventory tasks have the same importance as the machine setup and disturbance control tasks.

5) After each experimental treatment you will be asked to fill out a questionnaire.

6) After filling out the questionnaire you will be paid. 


\section{APPENDIX H}

\section{Likert-like Scale for Subjective Mental Workload}

Please evaluate the experimental treatment you just completed by placing an (x) on the Likert-like scale provided for each statements. Place the $(\mathrm{x})$ at the area that corresponds with your opinion of this statement. You may place your (x) between numbers.

\section{Example:}

The sky is blue-green.

\begin{tabular}{ccccccccc}
\hline & $\mid$ & $\mid$ & $\mid$ & $\mid$ & $\mid$ & $\mid$ & $\mid$ & $\mid$ \\
1 & 2 & 3 & 4 & 5 & 6 & 7 & 8 & 9 \\
Strongly & & Disagree & & Undecided & & Agree & & Strongly \\
Disagree & & & & & & & & Agree
\end{tabular}

\section{$\underline{\text { Mental Demand }}$}

1. The experimental treatment that I just completed was easy.

\begin{tabular}{ccccccccc}
\hline & $\mid$ & $\mid$ & $\mid$ & $\mid$ & $\mid$ & $\mid$ & $\mid$ & $\mid$ \\
1 & 2 & 3 & 4 & 5 & 6 & 7 & 8 & 9 \\
Strongly & & Disagree & & Undecided & & Agree & & Strongly \\
Disagree & & & & & & & & Agree
\end{tabular}

2. The experimental treatment that I just completed required too much thinking.

\begin{tabular}{c|cccccccc}
\hline & $\mid$ & $\mid$ & $\mid$ & $\mid$ & $\mid$ & $\mid$ & $\mid$ & $\mid$ \\
1 & 2 & 3 & 4 & 5 & 6 & 7 & 8 & 9 \\
Strongly & & Disagree & & Undecided & & Agree & & Strongly \\
Disagree & & & & & & & & Agree
\end{tabular}

$\underline{\text { Physical Demand }}$

3. The experimental treatment that I just completed required too much physical activity.

\begin{tabular}{ccccccccc}
\hline & $\mid$ & $\mid$ & $\mid$ & $\mid$ & $\mid$ & $\mid$ & $\mid$ & $\mid$ \\
1 & 2 & 3 & 4 & 5 & 6 & 7 & 8 & 9 \\
Strongly & & Disagree & & Undecided & & Agree & & Strongly \\
Disagree & & & & & & & & Agree
\end{tabular}




\section{Physical Demand (cont.)}

4. The experimental treatment that I just completed was not strenuous.

\begin{tabular}{ccccccccc}
\hline & $\mid$ & $\mid$ & $\mid$ & $\mid$ & $\mid$ & $\mid$ & $\mid$ & $\mid$ \\
1 & 2 & 3 & 4 & 5 & 6 & 7 & 8 & 9 \\
Strongly & & Disagree & & Undecided & & Agree & & Strongly \\
Disagree & & & & & & & Agree
\end{tabular}

\section{$\underline{\text { Temporal Demand }}$}

5. The experimental treatment that I just completed placed a significant amount of time pressure on me.

\begin{tabular}{ccccccccc}
\hline & $\mid$ & $\mid$ & $\mid$ & $\mid$ & $\mid$ & $\mid$ & $\mid$ & $\mid$ \\
1 & 2 & 3 & 4 & 5 & 6 & 7 & 8 & 9 \\
Strongly & & Disagree & & Undecided & & Agree & & Strongly \\
Disagree & & & & & & & & Agree
\end{tabular}

6. In the experimental treatment I just completed, the pace at which the tasks or task elements occurred was rapid and sometimes frantic.

\begin{tabular}{ccccccccc}
\hline & $\mid$ & $\mid$ & $\mid$ & $\mid$ & $\mid$ & $\mid$ & $\mid$ & $\mid$ \\
1 & 2 & 3 & 4 & 5 & 6 & 7 & 8 & 9 \\
Strongly & & Disagree & & Undecided & & Agree & & Strongly \\
Disagree & & & & & & & & Agree
\end{tabular}

\section{$\underline{\text { Performance }}$}

7. In the experimental treatment that I just completed, I think I was successful in accomplishing the goals set by the experimenter.

\begin{tabular}{ccccccccc}
\hline & $\mid$ & $\mid$ & $\mid$ & $\mid$ & $\mid$ & $\mid$ & $\mid$ & $\mid$ \\
1 & 2 & 3 & 4 & 5 & 6 & 7 & 8 & 9 \\
Strongly & & Disagree & & Undecided & & Agree & & Strongly \\
Disagree & & & & & & & & Agree
\end{tabular}

8. In the experimental treatment that I just completed, I am satisfied with my performance.

\begin{tabular}{ccccccccc}
\hline & $\mid$ & $\mid$ & $\mid$ & $\mid$ & $\mid$ & $\mid$ & $\mid$ & $\mid$ \\
1 & 2 & 3 & 4 & 5 & 6 & 7 & 8 & 9 \\
Strongly & & Disagree & & Undecided & & Agree & & Strongly \\
Disagree & & & & & & & & Agree
\end{tabular}


9. In the experimental treatment that I just completed, I was able to accomplish a satisfactory level of performance with minimum mental effort.

\begin{tabular}{ccccccccc}
\hline & $\mid$ & $\mid$ & $\mid$ & $\mid$ & $\mid$ & $\mid$ & $\mid$ & $\mid$ \\
1 & 2 & 3 & 4 & 5 & 6 & 7 & 8 & 9 \\
Strongly & & Disagree & & Undecided & & Agree & & Strongly \\
Disagree & & & & & & & & Agree
\end{tabular}

10. In the experimental treatment that I just completed, I was able to accomplish a satisfactorily level of performance with a minimum physical effort.

\begin{tabular}{ccccccccc}
\hline & $\mid$ & $\mid$ & $\mid$ & $\mid$ & $\mid$ & $\mid$ & $\mid$ & $\mid$ \\
1 & 2 & 3 & 4 & 5 & 6 & 7 & 8 & 9 \\
Strongly & & Disagree & & Undecided & & Agree & & Strongly \\
Disagree & & & & & & & & Agree
\end{tabular}

Frustration Level

11. While performing the experimental treatment that I just completed, I felt relaxed and complacent.

\begin{tabular}{ccccccccc}
\hline & $\mid$ & $\mid$ & $\mid$ & $\mid$ & $\mid$ & $\mid$ & $\mid$ & $\mid$ \\
1 & 2 & 3 & 4 & 5 & 6 & 7 & 8 & 9 \\
Strongly & & Disagree & & Undecided & & Agree & & Strongly \\
Disagree & & & & & & & & Agree
\end{tabular}

12. While performing the experimental treatment that I just completed, I felt insecure, discouraged, irritated, stressed, or annoyed.

\begin{tabular}{ccccccccc}
\hline & $\mid$ & $\mid$ & $\mid$ & $\mid$ & $\mid$ & $\mid$ & $\mid$ & $\mid$ \\
1 & 2 & 3 & 4 & 5 & 6 & 7 & 8 & 9 \\
Strongly & & Disagree & & Undecided & & Agree & & Strongly \\
Disagree & & & & & & & & Agree
\end{tabular}

Comments: 


\section{Appendix I}

\section{Computational Formulas}

$\underline{\text { Variables definition }}$

P_Hit $(\mathrm{H})=$ proportion of hits

P_FA $(\mathrm{FA})=$ proportion of false alarm

$z=$ standardized normal deviate associated with $\mathrm{H}$ or FA

$\mathrm{N}=$ noise

$\mathrm{SN}=$ signal-plus-noise

The ordinates for $\mathrm{N}$ and $\mathrm{SN}$ are calculated at $z$

$\mathrm{p}(\mathrm{N})=$ probability of noise

$\mathrm{p}(\mathrm{SN})=$ probability of signal-plus-noise

Perceptual Sensitivity

$$
\mathrm{d}^{\prime}=z_{\mathrm{FA}}-z_{\mathrm{H}}
$$

$\underline{\text { Response Bias }}$

$$
\begin{aligned}
& \beta=\frac{\operatorname{ordinate}(\mathrm{SN})}{\operatorname{ordinate}(\mathrm{N})} \\
& c=0.5\left(z_{\mathrm{FA}}+z_{\mathrm{H}}\right)
\end{aligned}
$$

\section{$\underline{\text { Ideal Beta }}$}

$$
\beta_{\mathrm{i}}=\frac{\mathrm{p}(\mathrm{N})}{\mathrm{p}(\mathrm{SN})}
$$




\section{Experiment Data}

\begin{tabular}{|c|c|c|c|c|c|c|c|c|}
\hline Subj. & D_T & Tsk & P_Hit & P_FA & $\mathbf{d}^{\prime}$ & B & $\boldsymbol{c}$ & Avg. Time (sec.) \\
\hline 1 & 1 & 1 & 0.5000 & 0.0117 & 2.2668 & 14.94 & 1.1334 & 1.67 \\
\hline 1 & 1 & 3 & 0.4254 & 0.0017 & 2.7409 & 62.35 & 1.5585 & 1.12 \\
\hline 1 & 1 & 5 & 0.6095 & 0.0083 & 2.6734 & 17.52 & 1.0587 & 1.11 \\
\hline 1 & 2 & 1 & 0.6642 & 0.0017 & 3.3529 & 58.16 & 1.2525 & 1.39 \\
\hline 1 & 2 & 3 & 0.5754 & 0.0017 & 3.1191 & 62.05 & 1.3694 & 1.36 \\
\hline 1 & 2 & 5 & 0.5725 & 0.0017 & 3.1117 & 62.35 & 1.3731 & 1.26 \\
\hline 2 & 1 & 1 & 0.6294 & 0.0050 & 2.9060 & 26.04 & 1.1227 & 1.70 \\
\hline 2 & 1 & 3 & 0.9478 & 0.0183 & 3.7140 & 2.13 & 0.2331 & 1.09 \\
\hline 2 & 1 & 5 & 0.8731 & 0.0083 & 3.5366 & 9.66 & 0.6271 & 1.11 \\
\hline 2 & 2 & 1 & 0.9577 & 0.1128 & 2.9363 & 0.46 & -0.2564 & 1.54 \\
\hline 2 & 2 & 3 & 0.9328 & 0.0814 & 2.8926 & 0.90 & -0.0506 & 1.82 \\
\hline 2 & 2 & 5 & 0.8618 & 0.0717 & 2.5516 & 1.66 & 0.1874 & 1.72 \\
\hline 3 & 1 & 1 & 0.8682 & 0.0548 & 2.7179 & 2.05 & 0.2410 & 1.07 \\
\hline 3 & 1 & 3 & 0.8483 & 0.0483 & 2.6907 & 2.26 & 0.3161 & 1.18 \\
\hline 3 & 1 & 5 & 0.9876 & 0.1578 & 3.2480 & 0.11 & -0.6204 & 1.04 \\
\hline 3 & 2 & 1 & 0.8725 & 0.0150 & 3.3083 & 4.37 & 0.5159 & 1.74 \\
\hline 3 & 2 & 3 & 0.9876 & 0.1412 & 3.3194 & 0.12 & -0.5847 & 1.33 \\
\hline 3 & 2 & 5 & 0.9129 & 0.0714 & 2.8242 & 1.21 & 0.0533 & 1.48 \\
\hline 4 & 1 & 1 & 0.5249 & 0.0050 & 2.6382 & 27.48 & 1.2566 & 0.90 \\
\hline 4 & 1 & 3 & 0.6393 & 0.0017 & 3.2855 & 59.38 & 1.2862 & 1.17 \\
\hline 4 & 1 & 5 & 0.7935 & 0.0083 & 3.2140 & 13.16 & 0.7884 & 1.07 \\
\hline 4 & 2 & 1 & 0.8769 & 0.0450 & 2.8550 & 1.94 & 0.2678 & 2.02 \\
\hline 4 & 2 & 3 & 0.8483 & 0.0050 & 3.6050 & 16.08 & 0.7733 & 1.34 \\
\hline 4 & 2 & 5 & 0.7139 & 0.0050 & 3.1406 & 23.61 & 1.0055 & 1.36 \\
\hline 5 & 1 & 1 & 0.7985 & 0.0116 & 3.1063 & 10.49 & 0.7169 & 0.83 \\
\hline 5 & 1 & 3 & 0.6592 & 0.0017 & 3.3392 & 58.16 & 1.2593 & 0.84 \\
\hline 5 & 1 & 5 & 0.9129 & 0.0615 & 2.9011 & 1.36 & 0.0917 & 1.09 \\
\hline 5 & 2 & 1 & 0.7886 & 0.0050 & 3.3774 & 19.88 & 0.8871 & 1.19 \\
\hline 5 & 2 & 3 & 0.8831 & 0.0150 & 3.3607 & 4.13 & 0.4897 & 1.01 \\
\hline 5 & 2 & 5 & 0.8035 & 0.0017 & 3.7831 & 44.44 & 1.0374 & 0.91 \\
\hline 6 & 1 & 1 & 0.8975 & 0.0150 & 3.4375 & 3.63 & 0.4513 & 1.51 \\
\hline 6 & 1 & 3 & 0.8085 & 0.0183 & 2.9625 & 5.61 & 0.6089 & 1.19 \\
\hline 6 & 1 & 5 & 0.7985 & 0.0017 & 3.7652 & 44.44 & 1.0463 & 1.23 \\
\hline 6 & 2 & 1 & 0.6940 & 0.0017 & 3.4362 & 56.00 & 1.2108 & 1.26 \\
\hline 6 & 2 & 3 & 0.8383 & 0.0017 & 3.9165 & 38.62 & 0.9707 & 1.14 \\
\hline 6 & 2 & 5 & 0.6244 & 0.0017 & 3.2460 & 60.44 & 1.3059 & 1.43 \\
\hline & & & & & & & & \\
\hline
\end{tabular}




\begin{tabular}{|c|c|c|c|c|c|c|c|c|}
\hline Subj. & D_T & Tsk & P_Hit & P_FA & $\mathbf{d}^{\prime}$ & $\mathbf{B}$ & $\boldsymbol{c}$ & Avg_Time (sec.) \\
\hline 7 & 1 & 1 & 0.5398 & 0.0017 & 3.0289 & 63.00 & 1.4145 & 1.26 \\
\hline 7 & 1 & 3 & 0.4900 & 0.0050 & 2.5507 & 27.50 & 1.3004 & 1.23 \\
\hline 7 & 1 & 5 & 0.5452 & 0.0249 & 2.0752 & 8.18 & 0.9240 & 1.45 \\
\hline 7 & 2 & 1 & 0.4502 & 0.0083 & 2.2702 & 18.07 & 1.2603 & 1.33 \\
\hline 7 & 2 & 3 & 0.5746 & 0.1283 & 1.3225 & 1.86 & 0.4731 & 2.10 \\
\hline 7 & 2 & 5 & 0.3209 & 0.0017 & 2.4638 & 56.76 & 1.6970 & 1.27 \\
\hline 8 & 1 & 1 & 0.8333 & 0.0083 & 3.3627 & 11.56 & 0.7140 & 1.49 \\
\hline 8 & 1 & 3 & 0.8075 & 0.0415 & 2.6022 & 3.15 & 0.4324 & 1.35 \\
\hline 8 & 1 & 5 & 0.8930 & 0.0083 & 3.6380 & 8.58 & 0.5764 & 1.31 \\
\hline 8 & 2 & 1 & 0.8930 & 0.0083 & 3.6380 & 8.58 & 0.5764 & 1.64 \\
\hline 8 & 2 & 3 & 0.9425 & 0.0017 & 4.5051 & 18.90 & 0.6764 & 1.21 \\
\hline 8 & 2 & 5 & 0.7289 & 0.0017 & 3.5384 & 52.48 & 1.1597 & 1.39 \\
\hline 9 & 1 & 1 & 0.8333 & 0.0017 & 3.8962 & 40.17 & 0.9808 & 1.22 \\
\hline 9 & 1 & 3 & 0.8085 & 0.0116 & 3.1425 & 10.16 & 0.6988 & 1.36 \\
\hline 9 & 1 & 5 & 0.9179 & 0.0814 & 2.7868 & 1.00 & 0.0023 & 1.26 \\
\hline 9 & 2 & 1 & 0.8184 & 0.1213 & 2.0777 & 1.31 & 0.1296 & 1.90 \\
\hline 9 & 2 & 3 & 0.9726 & 0.0581 & 3.4913 & 0.57 & -0.1747 & 1.31 \\
\hline 9 & 2 & 5 & 0.9527 & 0.1213 & 2.8401 & 0.52 & -0.2515 & 1.38 \\
\hline 10 & 1 & 1 & 0.8284 & 0.0050 & 3.5236 & 17.46 & 0.8139 & 1.34 \\
\hline 10 & 1 & 3 & 0.7587 & 0.0083 & 3.0975 & 14.20 & 0.8466 & 1.41 \\
\hline 10 & 1 & 5 & 0.8417 & 0.0150 & 3.1715 & 5.03 & 0.5843 & 1.58 \\
\hline 10 & 2 & 1 & 0.7075 & 0.0050 & 3.1219 & 23.61 & 1.0148 & 1.49 \\
\hline 10 & 2 & 3 & 0.7312 & 0.0017 & 3.5454 & 52.48 & 1.1562 & 1.41 \\
\hline 10 & 2 & 5 & 0.8085 & 0.0050 & 3.4482 & 18.72 & 0.8517 & 1.18 \\
\hline 11 & 1 & 1 & 0.9876 & 0.0482 & 3.9070 & 0.26 & -0.2909 & 1.61 \\
\hline 11 & 1 & 3 & 0.9826 & 0.0748 & 3.5516 & 0.36 & -0.3348 & 1.56 \\
\hline 11 & 1 & 5 & 0.7935 & 0.0856 & 2.1869 & 1.77 & 0.2748 & 1.25 \\
\hline 11 & 2 & 1 & 0.9527 & 0.0183 & 3.7618 & 2.13 & 0.2092 & 1.39 \\
\hline 11 & 2 & 3 & 0.9475 & 0.0917 & 2.9514 & 0.63 & -0.1453 & 1.54 \\
\hline 11 & 2 & 5 & 0.9175 & 0.1717 & 2.3359 & 0.59 & -0.2204 & 1.76 \\
\hline 12 & 1 & 1 & 0.7985 & 0.0083 & 3.2317 & 12.79 & 0.7795 & 1.13 \\
\hline 12 & 1 & 3 & 0.8582 & 0.0116 & 3.3423 & 8.34 & 0.5989 & 1.12 \\
\hline 12 & 1 & 5 & 0.7040 & 0.0083 & 2.9313 & 15.88 & 0.9297 & 1.09 \\
\hline 12 & 2 & 1 & 0.7338 & 0.0083 & 3.0197 & 15.10 & 0.8855 & 1.12 \\
\hline 12 & 2 & 3 & 0.6759 & 0.0249 & 2.4179 & 7.39 & 0.7527 & 1.43 \\
\hline 12 & 2 & 5 & 0.6095 & 0.0050 & 2.8538 & 26.46 & 1.1489 & 1.03 \\
\hline & & & & & & & & \\
\hline
\end{tabular}


$\underline{\text { Subjective Workload Questionnaire Scores }}$

\begin{tabular}{|c|c|c|c|c|c|c|c|c|}
\hline \multirow[b]{2}{*}{ Subj. } & \multirow[b]{2}{*}{ D_T } & \multirow[b]{2}{*}{ Tsk } & \multicolumn{2}{|c|}{ Mental Demand } & \multicolumn{2}{|c|}{ Physical Demand } & \multicolumn{2}{|c|}{ Temporal Demand } \\
\hline & & & Item 1 & Item 2 & Item 3 & Item 4 & Item 5 & Item 6 \\
\hline 1 & 1 & 1 & 3.5 & 6.5 & 4.5 & 7.0 & 5.0 & 4.0 \\
\hline 1 & 1 & 3 & 6.0 & 4.0 & 4.0 & 6.0 & 4.0 & 4.0 \\
\hline 1 & 1 & 5 & 5.5 & 6.0 & 4.0 & 5.0 & 4.0 & 6.0 \\
\hline 1 & 2 & 1 & 6.5 & 5.0 & 3.0 & 6.0 & 4.0 & 3.0 \\
\hline 1 & 2 & 3 & 6.0 & 6.0 & 3.0 & 6.0 & 5.0 & 4.0 \\
\hline 1 & 2 & 5 & 5.4 & 4.5 & 4.0 & 7.0 & 6.0 & 6.0 \\
\hline 2 & 1 & 1 & 3.0 & 3.0 & 3.0 & 1.0 & 6.0 & 2.0 \\
\hline 2 & 1 & 3 & 7.5 & 2.0 & 2.0 & 7.0 & 2.1 & 1.8 \\
\hline 2 & 1 & 5 & 6.8 & 3.0 & 5.2 & 6.8 & 1.2 & 1.2 \\
\hline 2 & 2 & 1 & 5.0 & 3.4 & 6.0 & 7.0 & 3.0 & 1.6 \\
\hline 2 & 2 & 3 & 7.0 & 2.0 & 3.0 & 6.5 & 3.0 & 1.0 \\
\hline 2 & 2 & 5 & 4.8 & 3.0 & 5.4 & 4.6 & 3.0 & 1.5 \\
\hline 3 & 1 & 1 & 3.0 & 3.0 & 7.0 & 3.0 & 3.0 & 3.0 \\
\hline 3 & 1 & 3 & 4.0 & 2.0 & 7.0 & 2.0 & 1.4 & 7.0 \\
\hline 3 & 1 & 5 & 7.0 & 2.9 & 5.9 & 2.9 & 3.9 & 6.9 \\
\hline 3 & 2 & 1 & 5.6 & 3.3 & 5.6 & 3.4 & 3.0 & 3.0 \\
\hline 3 & 2 & 3 & 6.9 & 3.0 & 3.9 & 2.9 & 4.0 & 3.0 \\
\hline 3 & 2 & 5 & 4.0 & 1.3 & 4.0 & 3.0 & 4.3 & 6.0 \\
\hline 4 & 1 & 1 & 7.0 & 3.7 & 6.2 & 4.5 & 2.0 & 1.9 \\
\hline 4 & 1 & 3 & 7.0 & 4.0 & 6.0 & 4.0 & 2.8 & 2.8 \\
\hline 4 & 1 & 5 & 6.7 & 4.3 & 6.0 & 5.6 & 2.6 & 3.0 \\
\hline 4 & 2 & 1 & 7.2 & 3.0 & 5.2 & 4.1 & 1.3 & 1.1 \\
\hline 4 & 2 & 3 & 7.0 & 3.0 & 3.5 & 7.4 & 2.6 & 2.0 \\
\hline 4 & 2 & 5 & 6.7 & 4.4 & 5.6 & 6.6 & 2.8 & 2.3 \\
\hline 5 & 1 & 1 & 7.8 & 1.3 & 2.2 & 7.8 & 1.8 & 1.6 \\
\hline 5 & 1 & 3 & 8.3 & 1.0 & 1.6 & 8.2 & 1.8 & 1.7 \\
\hline 5 & 1 & 5 & 8.0 & 1.5 & 1.5 & 9.0 & 3.0 & 2.4 \\
\hline 5 & 2 & 1 & 4.8 & 1.1 & 1.8 & 6.8 & 1.8 & 1.7 \\
\hline 5 & 2 & 3 & 7.0 & 1.7 & 1.5 & 7.8 & 1.9 & 1.8 \\
\hline 5 & 2 & 5 & 8.2 & 1.1 & 1.6 & 8.8 & 1.6 & 1.5 \\
\hline 6 & 1 & 1 & 7.0 & 3.0 & 2.0 & 6.8 & 3.5 & 3.0 \\
\hline 6 & 1 & 3 & 7.1 & 3.0 & 2.1 & 8.0 & 1.9 & 3.3 \\
\hline 6 & 1 & 5 & 7.6 & 2.5 & 2.8 & 7.2 & 2.6 & 3.0 \\
\hline 6 & 2 & 1 & 7.5 & 2.2 & 2.2 & 7.8 & 2.9 & 2.9 \\
\hline 6 & 2 & 3 & 7.5 & 2.2 & 3.1 & 7.5 & 3.0 & 3.1 \\
\hline 6 & 2 & 5 & 7.4 & 3.0 & 1.2 & 6.9 & 3.0 & 3.0 \\
\hline 7 & 1 & 1 & 6.0 & 3.0 & 5.0 & 6.0 & 3.0 & 3.1 \\
\hline 7 & 1 & 3 & 8.0 & 2.0 & 2.0 & 8.0 & 2.0 & 2.0 \\
\hline 7 & 1 & 5 & 7.0 & 3.0 & 1.0 & 8.6 & 3.0 & 5.0 \\
\hline 7 & 2 & 1 & 7.0 & 3.0 & 3.0 & 7.0 & 3.1 & 2.1 \\
\hline 7 & 2 & 3 & 5.8 & 3.0 & 1.1 & 7.0 & 2.0 & 4.0 \\
\hline 7 & 2 & 5 & 7.0 & 2.0 & 2.0 & 8.1 & 5.0 & 6.0 \\
\hline
\end{tabular}


$\underline{\text { Subjective Workload Questionnaire Scores }}$

\begin{tabular}{|c|c|c|c|c|c|c|c|c|}
\cline { 3 - 9 } \multicolumn{2}{c}{} & \multicolumn{2}{c|}{ Mental Demand } & \multicolumn{2}{c|}{ Physical Demand } & \multicolumn{2}{c|}{ Temporal Demand } \\
\hline Subj. & D_T & Tsk & Item 1 & Item 2 & Item 3 & Item 4 & Item 5 & Item 6 \\
\hline 8 & 1 & 1 & 7.7 & 1.6 & 5.7 & 5.5 & 1.7 & 1.6 \\
\hline 8 & 1 & 3 & 7.7 & 1.7 & 3.5 & 7.5 & 3.6 & 3.4 \\
\hline 8 & 1 & 5 & 7.5 & 2.5 & 5.4 & 4.5 & 3.5 & 4.4 \\
\hline 8 & 2 & 1 & 4.4 & 1.7 & 5.5 & 7.8 & 1.4 & 1.5 \\
\hline 8 & 2 & 3 & 7.6 & 1.6 & 5.6 & 5.5 & 2.6 & 2.4 \\
\hline 8 & 2 & 5 & 6.7 & 4.4 & 3.5 & 7.4 & 5.6 & 5.5 \\
\hline 9 & 1 & 1 & 8.3 & 2.8 & 2.2 & 7.8 & 1.6 & 2.2 \\
\hline 9 & 1 & 3 & 7.4 & 3.5 & 1.3 & 3.4 & 3.8 & 3.6 \\
\hline 9 & 1 & 5 & 6.7 & 3.8 & 3.6 & 4.8 & 2.3 & 3.7 \\
\hline 9 & 2 & 1 & 7.6 & 2.5 & 1.6 & 3.4 & 2.6 & 2.3 \\
\hline 9 & 2 & 3 & 7.5 & 2.3 & 2.6 & 2.7 & 3.6 & 2.2 \\
\hline 9 & 2 & 5 & 7.7 & 2.3 & 2.2 & 6.8 & 3.8 & 3.6 \\
\hline 10 & 1 & 1 & 6.0 & 3.0 & 3.0 & 5.0 & 4.0 & 3.0 \\
\hline 10 & 1 & 3 & 3.0 & 4.0 & 4.0 & 4.0 & 4.0 & 3.0 \\
\hline 10 & 1 & 5 & 2.7 & 3.0 & 3.0 & 3.0 & 6.3 & 5.6 \\
\hline 10 & 2 & 1 & 4.0 & 1.0 & 1.0 & 4.0 & 2.0 & 2.0 \\
\hline 10 & 2 & 3 & 4.0 & 3.0 & 3.0 & 3.0 & 4.0 & 3.0 \\
\hline 10 & 2 & 5 & 5.0 & 3.4 & 3.6 & 4.0 & 4.2 & 5.0 \\
\hline 11 & 1 & 1 & 7.0 & 3.0 & 3.0 & 7.0 & 3.0 & 3.0 \\
\hline 11 & 1 & 3 & 7.0 & 3.0 & 3.0 & 7.0 & 3.0 & 3.0 \\
\hline 11 & 1 & 5 & 7.0 & 3.0 & 3.0 & 7.0 & 3.0 & 3.0 \\
\hline 11 & 2 & 1 & 7.0 & 3.0 & 3.0 & 7.0 & 3.0 & 3.0 \\
\hline 11 & 2 & 3 & 7.0 & 3.0 & 3.0 & 7.0 & 3.0 & 3.0 \\
\hline 11 & 2 & 5 & 7.0 & 3.0 & 1.0 & 7.0 & 3.0 & 3.0 \\
\hline 12 & 1 & 1 & 9.0 & 2.0 & 2.5 & 2.0 & 3.9 & 3.0 \\
\hline 12 & 1 & 3 & 7.0 & 6.5 & 4.0 & 4.0 & 3.0 & 3.0 \\
\hline 12 & 1 & 5 & 6.0 & 6.6 & 4.1 & 6.5 & 7.0 & 8.0 \\
\hline 12 & 2 & 1 & 8.0 & 4.0 & 3.0 & 2.0 & 7.0 & 2.9 \\
\hline 12 & 2 & 3 & 7.0 & 4.1 & 3.0 & 4.1 & 8.0 & 4.0 \\
\hline 12 & 2 & 5 & 7.1 & 7.0 & 6.1 & 8.0 & 3.5 & 3.0 \\
\hline
\end{tabular}


Subjective Workload Questionnaire Scores

\begin{tabular}{|c|c|c|c|c|c|c|c|c|}
\hline \multirow[b]{2}{*}{ Subj. } & \multirow[b]{2}{*}{ D_T } & \multirow[b]{2}{*}{ Tsk } & \multicolumn{2}{|c|}{ Performance } & \multicolumn{2}{|c|}{ Effort } & \multicolumn{2}{|c|}{ Frustration Level } \\
\hline & & & Item 7 & Item 8 & Item 9 & Item 10 & Item 11 & Item 12 \\
\hline 1 & 1 & 1 & 3.0 & 3.0 & 3.0 & 6.9 & 4.0 & 5.0 \\
\hline 1 & 1 & 3 & 7.0 & 8.0 & 6.0 & 7.0 & 7.0 & 3.4 \\
\hline 1 & 1 & 5 & 7.0 & 4.5 & 4.5 & 5.4 & 4.0 & 5.0 \\
\hline 1 & 2 & 1 & 7.0 & 6.0 & 4.0 & 7.0 & 6.0 & 5.5 \\
\hline 1 & 2 & 3 & 7.0 & 7.0 & 6.0 & 7.0 & 7.0 & 5.0 \\
\hline 1 & 2 & 5 & 5.0 & 5.0 & 4.0 & 6.0 & 4.0 & 6.0 \\
\hline 2 & 1 & 1 & 5.0 & 3.0 & 4.0 & 7.0 & 3.0 & 6.5 \\
\hline 2 & 1 & 3 & 8.0 & 8.0 & 7.0 & 6.0 & 7.0 & 2.3 \\
\hline 2 & 1 & 5 & 8.0 & 8.0 & 7.0 & 7.0 & 7.0 & 3.0 \\
\hline 2 & 2 & 1 & 3.0 & 2.0 & 3.0 & 7.0 & 4.0 & 5.0 \\
\hline 2 & 2 & 3 & 8.0 & 7.0 & 6.5 & 6.5 & 7.0 & 3.0 \\
\hline 2 & 2 & 5 & 7.0 & 7.0 & 5.5 & 6.0 & 7.0 & 4.0 \\
\hline 3 & 1 & 1 & 7.0 & 8.9 & 4.0 & 3.0 & 7.0 & 3.0 \\
\hline 3 & 1 & 3 & 7.0 & 7.0 & 2.9 & 3.8 & 7.2 & 1.0 \\
\hline 3 & 1 & 5 & 7.0 & 8.8 & 4.0 & 3.0 & 7.0 & 3.0 \\
\hline 3 & 2 & 1 & 6.8 & 7.4 & 5.5 & 4.5 & 8.0 & 1.7 \\
\hline 3 & 2 & 3 & 7.0 & 9.0 & 7.0 & 4.0 & 4.0 & 5.3 \\
\hline 3 & 2 & 5 & 7.0 & 7.0 & 5.6 & 4.2 & 6.0 & 2.0 \\
\hline 4 & 1 & 1 & 6.6 & 6.4 & 7.2 & 5.5 & 7.0 & 2.2 \\
\hline 4 & 1 & 3 & 7.6 & 8.0 & 6.0 & 7.9 & 7.0 & 1.9 \\
\hline 4 & 1 & 5 & 6.2 & 6.5 & 4.4 & 5.4 & 7.0 & 2.0 \\
\hline 4 & 2 & 1 & 7.6 & 7.2 & 8.0 & 8.5 & 8.0 & 2.0 \\
\hline 4 & 2 & 3 & 7.0 & 6.8 & 7.2 & 6.1 & 6.6 & 1.4 \\
\hline 4 & 2 & 5 & 7.0 & 7.0 & 5.6 & 5.6 & 6.8 & 2.0 \\
\hline 5 & 1 & 1 & 7.8 & 7.0 & 7.8 & 8.2 & 7.1 & 3.2 \\
\hline 5 & 1 & 3 & 8.8 & 8.9 & 8.6 & 8.5 & 8.3 & 1.3 \\
\hline 5 & 1 & 5 & 8.0 & 7.0 & 9.0 & 7.0 & 7.0 & 1.6 \\
\hline 5 & 2 & 1 & 8.0 & 7.0 & 8.6 & 8.0 & 7.0 & 1.3 \\
\hline 5 & 2 & 3 & 7.7 & 8.0 & 8.0 & 7.6 & 7.9 & 1.6 \\
\hline 5 & 2 & 5 & 9.0 & 8.8 & 8.2 & 8.4 & 9.0 & 1.7 \\
\hline 6 & 1 & 1 & 7.0 & 6.2 & 6.8 & 8.0 & 7.0 & 3.0 \\
\hline 6 & 1 & 3 & 7.3 & 6.8 & 6.9 & 7.0 & 6.8 & 3.1 \\
\hline 6 & 1 & 5 & 7.5 & 6.8 & 7.2 & 7.2 & 7.2 & 1.8 \\
\hline 6 & 2 & 1 & 8.0 & 6.8 & 7.0 & 7.2 & 7.1 & 2.1 \\
\hline 6 & 2 & 3 & 7.7 & 7.1 & 7.0 & 6.8 & 7.5 & 2.7 \\
\hline 6 & 2 & 5 & 8.0 & 7.0 & 6.5 & 7.4 & 6.6 & 3.4 \\
\hline 7 & 1 & 1 & 8.0 & 8.0 & 8.0 & 8.0 & 7.0 & 2.0 \\
\hline 7 & 1 & 3 & 8.0 & 8.0 & 8.0 & 8.1 & 7.1 & 2.0 \\
\hline 7 & 1 & 5 & 8.0 & 7.0 & 7.0 & 8.0 & 7.0 & 3.0 \\
\hline 7 & 2 & 1 & 8.0 & 8.0 & 6.0 & 8.0 & 7.0 & 2.0 \\
\hline 7 & 2 & 3 & 7.0 & 6.0 & 7.0 & 8.0 & 5.0 & 2.0 \\
\hline 7 & 2 & 5 & 8.0 & 8.0 & 7.9 & 7.9 & 8.0 & 2.0 \\
\hline
\end{tabular}


$\underline{\text { Subjective Workload Questionnaire Scores }}$

\begin{tabular}{|c|c|c|c|c|c|c|c|c|}
\cline { 4 - 9 } \multicolumn{2}{c}{} & \multicolumn{2}{c|}{ Performance } & \multicolumn{2}{c|}{ Effort } & \multicolumn{2}{c|}{ Frustration Level } \\
\hline Subj. & D_T & Tsk & Item 7 & Item 8 & Item 9 & Item 10 & Item 11 & Item 12 \\
\hline 8 & 1 & 1 & 7.5 & 7.5 & 7.4 & 5.6 & 6.5 & 2.5 \\
\hline 8 & 1 & 3 & 5.5 & 4.5 & 6.6 & 7.7 & 7.7 & 2.6 \\
\hline 8 & 1 & 5 & 6.5 & 2.5 & 8.2 & 4.5 & 7.4 & 2.6 \\
\hline 8 & 2 & 1 & 7.7 & 7.6 & 7.5 & 5.4 & 8.5 & 2.5 \\
\hline 8 & 2 & 3 & 6.3 & 1.6 & 7.5 & 4.4 & 7.4 & 6.7 \\
\hline 8 & 2 & 5 & 5.5 & 6.3 & 7.6 & 6.5 & 6.3 & 3.6 \\
\hline 9 & 1 & 1 & 7.7 & 7.9 & 7.3 & 7.6 & 7.8 & 3.6 \\
\hline 9 & 1 & 3 & 6.8 & 6.4 & 5.5 & 7.3 & 7.6 & 2.6 \\
\hline 9 & 1 & 5 & 5.3 & 5.4 & 6.4 & 6.5 & 3.6 & 3.3 \\
\hline 9 & 2 & 1 & 4.6 & 4.8 & 3.8 & 4.8 & 7.3 & 3.7 \\
\hline 9 & 2 & 3 & 7.8 & 7.6 & 7.8 & 7.8 & 6.7 & 2.2 \\
\hline 9 & 2 & 5 & 7.7 & 7.7 & 6.7 & 7.8 & 5.5 & 2.2 \\
\hline 10 & 1 & 1 & 6.1 & 6.0 & 6.0 & 6.0 & 7.0 & 4.0 \\
\hline 10 & 1 & 3 & 4.4 & 3.6 & 3.6 & 4.2 & 6.0 & 3.6 \\
\hline 10 & 1 & 5 & 7.0 & 7.0 & 6.0 & 7.0 & 7.3 & 1.1 \\
\hline 10 & 2 & 1 & 7.0 & 7.0 & 4.0 & 5.0 & 7.0 & 1.0 \\
\hline 10 & 2 & 3 & 7.0 & 7.0 & 5.1 & 4.5 & 7.0 & 3.1 \\
\hline 10 & 2 & 5 & 6.4 & 6.6 & 6.3 & 6.4 & 6.0 & 3.0 \\
\hline 11 & 1 & 1 & 7.0 & 7.0 & 7.0 & 7.0 & 7.0 & 3.0 \\
\hline 11 & 1 & 3 & 7.0 & 7.0 & 7.0 & 7.0 & 7.0 & 3.0 \\
\hline 11 & 1 & 5 & 5.0 & 3.0 & 7.0 & 7.0 & 7.0 & 3.0 \\
\hline 11 & 2 & 1 & 7.0 & 7.0 & 7.0 & 7.0 & 7.0 & 3.0 \\
\hline 11 & 2 & 3 & 7.0 & 7.0 & 7.0 & 7.0 & 7.0 & 3.0 \\
\hline 11 & 2 & 5 & 5.0 & 5.0 & 7.0 & 9.0 & 7.0 & 3.0 \\
\hline 12 & 1 & 1 & 8.0 & 8.0 & 8.0 & 8.0 & 6.6 & 4.0 \\
\hline 12 & 1 & 3 & 8.0 & 8.0 & 6.0 & 6.0 & 4.0 & 6.0 \\
\hline 12 & 1 & 5 & 7.0 & 7.0 & 6.0 & 6.0 & 4.0 & 4.0 \\
\hline 12 & 2 & 1 & 8.0 & 8.0 & 8.0 & 7.0 & 6.6 & 4.0 \\
\hline 12 & 2 & 3 & 7.0 & 7.7 & 8.0 & 6.6 & 2.5 & 2.7 \\
\hline 12 & 2 & 5 & 8.0 & 8.0 & 6.6 & 7.0 & 8.6 & 2.5 \\
\hline
\end{tabular}




\section{Appendix J}

\section{Calculated DL for the Scratch and Specks Defects}

The DL, ogive curve, and least squared model of each subject was calculated for both Scratch (Line) and Speck (Blck Speck) defects using the Constant stimuli method described on Appendix E. The stimuli intensity and the DL are expressed in terms of the Visual Basic unit of measure called twip (1/20 of a printer's point, or its relation to the monitor pixels). 


\section{$\underline{\text { Subject } 1}$}

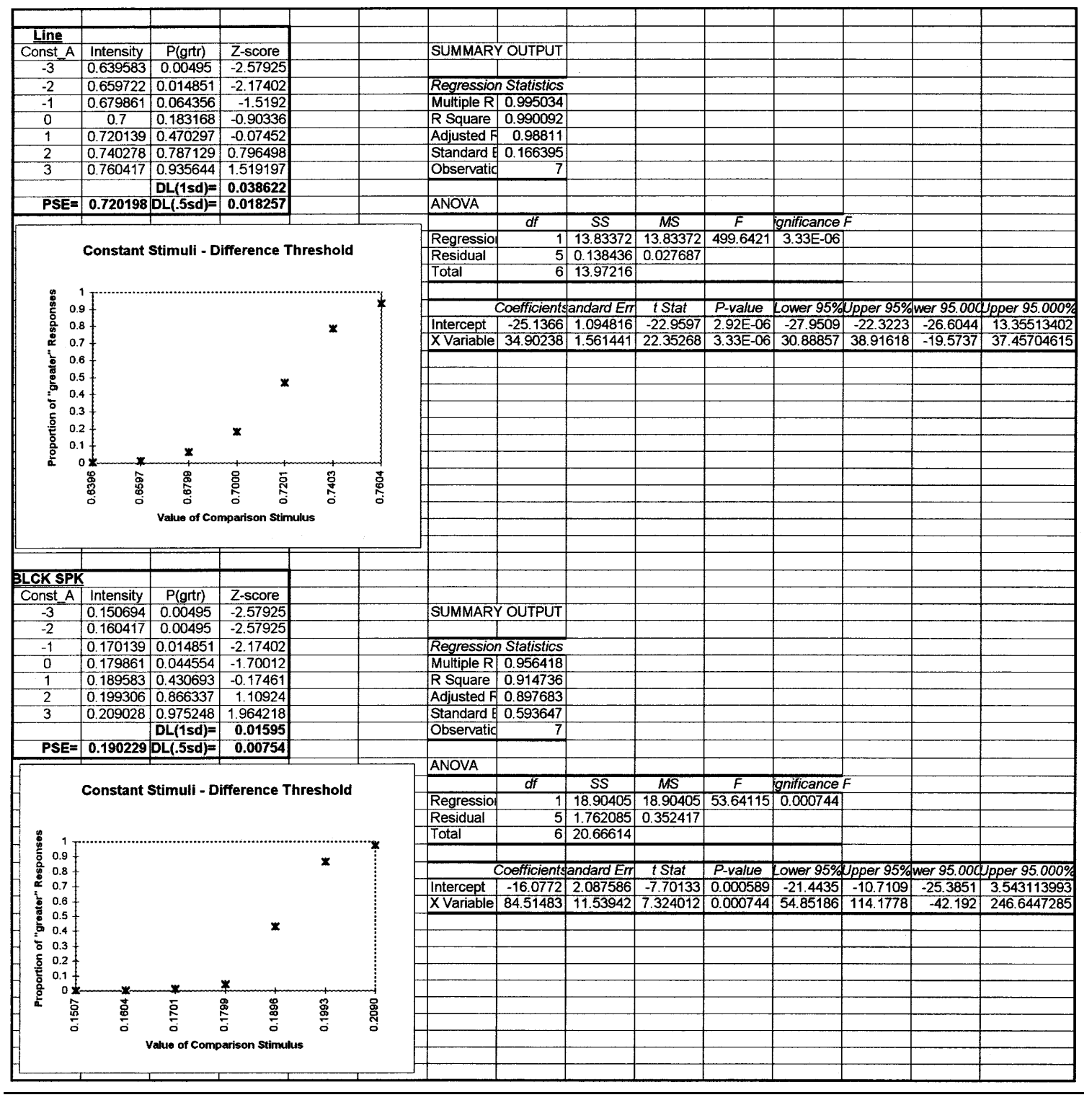




\section{$\underline{\text { Subject } 2}$}

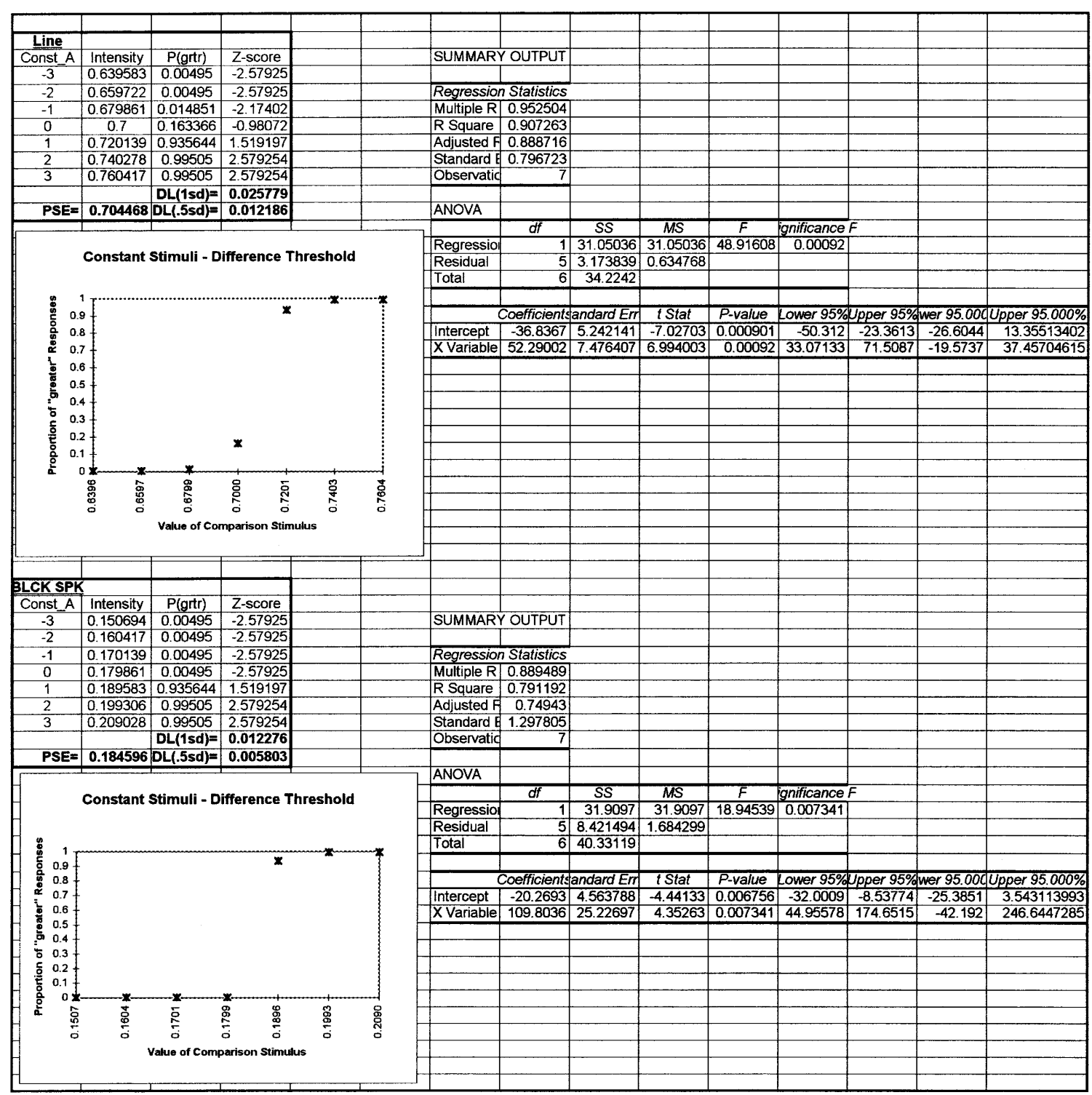




\section{$\underline{\text { Subject } 3}$}

\begin{tabular}{|c|c|c|c|c|c|c|c|c|c|c|c|c|c|c|}
\hline \multirow{2}{*}{\multicolumn{15}{|c|}{ Line }} \\
\hline & & & & & & & & & & & & & & \\
\hline Const_A & Intensity & $P$ (grtr) & Z-score & & & \multicolumn{2}{|c|}{ SUMMARY OUTPUT } & & & & & & & \\
\hline-3 & 0.639583 & 0.024752 & -1.96422 & & & & & & & & & & & \\
\hline-2 & 0.659722 & 0.00495 & -2.57925 & & & \multicolumn{2}{|c|}{ Regression Statistics } & & & & & & & \\
\hline-1 & 0.679861 & 0.064356 & -1.5192 & & & \multicolumn{2}{|c|}{\begin{tabular}{|l|l|} 
Regression Statistics \\
Multiple R & 0.961685 \\
\end{tabular}} & & & & & & & \\
\hline 0 & 0.7 & 0.193069 & -0.86664 & & & R Square & 0.924838 & & & & & & & \\
\hline 1 & 0.720139 & 0.430693 & -0.17461 & & & Adjusted F & 0.909805 & & & & & & & \\
\hline 2 & 0.740278 & 0.648515 & 0.381315 & & & Standard $\mathrm{A}$ & 0.382329 & & & & & & & \\
\hline 3 & 0.760417 & 0.816832 & 0.903356 & & & Observatic & & & & & & & & \\
\hline & & $D L(1 s d)=$ & 0.047901 & & & & & & & & & & & \\
\hline PSE $=$ & 0.729541 & $D L(.5 s d)=$ & 0.022643 & & & ANOVA & & & & & & & & \\
\hline & & & & & & & df & SS & MS & $F$ & gnificance $f$ & & & \\
\hline & & & & & & Regressio & 1 & 8.993127 & 8.993127 & 61.52276 & 0.000541 & & & \\
\hline & Constant & Stimuli - Di & Difference $T$ & hreshold & & Residual & 5 & 0.730878 & 0.146176 & & & & & \\
\hline & & & & & & Total & 6 & 9.724005 & & & & & & \\
\hline 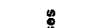 & ${ }^{1} \mathrm{~T}$ & $\ldots$ & , & ......... & & & & & & & & & & \\
\hline 0 . & & & & & & & Coefficients & andard Err & t Stat & $P$-value & Lower 95\% & Upper $95 \%$ & wer 95.000 & Jpper $95.000^{\circ}$ \\
\hline$\frac{\mathrm{a}}{4}$ & & & & & $*$ & Intercept & -20.5301 & 2.515583 & -8.16116 & 0.000449 & -26.9966 & -14.0636 & -26.6044 & 13.35513402 \\
\hline 0 . & & & & $\times$ & & X Variable & 28.14109 & 3.587756 & 7.843645 & 0.000541 & 18.91848 & 37.36369 & -19.5737 & 37.45704615 \\
\hline 0 & & & & $\mathbf{x}$ & & & & & & & & & & \\
\hline 0 & & & & & & & & & & & & & & \\
\hline$\overbrace{0}^{\circ}$ & & & * & & & & & & & & & & & \\
\hline$\frac{0}{t}$ & 3.3 & & & & & & & & & & & & & \\
\hline 吾 & 12 & & $\mathbf{x}$ & & & & & & & & & & & \\
\hline$\frac{2}{2}$ & & $\mathbf{x}$ & & & & & & & & & & & & \\
\hline & $\%$ & $\Phi$ & 8 & 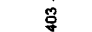 & 总 & & & & & & & & & \\
\hline & ठ & : & مَ & م̂ & 荢 & & & & & & & & & \\
\hline & & Value of Con & mparison Stin & utus & & & & & & & & & & \\
\hline 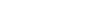 & & & & & & & & & & & & & & \\
\hline 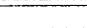 & & & & & & & & & & & & & & \\
\hline & & & & & & & & & & & & & & \\
\hline BLCK SPY & & & & & & & & & & & & & & \\
\hline Const_A & J Intensity & $P(g r t r)$ & Z-score & & & & & & & & & & & \\
\hline-3 & 0.150694 & 0.00495 & -2.57925 & & & SUMMARY & Y OUTPUT & & & & & & & \\
\hline-2 & 0.160417 & 0.00495 & -2.57925 & & & & & & & & & & & \\
\hline-1 & 0.170139 & 0.00495 & -2.57925 & & & Regression & in Statistics & & & & & & & \\
\hline 0 & 0.179861 & 0.00495 & -2.57925 & & & Multiple R & 0.875846 & & & & & & & \\
\hline 1 & 0.189583 & 0.222772 & -0.76286 & & & R Square & 0.767107 & & & & & & & \\
\hline 2 & 0.199306 & 0.99505 & 2.579254 & & & Adjusted F & 0.720528 & & & & & & & \\
\hline 3 & 0.209028 & 0.99505 & 2.579254 & & & Standard $\mathrm{E}$ & 1.28569 & & & & & & & \\
\hline & & $D L(1 s d)=$ & 0.013291 & & & Observatic & 7 & & & & & & & \\
\hline PSE $=$ & 0.188202 & $2 \mathrm{DL}(.5 \mathrm{sd})=$ & 0.006283 & & & & & & & & & & & \\
\hline & & & & & & ANOVA & & & & & & & & \\
\hline & Constant & Stimuli - D & lifference T & hreshold & & & $d f$ & SS & MS & $F$ & gnificance $F$ & & & \\
\hline & Constant & - Stmuit - D & oncerce & inestioia & & Regressio & 1 & 27.22333 & 27.22333 & 16.46905 & 0.009746 & & & \\
\hline & & & & & & Residual & 5 & \begin{tabular}{|l|}
8.264998 \\
\end{tabular} & 1.653 & & & & & \\
\hline 1 & & & & & & Total & 6 & 35.48833 & & & & & & \\
\hline & & & & & & & & & & & & & & \\
\hline 0.8 & & & & & & & Coefficients & andard Err & $t$ Stat & P-value & Lower $95 \%$ & upper 95\% & wer $95.00 \mathrm{~d}$ & Jpper 95.000\% \\
\hline 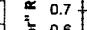 & & & & & & Intercept & -19.0875 & 4.521185 & -4.2218 & 0.008313 & \begin{tabular}{|l|}
-30.7096 \\
\end{tabular} & \begin{tabular}{|l|}
-7.46547 \\
\end{tabular} & -25.3851 & 3.543113993 \\
\hline 0.6 & & & & & & X Variable & 101.4206 & 24.99147 & 4.058207 & 0.009746 & 37.17805 & 165.6631 & -42.192 & 246.6447285 \\
\hline$=0.4$ & & & & & & & & & & & & & & \\
\hline 0.3 & & & & & & & & & & & & & & \\
\hline 0.2 & & & $\mathbf{x}$ & & & & & & & & & & & \\
\hline 0.1 & & & & & & & & & & & & & & \\
\hline 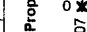 & & & 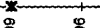 & & & & & & & & & & & \\
\hline \% & $\stackrel{\square}{\rightleftarrows}$ & $\stackrel{2}{?}$ & $\stackrel{\Xi}{\check{\infty}}$ & $\stackrel{g}{\circ}$ & ฉ్ & & & & & & & & & \\
\hline & & Value of Comp & parison Stimu & 0 & & & & & & & & & & \\
\hline & & & & & & & & & & & & & & \\
\hline & & & & & & & & & & & & & & \\
\hline
\end{tabular}




\section{$\underline{\text { Subject } 4}$}

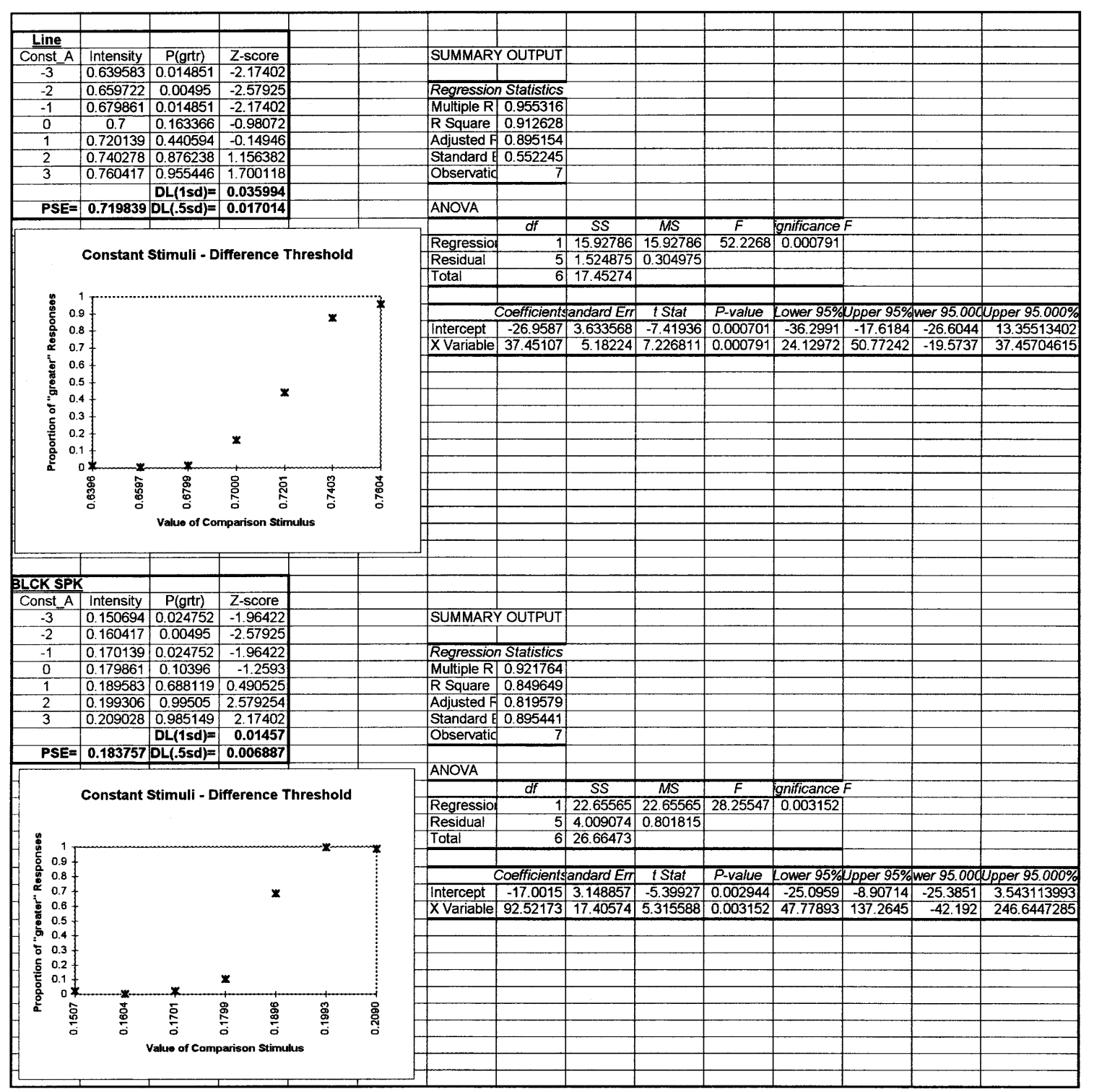




\section{$\underline{\text { Subject } 5}$}

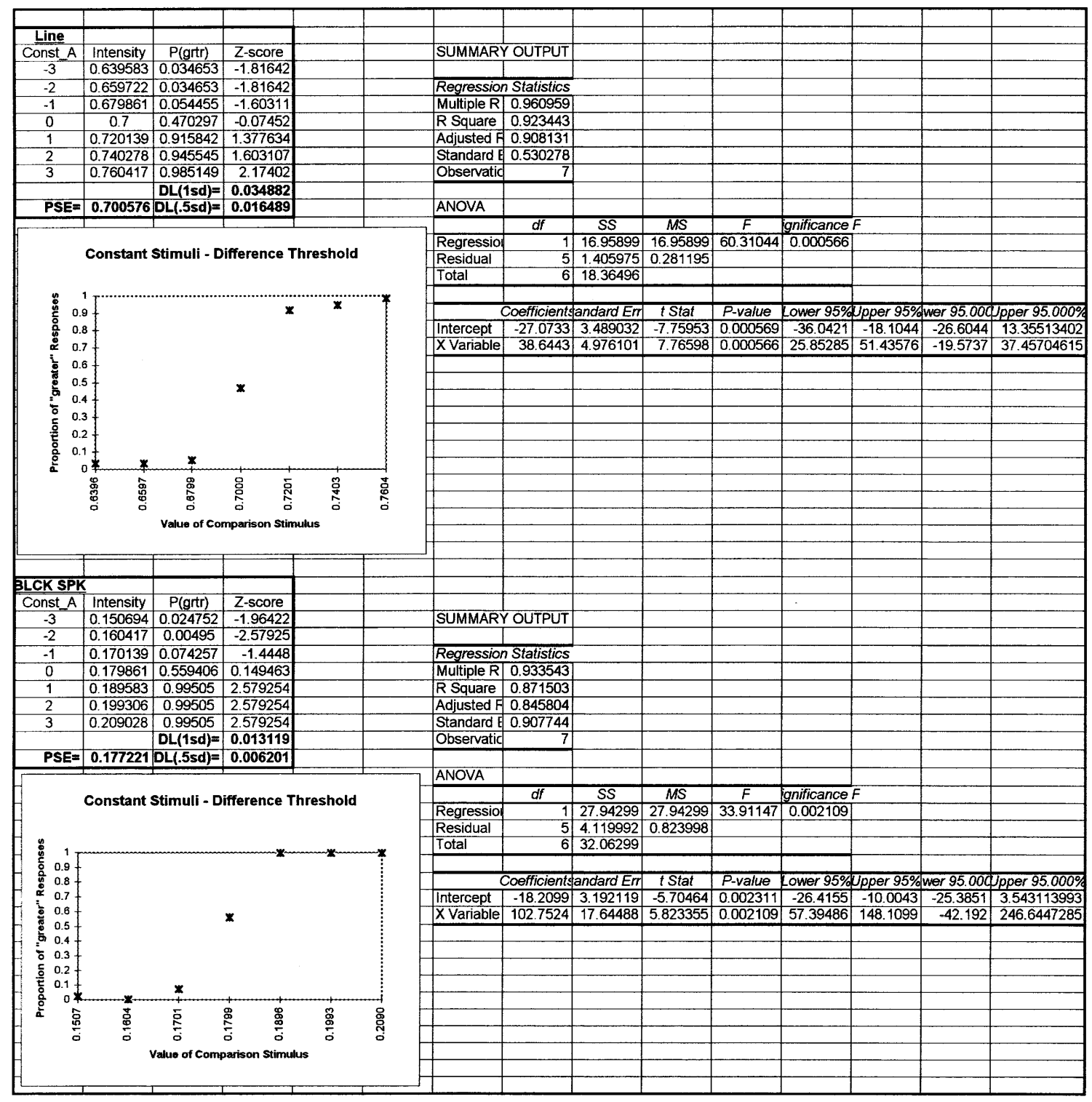




\section{$\underline{\text { Subject } 6}$}

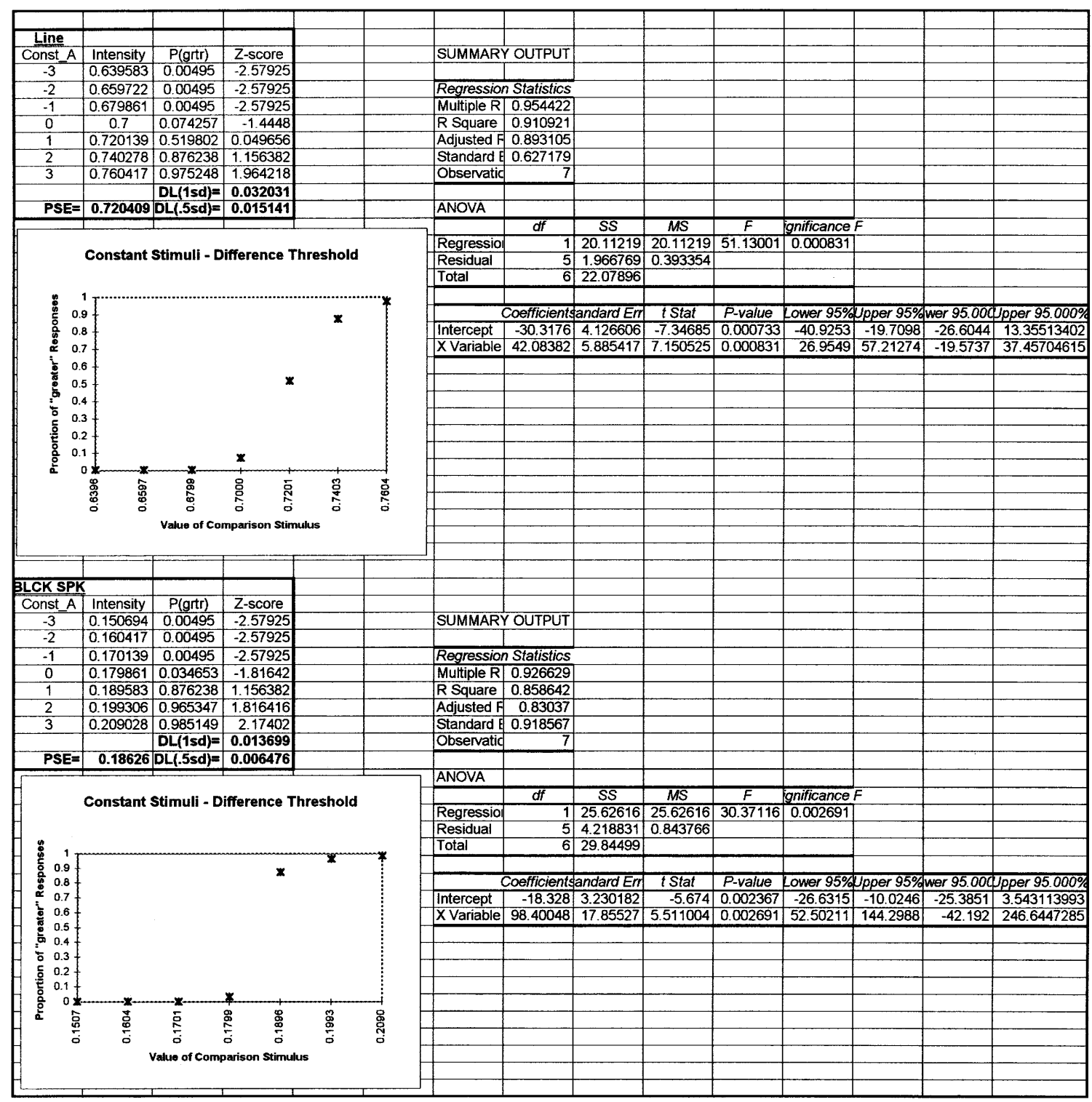




\section{$\underline{\text { Subject } 7}$}

\begin{tabular}{|c|c|c|c|c|c|c|c|c|c|c|c|c|c|c|}
\hline & & & & & & & & & & & & & & \\
\hline \multicolumn{15}{|l|}{ Line } \\
\hline \multirow{2}{*}{$\begin{array}{c}\text { Const_A } \\
-3\end{array}$} & Intensity & $\mathrm{P}(\mathrm{grt})$ & & & & \multicolumn{2}{|c|}{ SUMMARY OUTPUT } & & 1 & & \multirow{2}{*}{ 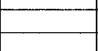 } & & & \\
\hline & 0.639583 & 0.00495 & $\frac{\text { Z-score }}{-2.57925}$ & & & \multicolumn{2}{|c|}{ - } & & & & & & & \\
\hline-2 & 0.659722 & 0.014851 & -2.17402 & & & Regression & in Statistics & & & & & & & \\
\hline-1 & 0.679861 & 0.024752 & -1.96422 & & & Multiple R & 0.983049 & & & & & & & \\
\hline 0 & $\begin{array}{l}0.7 \\
\end{array}$ & 0.252475 & -0.66672 & & & R Square & 0.966386 & & & & & & & \\
\hline 1 & 0.720139 & 0.579208 & 0.199868 & & & Adjusted F & 0.959663 & & & & & & & \\
\hline 2 & 0.740278 & 0.846535 & 1.021683 & & & Standard $\mathrm{E}$ & 0.319059 & & & & & & & \\
\hline 3 & 0.760417 & 0.905941 & 1.316166 & & & Observatic & 7 & & & & & & & \\
\hline & & $D L(1 \mathbf{s d})=$ & \begin{tabular}{|l|}
0.037552 \\
\end{tabular} & & & & & & & & & & & \\
\hline PSE $=$ & $=0.719287$ & $D L(.5 s d)=$ & \begin{tabular}{|l|}
0.017751 \\
\end{tabular} & & & ANOVA & & & & & & & & \\
\hline & & & & & & & $d f$ & SS & MS & $F$ & gnificance & & & \\
\hline & & & & & & Regressio & 1 & \begin{tabular}{|l|}
14.63316 \\
\end{tabular} & 14.63316 & 143.7459 & $7.12 \mathrm{E}-05$ & & & \\
\hline & Constant & Stimuli - D & Difference $\mathbf{T}$ & eshold & & Residual & 5 & \begin{tabular}{|l|}
0.508994 \\
\end{tabular} & 0.101799 & & & & & \\
\hline & & & & & & Total & 6 & 15.14216 & & & & & & \\
\hline 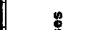 & & & & & & & & & & & & & & \\
\hline & $0.9+$ & & & & $\dot{*}$ & & Coefficients & andard Err & tStat & $P$-value & Lower 95\% & Upper 95\% & wer 95.000 & tpper $95.000 \%$ \\
\hline & & & & $\mathbf{x}$ & & Intercept & -25.82 & \begin{tabular}{|l|}
2.099291 \\
\end{tabular} & -12.2994 & $6.29 \mathrm{E}-05$ & -31.2164 & -20.4237 & -26.6044 & 13.35513402 \\
\hline 0 & & & & & & X Variable & 35.8967 & 2.994035 & 11.98941 & 7.12E-05 & 28.2003 & 43.5931 & -19.5737 & 37.45704615 \\
\hline 0 & 0.6 & & $\mathbf{x}$ & & & & & & & & & & & \\
\hline $\begin{array}{l}0 \\
0\end{array}$ & 0.5 & & & & & & & & & & & & & \\
\hline $\begin{array}{ll}i \\
5 & 0\end{array}$ & 0.3 & & & & & & & & & & & & & \\
\hline 产 & 0.2 & & * & & & & & & & & & & & \\
\hline 을 & 0.1 & & & & & & & & & & & & & \\
\hline 2 & $0 x$ & & & & & & & & & & & & & \\
\hline & 产 & 惫 & 苔 & $\stackrel{8}{8}$ & 営 & & & & & & & & & \\
\hline & & Value of Cor & omparison Stim & & & & & & & & & & & \\
\hline & & & & & & & & & & & & & & \\
\hline & & & & & & & & & & & & & & \\
\hline & & & & & & & & & & & & & & \\
\hline BLCK SPI & & & & & & & & & & & & & & \\
\hline Const_A & Intensity & $P$ (grtr) & Z-score & & & & & & & & & & & \\
\hline-3 & 0.150694 & 0.00495 & -2.57925 & & & SUMMARY & Y OUTPUT & & & & & & & \\
\hline-2 & 0.160417 & 0.024752 & -1.96422 & & & & & & & & & & & \\
\hline-1 & 0.170139 & 0.00495 & -2.57925 & & & Regression & istatistics & & & & & & & \\
\hline 0 & 0.179861 & 0.10396 & -1.2593 & & & Multiple R & 0.94833 & & & & & & & \\
\hline 1 & 0.189583 & 0.549505 & 0.124411 & & & R Square & 0.899329 & & & & & & & \\
\hline 2 & 0.199306 & 0.905941 & 1.316166 & & & Adjusted $\mathrm{F}$ & 0.879195 & & & & & & & \\
\hline 3 & 0.209028 & 0.985149 & 2.17402 & & & Standard & 0.665187 & & & & & & & \\
\hline & & $D L(1 s d)=$ & 0.015599 & & & Observatic & 7 & & & & & & & \\
\hline PSEI & $\begin{array}{l}=0.187742 \\
\end{array}$ & $\mathrm{DL}(.5 s \mathrm{~d})=$ & 0.007374 & & & & & & & & & & & \\
\hline & & & & & & ANOVA & & & & & & & & \\
\hline & Constant & stimuli - D & Jifference & eshold & & & $d f$ & SS & $M S$ & $F$ & gnificance & & & \\
\hline & & & & & & Regressia & 1 & 19.76395 & 19.76395 & 44.6669 & 0.001134 & & & \\
\hline & & & & & & Residual & 5 & \begin{tabular}{|l|}
2.212371 \\
\end{tabular} & 0.442474 & & & & & \\
\hline & & & & & & Total & 6 & 21.97632 & & & & & & \\
\hline 0.9 & & & & $\mathbf{x}$ & 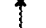 & & & & & & & & & \\
\hline 0.8 & & & & & & & Coefficients & andard Em & $t$ Stat & \begin{tabular}{|c|}
$P$-value \\
\end{tabular} & Lower 95\% & Upper 95\% & wer 95.000 & Jpper $95.000 \%$ \\
\hline 0.7 & & & & & & Intercept & -16.2239 & 2.339159 & -6.93577 & 0.000956 & -22.2369 & -10.2109 & -25.3851 & 3.543113993 \\
\hline 言 0.6 & & & $\mathbf{x}$ & & & X variable & 86.41563 & 12.93003 & 6.68333 & 0.001134 & 53.17799 & 119.6533 & -42.192 & 246.6447285 \\
\hline $\begin{array}{l}0.5 \\
=0.4\end{array}$ & & & & & & & & & & & & & & \\
\hline ¿ 0.3 & & & & & & & & & & & & & & \\
\hline 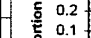 & & & x & & & & & & & & _. & & & \\
\hline a & & & $x^{2}$ & & & & & & & & & & & \\
\hline$\stackrel{0}{2}$ & : & $\bar{\Sigma}$ & 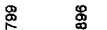 & 睥 & 品 & & & & & & & & & \\
\hline & & 5 & $\frac{0}{0}$ & $\frac{\sigma}{0}$ & స్ & & & & & & & & & \\
\hline 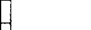 & & Value of com & parison Stimult & & & & & & & & & & & \\
\hline & & & & & & & & & & & & & & \\
\hline
\end{tabular}




\section{$\underline{\text { Subject } 8}$}

\begin{tabular}{|c|c|c|c|c|c|c|c|c|c|c|c|c|c|c|}
\hline & & & & & & & & & & & & & & \\
\hline \multicolumn{15}{|l|}{ Line } \\
\hline Const_A & Intensity & $\mathrm{P}(\mathrm{grtr})$ & \multirow{2}{*}{$\begin{array}{l}\text { Z-score } \\
-2.57925\end{array}$} & & & \multicolumn{2}{|c|}{ SUMMARY OUTPUT } & & & & & & & \\
\hline-3 & 0.639583 & 0.00495 & & & & & & & & & & & & \\
\hline-2 & 0.659722 & 0.00495 & -2.57925 & & & & & & & & & & \\
\hline-1 & 0.679861 & 0.024752 & -1.96422 & & & \multicolumn{2}{|c|}{\begin{tabular}{|l|r}
\multicolumn{2}{|c|}{ Regression } \\
Multiplistics & 0.97633 \\
\end{tabular}} & & & & & & & \\
\hline 0 & 0.7 & 0.232673 & -0.73007 & & & \multirow{2}{*}{\multicolumn{2}{|c|}{\begin{tabular}{|l|r|} 
R Square & 0.95322 \\
Adjusted F & 0.943864 \\
\end{tabular}}} & & & & & & & \\
\hline 1 & 0.720139 & 0.648515 & 0.381315 & & & & & & & & & & & \\
\hline 2 & 0.740278 & 0.975248 & 1.964218 & & & Standard E & 0.50379 & & & & & & & \\
\hline 3 & 0.760417 & 0.99505 & 2.579254 & & & Observatio & & & & & & & & \\
\hline & & $D L(1 \mathbf{s d})=$ & 0.028249 & & & & & & & & & & & \\
\hline PSE $=$ & 0.708766 & $D L(.5 s d)=$ & 0.013353 & & & ANOVA & & & & & & & & \\
\hline & & & & & & & $d f$ & $S S$ & MS & $F$ & gonificance & $F$ & & \\
\hline & & & & & & Regressior & 1 & 25.85859 & 25.85859 & 101.8838 & 0.000163 & & & \\
\hline & Constant & Stimuli - D & Difference $\mathbf{T}$ & reshold & & Residual & 5 & 1.269024 & 0.253805 & & & & & \\
\hline & & & & & & Total & 6 & 27.12761 & & & & & & \\
\hline & & & & $\mathbf{x}$ & & & & & & & & & & \\
\hline 啇 0 . & & & & & & & Coefficients & Tandard Err & $t$ Stat & \begin{tabular}{|l|}
$P$-value \\
\end{tabular} & Lower 95\% & Upper 95\% & wer 95.000 & pper $95.000^{\circ}$ \\
\hline$\frac{\mathrm{O}}{\mathrm{m}}$ & & & & & & Intercept & -33.8213 & 3.314753 & -10.2033 & 0.000155 & \begin{tabular}{|l|}
5 \\
\end{tabular} & -25.3005 & -26.6044 & 13.355134 \\
\hline $\begin{array}{ll}0 & 0 . \\
\Sigma & 0\end{array}$ & & & & & & X Variable & 47.71862 & 4.727541 & 10.09375 & 0.000163 & 35.56611 & 59.87113 & -19.5737 & 37.4570461 \\
\hline 密 0 & & & $x^{2}$ & & & & & & & & & & & \\
\hline 0 . & & & & & & & & & & & & & & \\
\hline$\frac{0}{0} 0$. & & & & & & & & & & & & & & \\
\hline$\underline{0}$ & & & & & & & & & & & & & & \\
\hline 윻 & & & $\mathbf{x}$ & & & & & & & & & & & \\
\hline$\frac{0}{2}$ & & & & & & & & & & & & & & \\
\hline & $0 *-$ & +4 & & & & & & & & & & & & \\
\hline & 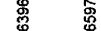 & : & §్ి & 槑 & 屯্ & & & & & & & & & \\
\hline & 0 & & 00 & & & & & & & & & & & \\
\hline & & Value of $\mathrm{Co}$ & inparison Stin & & & & & & & & & & & \\
\hline & & & & & & & & & & & & & & \\
\hline 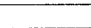 & & & & & & & & & & & & & & \\
\hline BLCK SPK & & & & & & & & & & & & & & \\
\hline Const_A & Intensity & $P($ grtr) & Z-score & & & & & & & & & & & \\
\hline-3 & 0.150694 & 0.014851 & -2.17402 & & & SUMMARY & Y OUTPUT & & & & & & & \\
\hline-2 & 0.160417 & 0.00495 & -2.57925 & & & & & & & & & & & \\
\hline-1 & 0.170139 & 0.00495 & -2.57925 & & & Regression & $n$ Statistics & & & & & & & \\
\hline 0 & 0.179861 & 0.00495 & -2.57925 & & & Multiple R & \begin{tabular}{|l|l|}
0.847487 \\
\end{tabular} & & & & & & & \\
\hline 1 & 0.189583 & 0.99505 & 2.579254 & & & R Square & \begin{tabular}{|l|l|}
0.718235 \\
\end{tabular} & & & & & & & \\
\hline 2 & 0.199306 & 0.99505 & 2.579254 & & & Adjusted F & 0.661881 & & & & & & & \\
\hline 3 & 0.209028 & 0.99505 & 2.579254 & & & Standard E & 1.574054 & & & & & & & \\
\hline & & $D L(1 s d)=$ & \begin{tabular}{|l|}
0.012341 \\
\end{tabular} & & & Observatio & & & & & & & & \\
\hline PSE $=$ & 0.182704 & $\mathrm{DL}(.5 \mathrm{sd})=$ & 0.005833 & & & & & & & & & & & \\
\hline & & & & & & ANOVA & & & & & & & & \\
\hline & Constant & Stimuli - D & ifference T & reshold & & & $d f$ & SS & MS & $F$ & ignificance & $F$ & & \\
\hline & Comstanti & 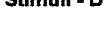 & & IEsiloid & & Regressior & 1 & 31.57825 & \begin{tabular}{|l|}
31.57825 \\
\end{tabular} & 12.74526 & 0.016043 & & & \\
\hline & & & & & & Residual & 5 & 12.38824 & \begin{tabular}{|l|}
2.477647 \\
\end{tabular} & & & & & \\
\hline 1 & . & $\ldots$ & ............ & ................. & & Total & 6 & 43.96648 & & & & & & \\
\hline 0.9 & I & & & & & & & & & & & & & \\
\hline 0.8 & & & & & & & Coefficients & andard Err & tStat & $P$-value & Lower 95\% & Upper 95\% & wer 95.000 & Jpper $95.000^{\circ}$ \\
\hline 0.7 & & & & & & Intercept & -19.9571 & 5.535229 & -3.60548 & 0.015454 & \begin{tabular}{|c|} 
\\
\end{tabular} & -5.72841 & -25.3851 & 3.54311399 \\
\hline 焉 0.6 & & & & & & X Variable & 109.2319 & \begin{tabular}{|l|}
30.59674 \\
\end{tabular} & 3.57005 & \begin{tabular}{|l|}
0.016043 \\
\end{tabular} & \begin{tabular}{|l|l|}
30.58059 \\
\end{tabular} & 187.8832 & -42.192 & 246.644728 \\
\hline 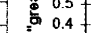 & & & & & & & & & & & & & & \\
\hline 50.3 & & & & & & & & & & & & & & \\
\hline$\underline{\underline{\sigma}} 0.2$ & & & & & & & & & & & & & & \\
\hline $\bar{E} 0.1$ & & & & & & & & & & & & & & \\
\hline 高 $0 *$ & $x$ & $-x-1$ & $-x-$ & $+\cdots$ & -1 & & & & & & & & & \\
\hline के & క్ & & $\stackrel{\circ}{9}$ & 恋 & 용 & & & & & & & & & \\
\hline & & $\div$ & $\stackrel{5}{0}$ & $\check{0}$ & ב్ర & & & & & & & & & \\
\hline & & Value of Comp & parison Stimu & & & & & & & & & & & \\
\hline & & & & & & & & & & & & & & \\
\hline
\end{tabular}




\section{$\underline{\text { Subject } 9}$}

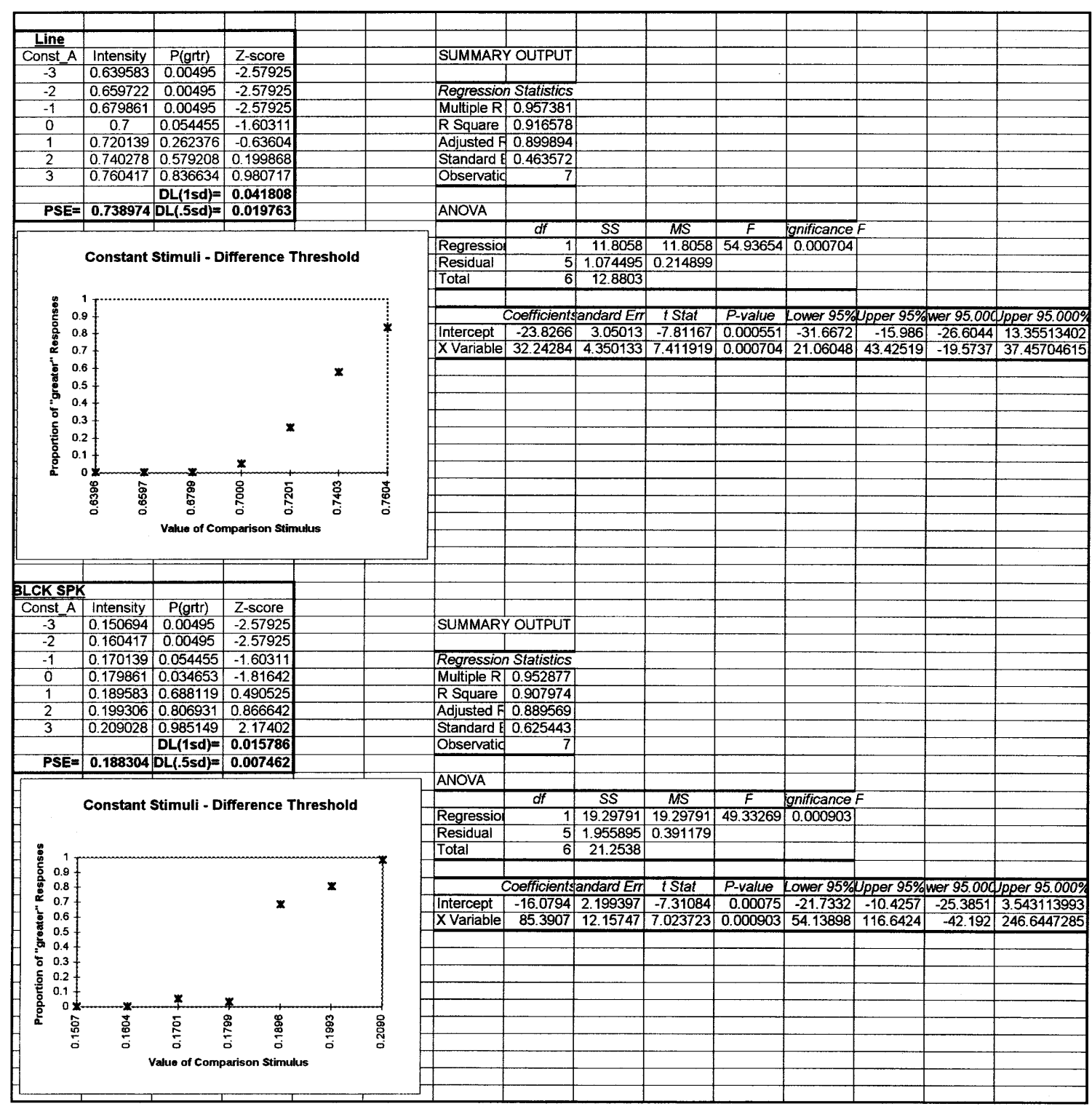




\section{$\underline{\text { Subject } 10}$}

\begin{tabular}{|c|c|c|c|c|c|c|c|c|c|c|c|c|c|c|}
\hline \multicolumn{15}{|l|}{ Line } \\
\hline \multirow{2}{*}{$\frac{\text { Const A }}{-3}$} & Intensity & $P(g r t r)$ & Z-score & & & \multicolumn{2}{|c|}{ SUMMARY OUTPUT } & & & & & & & \\
\hline & 0.63958 & 0.00495 & -2.57925 & & & & & & & & & & & \\
\hline-2 & 0.65972 & 0.00495 & \multirow{2}{*}{$\begin{array}{r}-2.57925 \\
-2.17402\end{array}$} & & & \multicolumn{2}{|c|}{ Regression Statistics } & & & & & & & \\
\hline-1 & 0.67986 & 0.01485 & & & & Multiple R & 0.97299 & & & & & & & \\
\hline 0 & 0.7 & 0.30198 & -0.51871 & & & R Square & 0.94672 & & & & & & & \\
\hline 1 & 0.72014 & 0.70792 & 0.54732 & & & Adjusted F & 0.93606 & & & & & & & \\
\hline 2 & 0.74028 & 0.96535 & 1.81642 & & & Standard E & 0.51675 & & & & & & & \\
\hline 3 & 0.76042 & 0.98515 & 2.17402 & & & Observatio & 7 & & & & & & & \\
\hline & & $D L(1$ sd) $=$ & 0.02949 & & & & & & & & & & & \\
\hline PSE $=$ & 0.71036 & $\mathrm{DL}(.5 \mathrm{sd})=$ & 0.01394 & & & ANOVA & & & & & & & & \\
\hline & & & & & & & $d f$ & SS & MS & $F$ & jignificance & $F$ & & \\
\hline & & & & & & Regressior & 1 & 23.7222 & 23.7222 & 88.837 & 0.00023 & & & \\
\hline & Constant & Stimuli - D & ifference $\mathrm{T}$ & hreshold & & Residual & 5 & 1.33515 & 0.26703 & & & & & \\
\hline & & & & & & Total & 6 & 25.0574 & & & & & & \\
\hline 1 & 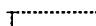 & 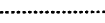 & 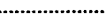 & - & $\cdots * *$ & & & & & & & & & \\
\hline & & & & & & & Coefficients & andard Er & t Stat & $P$-value & Lower 95\% & Upper 95\% & wer 95.000 & per 95.00 \\
\hline$\frac{\overline{0}}{50} 0.8$ & & & & & & Intercept & -32.4668 & 3.40002 & -9.549 & 0.00021 & -41.2068 & -23.7268 & -26.6044 & 13.3551 \\
\hline \& 0.7 & & & $\boldsymbol{*}$ & & & X Variable & 45.7049 & 4.84915 & 9.42534 & 0.00023 & 33.2398 & 58.1701 & -19.5737 & 37.457 \\
\hline i 0.6 & & & & & & & & & & & & & & \\
\hline 0.5 & & & & & & & & & & & & & & \\
\hline 0.4 & & & & & & & & & & & & & & \\
\hline$\stackrel{0}{\tilde{c}} 0.3$ & & & $\boldsymbol{*}$ & & & & & & & & & & & \\
\hline 0.2 & & & & & & & & & & & & & & \\
\hline 0.1 & & & & & & & & & & & & & & \\
\hline a & $x-$ & & & & & & & & & & & & & \\
\hline & 畣 & 疍 & 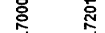 & $\frac{3}{3}$ & ष्षे & & & & & & & & & \\
\hline & & 足 & $\circ \quad 0$ & & & & & & & & & & & \\
\hline & & Value of Cor & mparlson Stim & & & & & & & & & & & \\
\hline & & & & & & & & & & & & & & \\
\hline & & & & & & & & & & & & & & \\
\hline BLCK SPK & & & & & & & & & & & & & & \\
\hline Const_A & Intensity & $P($ grtr) & Z-score & & & & & & & & & & & \\
\hline-3 & 0.15069 & 0.00495 & -2.57925 & & & SUMMARY & OUTPUT & & & & & & & \\
\hline-2 & 0.16042 & 0.00495 & -2.57925 & & & & & & & & & & & \\
\hline-1 & 0.17014 & 0.00495 & -2.57925 & & & Regression & 7 Statistics & & & & & & & \\
\hline 0 & 0.17986 & 0.08416 & -1.37763 & & & \begin{tabular}{|l|} 
Multiple R \\
\end{tabular} & 0.94326 & & & & & & & \\
\hline 1 & 0.18958 & 0.87624 & 1.15638 & & & R Square & 0.88975 & & & & & & & \\
\hline 2 & 0.19931 & 0.98515 & 2.17402 & & & Adjusted F & 0.8677 & & & & & & & \\
\hline 3 & 0.20903 & 0.99505 & 2.57925 & & & Standard & 0.85437 & & & & & & & \\
\hline & & $D L(1 \mathrm{sd})=$ & 0.01278 & & & Observatio & 7 & & & & & & & \\
\hline PSE $=$ & 0.1842 & $D L(.5 s d)=$ & 0.00604 & & & & & & & & & & & \\
\hline & & & & & & ANOVA & & & & & & & & \\
\hline & Constant & Stimuli - D & ifference $T$ & hreshold & & & $d f$ & SS & MS & $F$ & gnificance & $F$ & & \\
\hline & & stimuin - D & Inerence I & inestioia & & Regressior & 1 & 29.4538 & 29.4538 & 40.3506 & \begin{tabular}{|l|}
0.00143 \\
\end{tabular} & & & \\
\hline & & & & & & Residual & 5 & 3.64974 & 0.72995 & & & & & \\
\hline $1 T$ & & $\cdots$ & 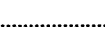 & $\cdots \cdots$ & $\cdots \times$ & Total & 6 & 33.1036 & & & & & & \\
\hline & & & & & & & & & & & & & & \\
\hline 항 0.8 & & & $\mathbf{x}$ & & & & Coefficients & andard En & $t$ Stat & $P$-value & Lower 95\% & Upper 95\% & wer 95.000 & per 95.000 \\
\hline 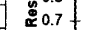 & & & & & & Intercept & -19.4322 & 3.00443 & -6.46784 & 0.00132 & -27.1553 & -11.709 & -25.3851 & 3.54311 \\
\hline 0.6 & & & & & & $X$ Variable & 105.494 & 16.6074 & 6.35221 & 0.00143 & 62.803 & 148.184 & -42.192 & 246.645 \\
\hline 0.5 & & & & & & & & & & & & & & \\
\hline$\overbrace{0.4}$ & & & & & & & & & & & & & & \\
\hline 0.3 & & & & & & & & & & & & & & \\
\hline 0.2 & & & & & & & & & & & & & & \\
\hline : 0.1 & & & * & & & & & & & & & & & \\
\hline $0 x$ & 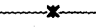 & $-x$ & & & & & & & & & & & & \\
\hline 0.1507 & 0.1604 & $0.1701 \quad 0.1$ & $1799 \quad 0.1896$ & 0.1993 & 0.2090 & & & & & & & & & \\
\hline & & Vallue of Comp & sarison Stmulu & & & & & & & & & & & \\
\hline & & & & & & & & & & & & & & \\
\hline
\end{tabular}




\section{$\underline{\text { Subject } 11}$}

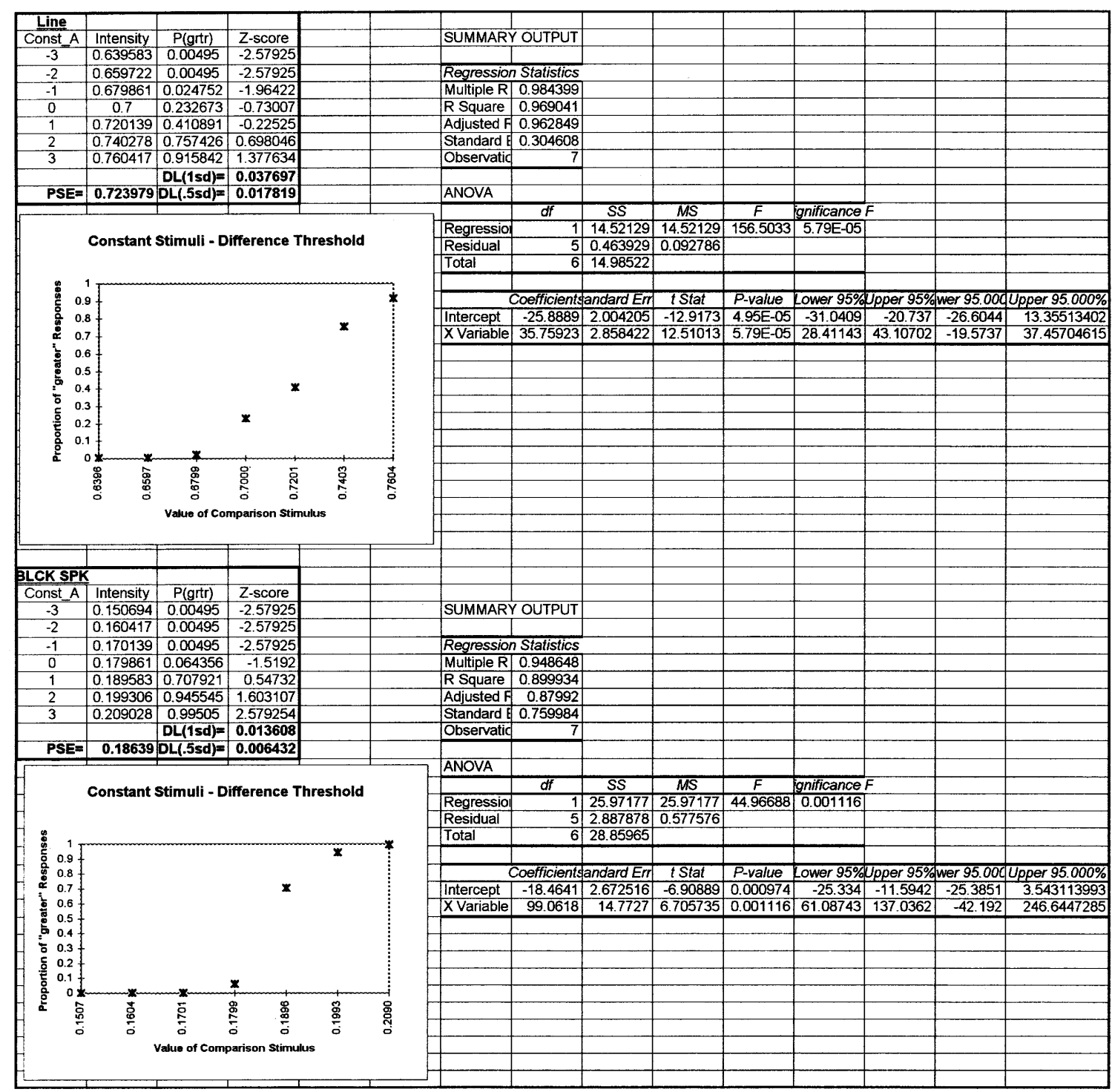




\section{$\underline{\text { Subject } 12}$}

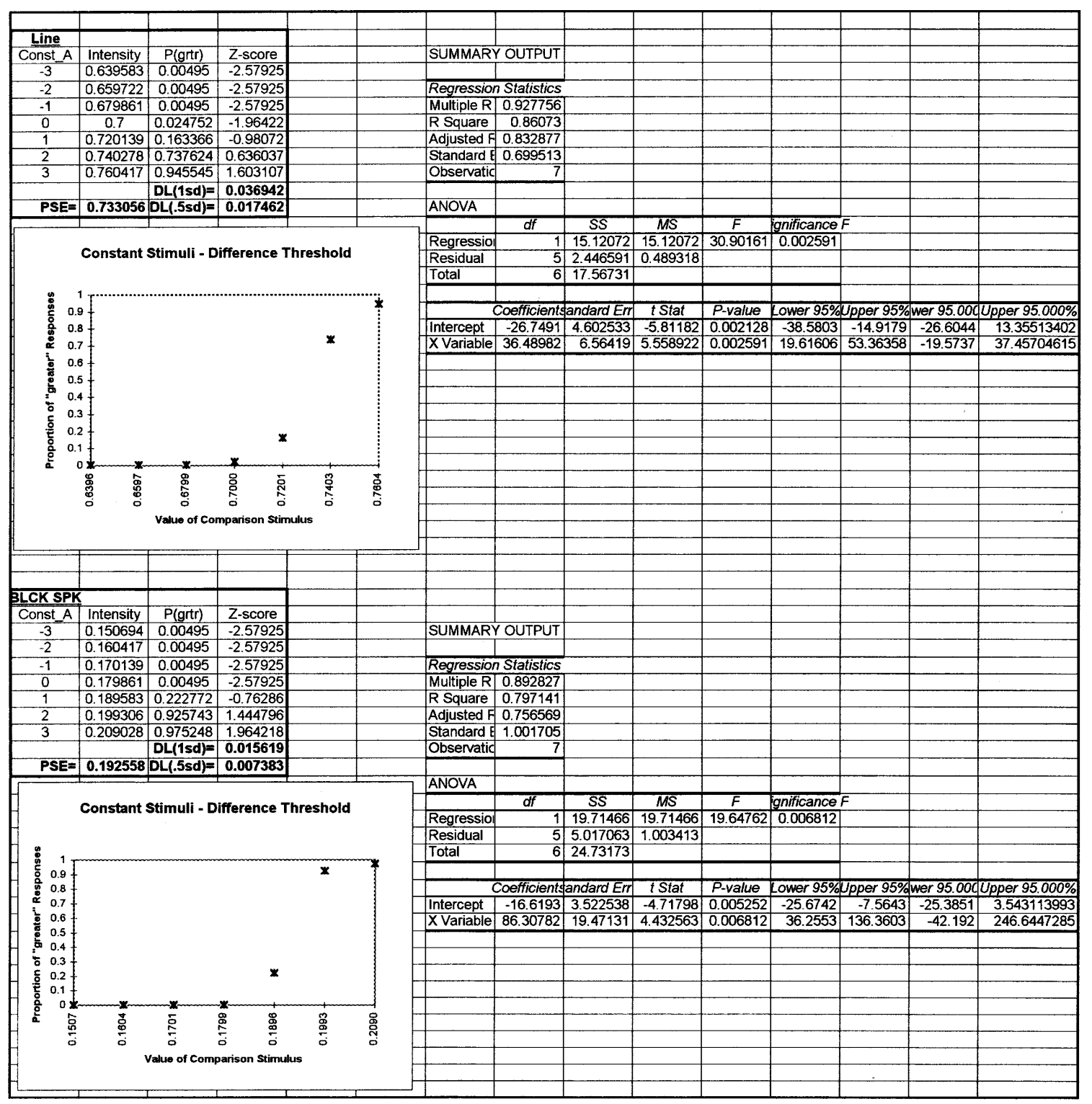




\section{VITA}

José A. Pesante Santana received a Ph.D. degree in Industrial and Systems Engineering from the Virginia Polytechnic Institute and State University, an M.S.I.E. degree from the Georgia Institute of Technology, and a B.S.I.E. degree from the University of Puerto Rico at Mayagüez. He has worked as a Manufacturing Development Engineer for Hewlett-Packard and as a Quality Engineer for Baxter Healthcare Corporation. His primary research interests are in the areas of statistical process control and human factors in manufacturing. He is an active member of Alpha Pi Mu, Institute of Industrial Engineering, and Human Factors and Ergonomic Society. 